\title{
VARIAÇÕES NOS ATRIBUTOS DE SOLOS E NO DESENVOLVIMENTO DO TOMATEIRO EM ESTUFA COM APLICAÇÃO DE MATERIAIS ORGÂNICOS
}

\author{
SIMONE DA COSTA MELLO
}

Engenheiro Agrônomo

Orientador: Prof. Dr. GODOFREDO CESAR VITTI

Tese apresentada à Escola Superior de Agricultura "Luiz de Queiroz", Universidade de São Paulo, para obtenção do título de Doutor em Agronomia, Área de Concentração: Solos e Nutrição de Plantas.

PIRACICABA

Estado de São Paulo - Brasil

Dezembro - 1998 
Dados Internacionais de Catalogação na Publicação (CIP)

DIVISĀO DE' BIBLIOTECA E DOCUMENTAÇĀO - Campus "Luiz de Queiroz"/USP

Mello, Simone da Costa

Variaçōes nos atributos de solos e no desenvolvimento do tomateiro em estufa

com aplicação de materiais orgânicos / Simone da Costa Mello. - - Piracicaba, 1998.

100 p. : il.

Tese (doutorado) - E Escola Superior de Agricultura Luiz de Queiroz, 1998.

Bibliografia.

1. Adubação orgânica 2. Cama de galinheiro 3. Cavaco de eucalipto 4. Estufa 5. Lodo de cervejaria 6. Matéria orgânica 7. Propriedade fisico-química do solo 8.

Relação solo-planta 9. Resíduo urbano 10. Tomate I. Título 


\section{Errata}

MELLO, S.C. Variações nos atributos de solos e no desenvolvimento do tomateiro em estufa com aplicação de materiais orgânicos.

$\begin{array}{ccccc}\text { p. } & \text { ítem } & \text { linha } & \text { onde se lê } & \text { leia-se } \\ 24 & - & \text { quarta } & \log 10 & \log \mathrm{x} \\ 39 & \text { Tabela } 8 & \text { oitava } & \text { matéria orgânica }\left(\mathrm{g} \mathrm{kg}^{-1}\right) & \text { matéria orgânica }\left(\mathrm{g} \mathrm{dm}^{-3}\right) \\ 72 & \text { Tabela 19 } & \text { oitava } & \text { M.O. }\left(\mathrm{g} \mathrm{kg}^{-1}\right) & \text { M.O. }\left(\mathrm{g} \mathrm{dm}^{-3}\right)\end{array}$


Aos meus pais

Marcos e Araçi

\section{OFEREÇO}

Ao meu irmão

Paulo

DEDICO 


\section{AGRADECIMENTOS}

Ao professor Godofredo Cesar Vitti, pela orientação, carinho e amizade.

Aos professores Klaus Reichardt, Paulo Leonel Libardi, Jorge de Castro Kiehl e Quirino A. C. Carmello pelas correções e sugestões oferecidas.

Aos funcionários do Departamento de Ciência do Solo, Marcos A. F. de Camargo, Wladmir J. Rosignaldo, Luiz A. S. Junior, João A. R. Granja, Leandro L. Goia, José I. da Silva e Wanda M. Zancheta pelas execuções das análises químicas de solo e de planta, e à Denise L. C. Mescolotti pela colaboração nas análises de respirometria.

Ao CNPq pela bolsa de estudos concedida.

Às bibliotecárias Eliana M. G. Sabino e Kátia A. Ferraz pelos auxílios prestados.

Aos amigos Hamilton, Guilherme, Flávio e Cristiano pelas colaborações prestadas.

A todos os integrantes do Gape (Grupo de Apoio a Pesquisa e Extensão) pela convivência e bons momentos. 


\section{SUMÁRIO}

Página

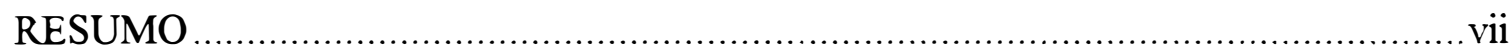

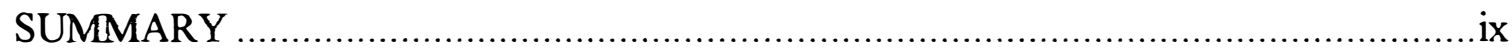

1 INTRODUÇÃO

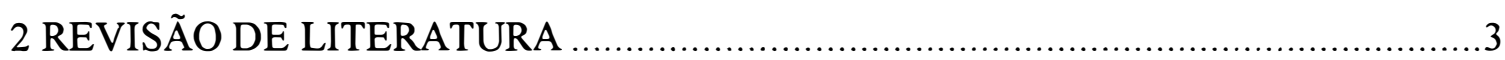

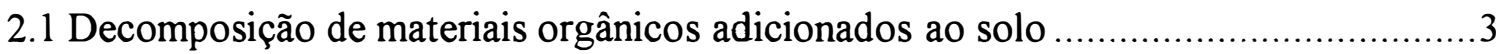

2.2 Efeitos da adição de resíduos orgânicos em atributos biológicos do solo....................4

2.3 Efeitos da adição de resíduos orgânicos em atributos químicos do solo.....................7

2.4 Efeitos da adição de resíduos orgânicos em atributos fisicos do solo........................11

2.5 Nutrição e adubação orgânica do tomateiro.......................................................... 14

3 EFEITOS DE RESÍDUOS ORGÂNICOS NO DESENVOLVIMENTO.

DO TOMATEIRO E NOS ATRIBUTOS QUÍMICOS DO SOLO, SOB

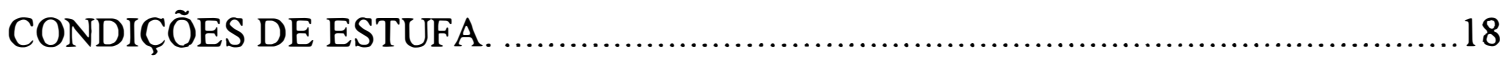

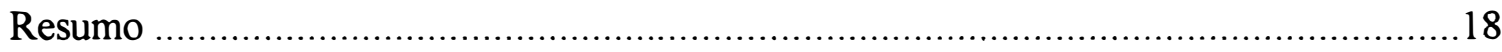

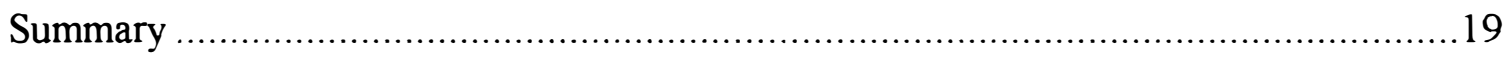

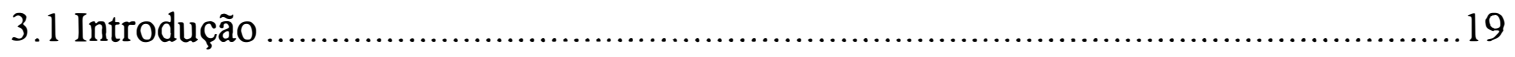

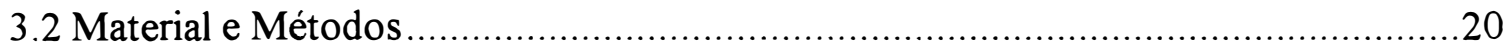

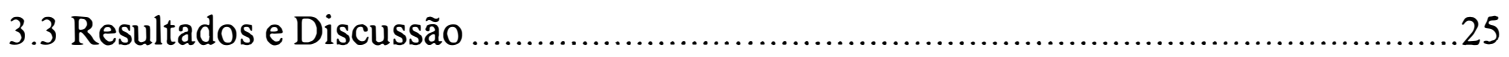

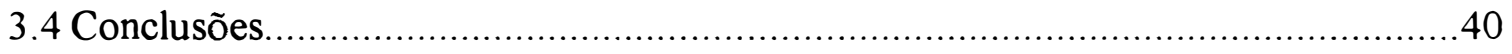

4 DECOMPOSIÇÃO DE MATERIAIS ORGÂNICOS E EFEITOS

DE SUAS APLICAÇÕES NA BIOMASSA MICROBIANA E NOS ATRIBUTOS FÍSICOS DO SOLO ..................................................................

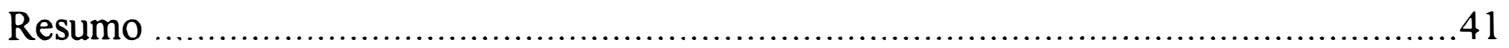

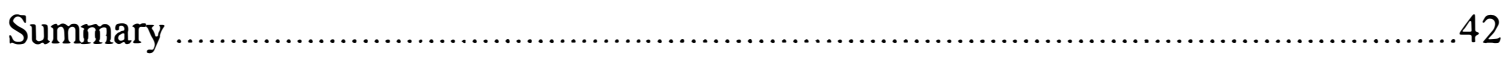

4.1 Introdução

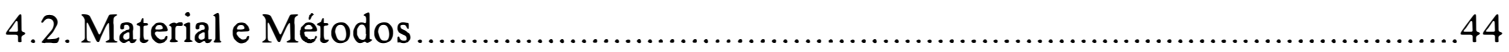

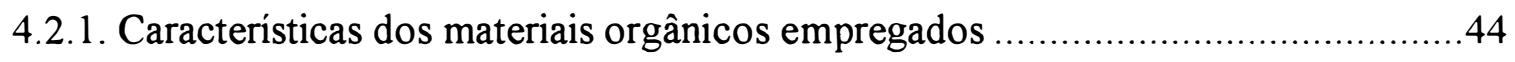

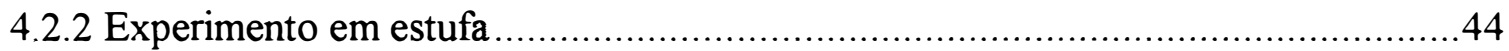




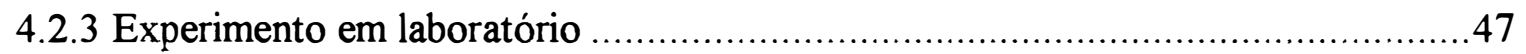

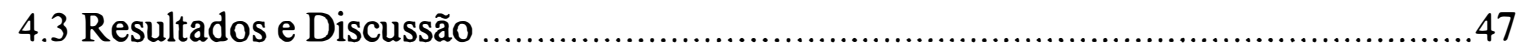

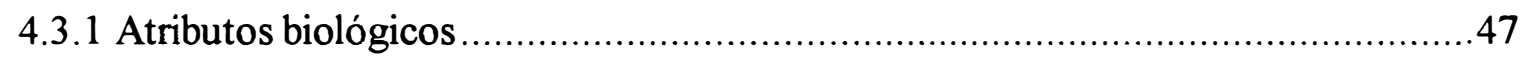

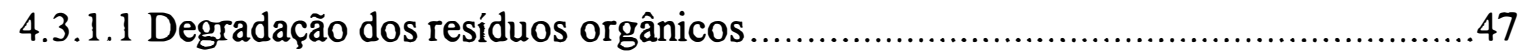

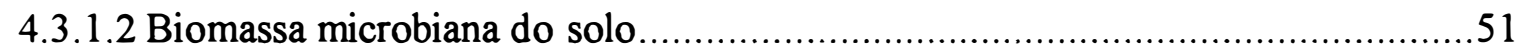

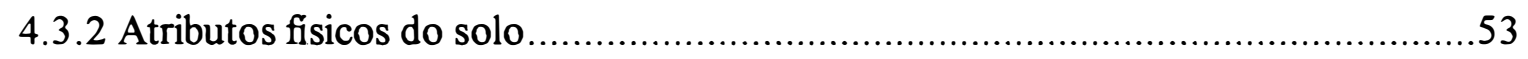

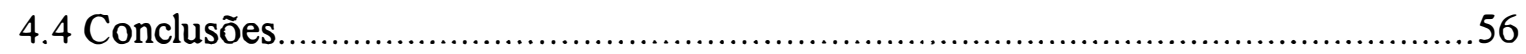

5 INFLUÊNCIA DE MATERIAIS ORGÂNICOS NO DESENVOLVIMENTO.

DO TOMATEIRO E NAS CARACTERÍSTICAS QUÍMICAS DO.............

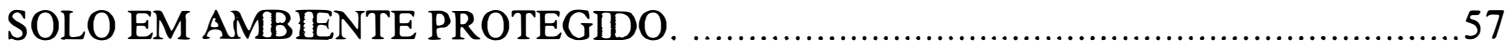

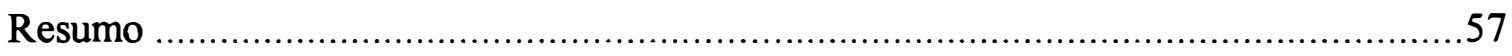

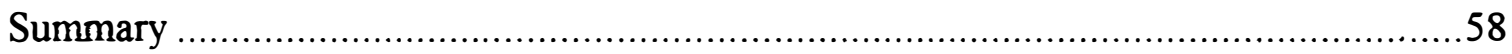

5.1 Introdução

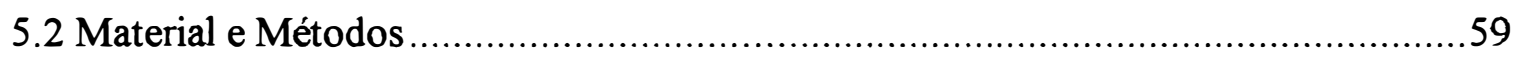

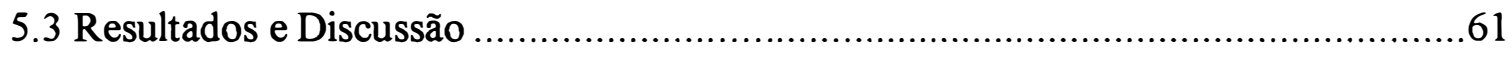

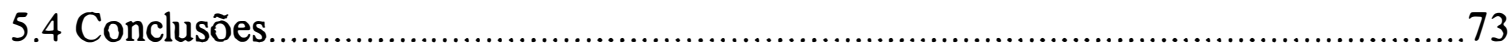

6 DEGRADAÇÃO DE MATERIAIS ORGÂNICOS E EFEITOS DE.

SUAS APLICAÇÕES NA BIOMASSA MICROBIANAE NOS

ATRIBUTOS FÍSICOS DE UM LATOSSOLO VERMELHO-

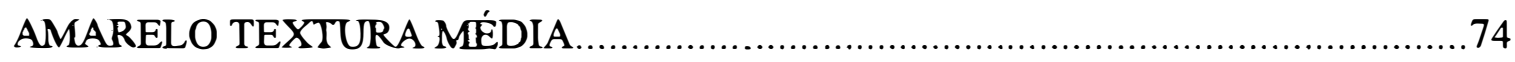

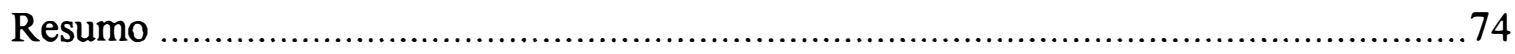

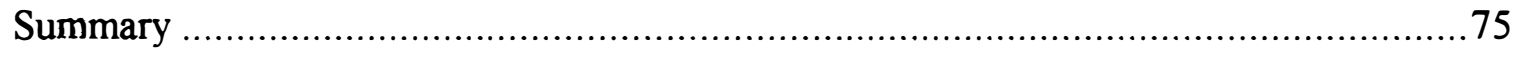

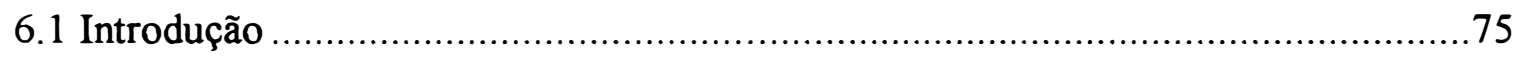

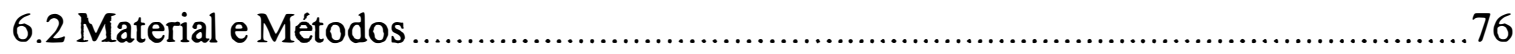

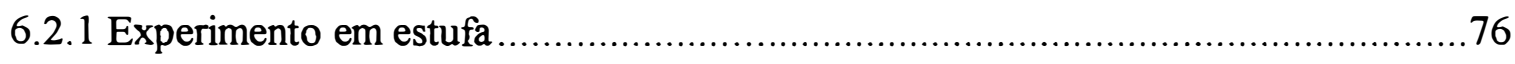

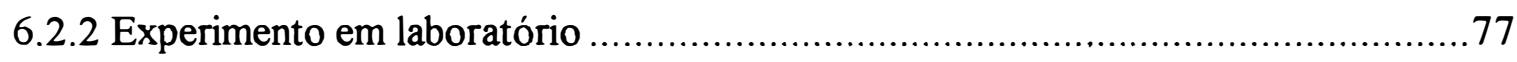

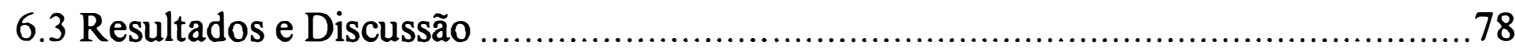

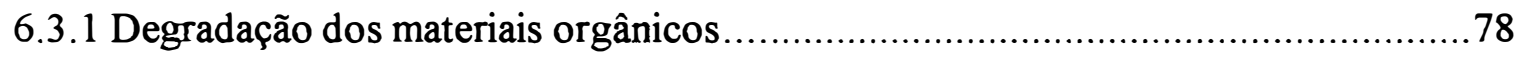

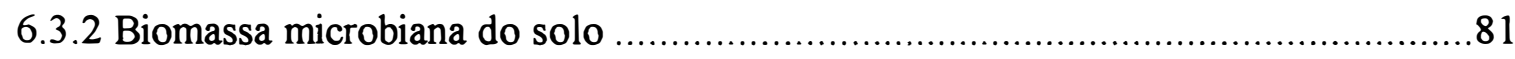

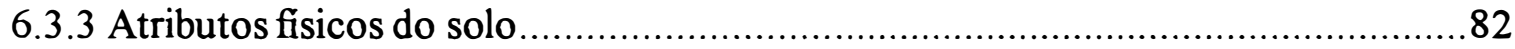




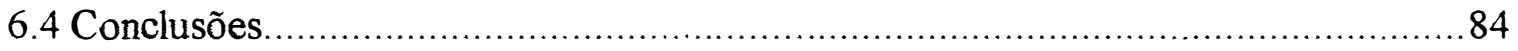

7 CONCLUSÕES

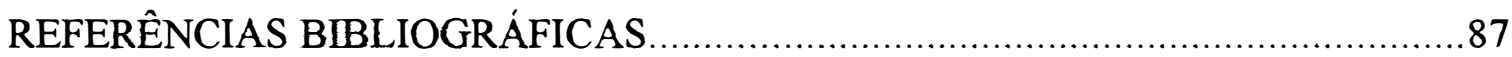




\title{
VARIAÇÕES NOS ATRIBUTOS DE SOLOS E NO DESENVOLVIMENTO DO TOMATEIRO EM ESTUFA COM APLICAÇÃO DE MATERIAIS ORGÂNICOS
}

\author{
Autora: SIMONE DA COSTA MELLO \\ Orientador: Prof. Dr. GODOFREDO CESAR VITTI
}

\section{RESUMO}

Com o objetivo de avaliar os efeitos da aplicação de materiais orgânicos em atributos químicos, biológicos e físicos de dois solos e no desenvolvimento do tomateiro, experimentos em estufa foram conduzidos em Piracicaba e em Limeira (SP) com solos classificados como Podzólico Vermelho-Amarelo abrupto A moderado textura arenosa/módia (A) e Latossolo Vermelho-Amarelo álico A moderado textura média (B), respectivamente. $\mathrm{O}$ delineamento experimental, para ambos os locais, foi o de blocos casualizados com quatro repetições, no esquema fatorial $3 \times 4$ : três materiais orgânicos (composto de lodo de cervejaria + cavaco de eucalipto, composto de lixo e cama de frango) e quatro doses equivalentes a $0,100,150$ e $200 \mathrm{~kg} \mathrm{ha}^{-1}$ de $\mathrm{N}$. Outro experimento foi conduzido em laboratório a fim de avaliar a velocidade de decomposição destes materiais orgânicos em ambos os solos.

A produção total de tomate não aumentou com a adição dos materiais orgânicos em ambos os solos. A adição de $200 \mathrm{~kg} \mathrm{ha}^{-1}$ de $\mathrm{N}$ como composto de lodo de cervejaria + cavaco de eucalipto elevou o teor de cálcio e a capacidade de troca de cátions ao $\mathrm{pH}$ 7,0 dos dois solos. Os teores de $\mathrm{P}$ e de $\mathrm{K}$ aumentaram nos solos $\mathrm{A}$ e $\mathrm{B}$, respectivamente, através da aplicação da cama de frango na dose equivalente a $150 \mathrm{~kg} \mathrm{ha}^{-1} \mathrm{de} \mathrm{N}$. Os teores de $\mathrm{P}$ também aumentaram com a adição de $150 \mathrm{~kg} \mathrm{ha}^{-1}$ de $\mathrm{N}$ na forma de composto de lixo, no solo A.

A velocidade de decomposição dos materiais orgânicos nos dois solos obedeceu a seguinte ordem: cama de frango $\approx$ composto de lixo > composto de lodo de cervejaria + 
cavaco de eucalipto.

No solo A, a biomassa microbiana foi superior para o composto de lixo em relação aos demais, sendo que no solo $B$ os maiores valores foram obtidos com a adição do composto de lodo de cervejaria + cavaco de eucalipto. As doses do composto de lixo e a dose da cama de frango equivalente a $150 \mathrm{~kg} \mathrm{ha}^{-1}$ de $\mathrm{N}$ aumentaram a biomassa microbiana em relação ao controle, no solo A. Entretanto, esta característica não foi alterada com a aplicação dos materiais orgânicos no solo B.

Nos dois solos, a dose mais elevada do composto de lodo de cervejaria + cavaco de eucalipto reduziu a densidade do solo e aumentou o conteúdo de água na capacidade de campo ( 0,1 bar) e no ponto de murcha permanente (15 bar). No solo A, a aplicação de $100 \mathrm{~kg} \mathrm{ha}^{-1}$ de $\mathrm{N}$ como composto de lixo incrementou o conteúdo de água “disponível". 


\title{
CHANGES IN SOIL PROPERTIES AND TOMATO DEVELOPMENT IN GREENHOUSE WITH ORGANIC MATERIALS APPLICATION
}

\author{
Author: SIMONE DA COSTA MELLO \\ Adviser: Prof. Dr. GODOFREDO CESAR VITTI
}

\section{SUMMARY}

With the objective of evaluating the effects of the application organic materials on chemical, biological and physical properties of two soils and on tomato growth, greenhouse experiments were carried out in Piracicaba and Limeira (SP) Brazil on Ultisol (A) and Oxisol (B) soils, respectively. The experimental design consisted of randomized blocks with treatments that were disposed in a factorial design of $3 \times 4$ : three organic wastes (beershop sludge + eucaliptus chip compost, urban solid waste compost and chicken litter) and four rates equivalent to $0,100,150$ e $200 \mathrm{~kg} \mathrm{ha}^{-1}$ of nitrogen, with four replications. An additional experiment was carried out in the laboratory to compare the decomposition of these organic materials at the rates above mentioned for the two soils.

The tomato fruit yield did not increase with the addition of organic materials for both soils. The beershop sludge + eucaliptus chip compost at the rate equivalent to 200 $\mathrm{kg} \mathrm{ha}^{-1}$ of $\mathrm{N}$ increased the calcium content and the cation exchange capacity of the two soils. The $\mathrm{P}$ and $\mathrm{K}$ levels increased in soils $\mathrm{A}$ and $\mathrm{B}$, respectively, with the addition of chicken litter at the rate equivalent to $150 \mathrm{~kg} \mathrm{ha}^{-1}$ of $\mathrm{N}$. The application of this rate through urban solid waste compost enhanced the $\mathrm{P}$ contents of soil $\mathrm{A}$.

The decomposition rate of organic materials in both soils followed the order: chicken litter $\approx$ urban solid waste compost $>$ beershop sludge + eucaliptus chip compost.

For the soil A, the microbial biomass was higher for the urban solid waste 
compost as compared to other organic materials, while in soil B the highest microbial biomass content was obtained with the beershop sludge + eucaliptus chip compost. The application rastes of urban solid waste compost and chicken litter at the rate equivalent to $150 \mathrm{~kg} \mathrm{ha}^{-1}$ of $\mathrm{N}$ increased microbial biomass in respect to the control for the soil A. For the soil B, however, this caractheristic did not change with the application of organic materials.

The beershop sludge + eucaliptus chip compost, at the highest rate, decreased the soil bulk density and increased the soil water content corresponding to the 0.1 and 15 bar suctions, for the two soils. For the soil $\mathrm{A}$, the application of urban solid waste compost at the rate equivalent to $100 \mathrm{~kg} \mathrm{ha}^{-1}$ of $\mathrm{N}$ increased the "avaliable" water content. 


\section{INTRODUÇÃO}

Com a expansão agrícola e industrial, juntamente com o crescimento populacional, grandes quantidades de resíduos são geradas, cujos meios empregados para o descarte, entre os quais, as águas superficiais, os aterros e a incineração estão se tornando inviáveis por razões econômicas e ecológicas. No que diz respeito aos resíduos produzidos pelo homem, o lodo de esgoto e a fração orgânica do lixo urbano são os mais expressivos, representando de 50 a $75 \%$ do total do lixo produzido nos países em desenvolvimento. Diante deste contexto, as atenções tem se voltado mais para os resíduos orgânicos em virtude de sua grande produção e potencial de contaminação para o ambiente e para a saúde pública.

Com o surgimento de novos processos de tratamento, que permitem a redução do potencial poluidor desses materiais, seu uso agronômico, como fonte de nutrientes às plantas e como condicionadores dos solos, tem constituído em alternativa interessante na preservação da qualidade ambiental. Dessa forma, é necessário avaliar os efeitos da adição dos resíduos orgânicos no sistema solo-planta, uma vez que diversos fatores são responsáveis pelas alterações decorrentes do seu uso, dentre os quais são fundamentais a quantidade e a composição química dos materiais orgânicos. Os resíduos de origem urbana, especialmente o lodo de esgoto, o lixo urbano e os de natureza animal são os mais estudados. Pouco se sabe sobre os efeitos de resíduos de origem industrial, como o lodo gerado pelas indústrias de cervejarias, em atributos do solo e no desenvolvimento das plantas.

Considerando os aspectos descritos, os objetivos deste trabalho foram comparar a velocidade de decomposição de três materiais orgânicos (composto de lodo de 
cervejaria + cavaco de eucalipto, composto de lixo e cama de frango) em condições de laboratório e estudar os efeitos de suas aplicações nos atributos de dois solos e no desenvolvimento do tomateiro cultivado em estufa, nas regiões de Piracicaba e de Limeira (SP). 


\section{REVISÃO DE LITERATURA}

\subsection{Decomposição de materiais orgânicos adicionados ao solo}

A decomposição de materiais orgânicos adicionados no solo depende de uma série de fatores relacionados às características do substrato orgânico, do solo e das condições climáticas. No que diz respeito ao substrato, a sua composição química, relação $\mathrm{C} / \mathrm{N}$ e a quantidade a ser aplicada, são os que mais afetam a taxa de degradação dos materiais orgânicos.

Os resíduos orgânicos são constituídos por diferentes compostos, que apresentam graus distintos de decomposição. Materiais ricos em açúcares simples, aminoácidos, algumas proteínas e polissacarídeos, são rapidamente e completamente utilizados pelos microorganismos decompositores, degradando-se em poucas horas ou dias. Materiais mais resistentes como ligninas, outras substâncias fenólicas e gorduras decompõem-se mais lentamente (Brady, 1983). Barreto (1995) estudou o comportamento de diferentes resíduos orgânicos no solo e constatou que materiais ricos em substâncias orgânicas mais simples apresentaram maior velocidade de decomposição em relação aqueles formados por substâncias mais complexas. Segundo este autor, a velocidade de decomposição dos resíduos obedeceu a seguinte ordem: torta de filtro $>$ lodo de esgoto $\cong$ composto de lixo $>$ lodo petroquímico.

A relação $\mathrm{C} / \mathrm{N}$ do material estabelecerá se a mineralização ou imobilização do $\mathrm{N}$ vai predominar durante a sua decomposição. Segundo Webber \& Beauchamp (1977) o N inorgânico tende a ser imobilizado com materiais que apresentam relação $\mathrm{C} / \mathrm{N}$ maior que 35/1. Além disso, o conteúdo de $\mathrm{N}$ é especialmente importante, sendo que, de maneira geral, resíduos com teores de $\mathrm{N}$ superiores a $15 \mathrm{~g} \mathrm{~kg}^{-1}$ de $\mathrm{N}$ e relação $\mathrm{C} / \mathrm{N}$ baixa são 
rapidamente decomponíveis (Oliveira Filho et al., 1987).

A quantidade do resíduo a ser adicionada no solo tem pouco efeito sobre a sua taxa de decomposição até aproximadamente 1,5 a 2,0 \% do peso do solo seco (Martin \& Focht, 1977). Porém, doses mais elevadas podem fazer com que os materiais se decomponham mais lentamente. Sommerfeldt et al. (1988), avaliando os efeitos da aplicação de 30 a $180 \mathrm{Mg} \mathrm{ha}^{-1}$ de esterco de bovino em um solo argiloso, constataram que as menores taxas de decomposição foram referentes às doses maiores.

Para a avaliação da taxa de decomposição dos materiais orgânicos no solo, a determinação da evolução de $\mathrm{CO}_{2}$, a partir de amostras de terra incubadas com os materiais orgânicos, em condições de laboratório, tem sido o método mais comumente empregado. De acordo com Cerri et al. (1994), é possivel através deste procedimento obter, em tempo relativamente curto, informações seguras sobre o comportamento de resíduos orgânicos no solo. Em condições de campo, as medições de $\mathrm{CO}_{2}$ sofrem maior influência de fatores de variação (Naganawa et al., 1989).

\subsection{Efeitos da adição de resíduos orgânicos em atributos biológicos do solo}

Quando resíduos orgânicos são adicionados ao solo podem ocorrer alterações na biomassa microbiana, uma vez que a matéria orgânica fresca é o substrato indispensável para a maior parte dos microorganismos e o crescimento ou declínio dessa biomassa microbiana são dirigidos através da disponibilidade e da dinâmica da entrada de substrato energético no ecossistema (Cardoso, 1992). Desde que não ocorra limitações climáticas para a sobrevivência dos microorganismos, a entrada de matéria orgânica fresca consiste no fator de maior impacto sobre a atividade microbiana .

A biomassa microbiana é definida como o componente microbiano vivo do solo, composta por bactérias, fungos, microfauna e algas e responde rapidamente a adição de carbono e nitrogênio prontamente disponíveis (Nordgren, 1992). Ela exerce influência na transformação da matéria orgânica e no armazenamento de carbono e nutrientes (Jenkinson \& Ladd, 1981) e atua como fonte e dreno de nutrientes na maioria dos ecossistemas terrestres (Okano et al., 1989).

Os efeitos das aplicações de materiais orgânicos sobre a biomassa microbiana 
estão relacionados a vários fatores, dentre os quais, a taxa de decomposição dos resíduos, a sua quantidade a ser aplicada e o teor de carbono orgânico do solo são relevantes.

Diferentes tipos de materiais orgânicos podem apresentar taxas distintas de decomposição, resultando em variações na disponibilidade de substrato, consequentemente no tamanho da biomassa microbiana. Witter et al. (1993) verificaram que as aplicações anuais de lodo de esgoto e adubo orgânico (esterco de curral com restos de feno) em quantidade equivalente a $4 \mathrm{Mg} \mathrm{ha}^{-1}$ de matéria orgânica, por um período de 36 anos, reduziram e aumentaram a biomassa microbiana para 132 e $402 \mu \mathrm{g} \mathrm{C}$ $\mathrm{g}^{-1}$ de solo, respectivamente, em relação à área não adubada, cujo valor da biomassa foi de $190 \mu \mathrm{g} \mathrm{C} \mathrm{g}^{-1}$ de solo. A diminuição da biomassa $\mathrm{C}$ foi relacionada a menor disponibilidade do $\mathrm{C}$ adicionado para a decomposição microbiana e formação da biomassa, uma vez que o lodo de esgoto foi menos degradável que o outro adubo orgânico. Entretanto, a taxa de respiração aumentou para ambos os resíduos, não sendo afetada, portanto, pelo tipo de carbono orgânico incorporado ao solo.

De modo geral, baixas taxas de materiais orgânicos aplicadas no solo promovem pequenos incrementos ou não exercem influência na biomassa microbiana e no conteúdo de carbono orgânico total. Em experimento de longa duração (36 anos), as aplicações de 13,$4 ; 20,2$ e $26,9 \mathrm{Mg} \mathrm{ha}^{-1}$ de adubo orgânico (resultante da mistura de esterco de curral com restos de feno), a cada três anos, não aumentaram a biomassa microbiana e a respiração do solo e proporcionaram incrementos pequenos no teor de carbono, devido ao uso de taxas baixa a moderada (Campbell et al., 1986). Por outro lado, Kanazawa et al. (1988) estudando a aplicação de $6 \mathrm{Mg} \mathrm{ha}^{-1}$ de adubo orgânico por 5 anos, observaram que a biomassa microbiana aumentou para $59,8 \mathrm{mg} \mathrm{C} 100 \mathrm{~g}^{-1}$ de solo em relação ao controle (29,8 mg C $100 \mathrm{~g}^{-1}$ solo). Houve correlação positiva (coeficiente de correlação de 0,866 ) entre a biomassa microbiana e a evolução de $\mathrm{CO}_{2}$, mostrando que a biomassa microbiana do solo pode ser estimada pela respiração.

Em experimento realizado por 5 anos, em solo de textura média, os níveis de biomassa microbiana foram $10 \%$ superiores, também com o emprego de pequenas taxas anuais de adubo orgânico (Fraser et al., 1988). Em solo de textura franco-arenosa, a 
adição de 3,8 $\mathrm{Mg} \mathrm{ha}^{-1}$ de adubo orgânico (esterco de curral com restos de feno), por 10 anos, elevou o conteúdo de carbono orgânico dos solos de 4 para $5 \mathrm{~g} \mathrm{~kg}^{-1}$ e da biomassa microbiana de 180 para $330 \mu \mathrm{g} \mathrm{C} \mathrm{g}^{-1}$ de solo (Goyal et al., 1992).

O tamanho da biomassa microbiana também depende do nível de matéria orgânica do solo e representa normalmente de 2 a $5 \%$ do carbono orgânico total (Jenkinson \& Ladd, 1981). Relações entre a biomassa microbiana e o carbono orgânico do solo tem sido demonstradas em solos com menos de $25 \mathrm{~g} \mathrm{~kg}^{-1}$ de carbono orgânico (Anderson \& Domsch, 1989). Em solo de textura média, com $15 \mathrm{~g} \mathrm{~kg}^{-1}$ de carbono orgânico e pH 6,5, a adição de resíduo orgânico em dose equivalente a $80 \mathrm{~kg}$ de $\mathrm{N}$ mais $1800 \mathrm{~kg}$ de $\mathrm{C}^{-1}{ }^{-1}$ ano ${ }^{-1}$, por um período de 27 anos, proporcionou correlação altamente significativa entre a biomassa microbiana e o teor de matéria orgânica do solo. $\mathrm{O}$ valor da biomassa foi de 34 $\mu \mathrm{g} \mathrm{g} \mathrm{g}^{-1}$ de solo e a taxa respiratória do solo foi de $176 \mu \mathrm{g} \mathrm{CO}_{2} \mathrm{~g}^{-1} \mathrm{dia}^{-1}$, correspondentes a incrementos de 67,5 e 72,5\%, respectivamente (Schnürer et al., 1985).

Amostras de solo foram coletadas de uma área experimental que recebeu aplicações anuais de $0,15,30,45,60$ e $90 \mathrm{Mg} \mathrm{ha}^{-1}$ de adubo orgânico por 23 anos. Tais amostras e outras provenientes de uma área não adubada foram tratadas com as mesmas doses e incubadas por 12 meses. A adição de adubo orgânico em solo previamente não adubado elevou a biomassa microbiana durante os três meses de incubação seguido de um declínio gradual. A respiração, medida pela evolução de $\mathrm{CO}_{2}$, aumentou com a adição do material orgânico, cujos valores variaram de 68 a $205 \mu \mathrm{g} \mathrm{C}^{-\mathrm{CO}_{2} \mathrm{~g}^{-1} \text { solo dia }}{ }^{-1}$. A biomassa microbiana foi positivamente correlacionada com o conteúdo de carbono orgânico. Nas amostras de solo coletadas da área tratada, a biomassa microbiana também aumentou com a aplicação do material, alcançando valor máximo aos três meses, declinando posteriormente. $\mathrm{O}$ declínio na biomassa microbiana foi observado devido à exaustão de carbono disponivel no solo. A atividade respiratória também apresentou o mesmo cemportamento (Goyal et al., 1993).

Incrementos na biomassa microbiana e no conteúdo de carbono orgânico do solo foram constatados por Fließbach et al. (1994), com aplicações anuais, por 10 anos, de 5 e $15 \mathrm{Mg} \mathrm{ha}^{-1}$ de lodo de esgoto, que tinha baixo conteúdo de metal pesado. A aplicação de 
$45 \mathrm{Mg} \mathrm{ha}^{-1}$ anual de adubo orgânico, por três anos, em um solo com pH de 6,46; $2,1 \mathrm{~g}$ $\mathrm{kg}^{-1}$ de $\mathrm{N}$ e 49,6 $\mathrm{g} \mathrm{kg}^{-1}$ de matéria orgânica, promoveu a maior taxa de respiração do solo, utilizada como estimativa da atividade biológica, evidenciando a eficiência do material aplicado no aumento da população de microorganismos, como fonte de carbono prontamente disponivel, dos quais os microorganismos sobrevivem (Ancheng \& $\mathrm{Xi}$, 1994).

Mudanças na biomassa microbiana pela aplicação de adubo orgânico e fertilizante inorgânico, isolados ou combinados foram estudadas por dois ciclos anuais de arroz. Os maiores valores de biomassa foram correspondentes ao tratamento adubo mais fertilizante inorgânico. Como o solo em questão apresentava baixos teores de $\mathrm{C}$ e de $\mathrm{N}$, ou seja, 7,2 e $0,7 \mathrm{~g} \mathrm{~kg}^{-1}$, respectivamente, a combinação destes fertilizantes forneceu uma quantidade balanceada de nutrientes e de $\mathrm{C}$, que proporcionaram níveis maiores de biomassa microbiana (Ghoshal \& Singh, 1995).

Em experimento de longa duração, durante o período de 1875 a 1989, Houot \& Chaussod (1995) observaram que os valores de biomassa microbiana foram maiores quando se empregou $10 \mathrm{Mg} \mathrm{ha}^{-1}$ anuais de adubo orgânico (esterco de curral com restos de feno) em relação à adubação mineral.

\subsection{Efeitos da adição de resíduos orgânicos em atributos químicos do solo}

A matéria orgânica exerce importantes funções no solo, como condicionador da reação do solo e da capacidade de troca de cátions, além de fornecer nutrientes às plantas e à microflora do solo (Oliveira Filho et al.,1987).

Como fonte de nutrientes, os resíduos orgânicos normalmente apresentam quantidades apreciáveis de $\mathrm{N}, \mathrm{P}, \mathrm{S}$ e micronutrientes. $\mathrm{O}$ nitrogênio é essencialmente armazenado no solo nas formas orgânicas, sendo que o fósforo na matéria orgânica representa de 15 a $80 \%$ do fósforo total do solo e o enxofre orgânico contribui com 50 a $70 \%$ do total (Kiehl, 1985).

Quando os resíduos orgânicos são empregados como fonte de nitrogênio, a disponibilidade do elemento dependerá, dentre outras características, do seu teor no material, da relação $\mathrm{C} / \mathrm{N}$ e da velòcidade de decomposição. Epstein et al. (1976) 
trabalhando com lodo de esgoto (22,9 $\mathrm{g} \mathrm{kg}^{-1}$ de $\mathrm{N}$ e relação $\mathrm{C} / \mathrm{N}$ de $\left.10 / 1\right)$ e composto de lodo $\left(9,3 \mathrm{~g} \mathrm{~kg}^{-1}\right.$ de $\mathrm{N}$ e relação $\mathrm{C} / \mathrm{N}$ de $\left.14 / 1\right)$, observaram que as adições de 160 e 240 $\mathrm{Mg} \mathrm{ha}^{-1}$ de lodo de esgoto elevaram os teores de $\mathrm{N}$ no solo de $0,9 \mathrm{~g} \mathrm{~kg}^{-1}$ para 2,5 e 2,7 $\mathrm{g}$ $\mathrm{kg}^{-1}$, respectivamente, após um mês da incorporação do material, sendo que os teores de $\mathrm{N}$ não aumentaram significativamente com a adição do composto de lodo, evidenciando a mineralização mais rápida do lodo de esgoto com relação $\mathrm{C} / \mathrm{N}$ menor e maior teor de $\mathrm{N}$.

Quanto ao fósforo, potássio, cálcio e magnésio, a aplicação de resíduos orgânicos tem aumentado o teor destes nutrientes no solo (Lund \& Doss, 1980; Holanda et al., 1982). Gerber et al. (1981) observaram que a adição de lodo de esgoto em solo arenoso, em quantidade equivalente a $112 \mathrm{~kg} \mathrm{ha}^{-1}$ de $\mathrm{N}$, proporcionou aumentos significativos nos teores de $\mathrm{P}, \mathrm{K}, \mathrm{Ca}$ e $\mathrm{Mg}$ no solo em relação à aplicação de 112-67-67 $\mathrm{kg} \mathrm{ha}^{-1}$ de $\mathrm{N}, \mathrm{P}_{2} \mathrm{O}_{5}$ e $\mathrm{K}_{2} \mathrm{O}$ na forma de fertilizante mineral.

Além de alterar os teores dos elementos no solo, a aplicação de resíduos orgânicos pode afetar uma das propriedades físico-químicas mais importante dos solos, que é a capacidade de troca de cátions. Ao serem adicionados ao solo, sofrem decomposição pelos microorganismos dando origem a vários componentes, dentre os quais o húmus. $\mathrm{O}$ húmus constitui-se na matéria orgânica em estádio avançado de decomposição e neossíntese no solo, que apresenta elevada atividade de superficie, gerada pela dissociação de diversos radicais orgânicos presentes nos polímeros que a compõem (Sposito, 1989). Dessa forma, a participação do húmus na capacidade de troca de cátions é bem superior quando comparada com a dos colóides inorgânicos do solo (Kiehl, 1985). Quando se trata de solos de região sob clima tropical, como os do Brasil, onde o intemperismo mais intenso determina a ocorrência de minerais de argila com menor capacidade de retenção de cátions, a contribuição da matéria orgânica no complexo de cargas negativas é ainda mais significativa. Raij (1969) observou estreitas correlações entre a CTC e o carbono em 22 perfis de solo do Estado de São Paulo, conferindo à matéria orgânica contribuições de até $74 \%$ da CTC total. Entretanto, as cargas da matéria orgânica são dependentes do $\mathrm{pH}$, de forma que a sua contribuição na retenção de cátions depende da acidez do solo (Kiehl, 1985). Logo, os efeitos da adição de resíduos orgânicos na CTC e no pH estão relacionados, em virtude da dependência 
entre estes parâmetros.

Incrementos na capacidade de troca de cátions foram obtidos pelas adições de 80 a $240 \mathrm{Mg} \mathrm{ha}^{-1}$ de composto de lodo, sendo que a dose mais elevada proporcionou acréscimo de $300 \%$ na CTC efetiva (Epstein et al., 1976). Em um Latossolo Vermelho Escuro com pH de 5,7, as aplicações de 1 e $5 \%$ de material orgânico (em peso seco) elevaram a CTC do solo ao pH 7,0 (Urquiaga et al., 1982). Ndayegamiye \& Côté (1989) observaram incrementos na capacidade de troca de cátions de 7,6 e 15,2\%, respectivamente, com a aplicação de 40 e $60 \mathrm{Mg} \mathrm{ha}^{-1}$ de adubo orgânico (esterco de curral misturado com restos de feno), sem contudo ter sido constatado mudança no $\mathrm{pH}$ do solo, devido à aplicação de calcário antes da instalação do experimento. Os aumentos na CTC foram atribuídos aos incrementos no conteúdo de carbono orgânico do solo.

Melo et al. (1994) observaram elevação na CTC quando $32 \mathrm{Mg} \mathrm{ha}^{-1}$ de lodo de esgoto foi aplicado ao solo. Em doses menores, ou seja 4,8 e $16 \mathrm{Mg} \mathrm{ha}^{-1}$, tal característica do solo não foi afetada. Resultados semelhantes foram constatados após a incorporação de $200 \mathrm{Mg} \mathrm{ha}^{-1}$ de composto de lixo urbano, que não promoveu alterações no pH e na CTC em relação à aplicação de 7,2 $\mathrm{Mg} \mathrm{ha}^{-1}$ da fórmula 8-15-15 (Murillo et al., 1989). Giusquiani et al. (1988) também não observaram incrementos na CTC com a adição de $50 \mathrm{Mg} \mathrm{ha}^{-1}$ de composto de lixo urbano, em dois tipos de solos, com valores de $\mathrm{pH}$ de 7,7 e 7,8, respectivamente.

A adição de materiais orgânicos pode também modificar o comportamento do carbono nativo do solo. Quando grandes quantidades de materiais orgânicos são adicionadas nos solos os teores de matéria orgânica podem ser elevados. Aumentos no conteúdo de matéria orgânica foram obtidos através das aplicações de 200 e $400 \mathrm{Mg} \mathrm{ha}^{-1}$ de composto de lixo urbano (Murillo et al., 1989). As adições de composto de lixo urbano misturado com lodo de esgoto em quantidades equivalentes a 1,25;2,41 e 4,79\% e 2,$11 ; 4,09$ e 8,23 \% de matéria orgânica, respectivamente, nos solos de textura arenosa e argilosa, elevaram o conteúdo de matéria orgânica do solo, sem provocar alteração no pH (Pera et al., 1983).

Por outro lado, pequenas quantidades de materiais orgânicos aplicadas em solos sob intenso cultivo podem não aumentar o teor de matéria orgânica do solo, uma vez que 
as condições para a decomposição da matéria orgânica são favoráveis (Baldock \& Musgrave, 1980)./Mugwira (1979) verificou que a adição de esterco de gado leiteiro em quantidades inferiores a $45 \mathrm{Mg} \mathrm{ha}^{-1}$ não aumentou o conteúdo de matéria orgânica do solo. Além disso, resíduos orgânicos com relação $\mathrm{C} / \mathrm{N}$ estreita, de fácil decomposição podem manter ou reduzir o teor de matéria orgânica no solo, pois 60 a $80 \%$ do carbono orgânico é perdido na forma de $\mathrm{CO}_{2}$ pela ação microbiana (Alexander, 1977). Entretanto, Maskina et al. (1988) observaram que as aplicações de esterco de gado, de galinha e de porco em doses pequenas equivalentes a 60,75 e $80 \mathrm{~kg} \mathrm{ha}^{-1}$ de $\mathrm{N}$, respectivamente, aumentaram significativamente os teores de carbono orgânico do solo. Incremento no conteúdo de carbono do solo também foi comprovado com a adição de $12 \mathrm{Mg} \mathrm{ha}^{-1} \mathrm{de}$ adubo orgânico (esterco de curral misturado com restos de feno) após o cultivo de arroz e trigo (Gill \& Meelu, 1982).

Outra propriedade físico-química do solo que tem sido alterada com a aplicação de materiais orgânicos é a acidez. Segundo Mattiazzo \& Glória (1987), os resíduos orgânicos podem elevar o $\mathrm{pH}$ do solo através da produção de íons $\mathrm{OH}$ quando o oxigênio atua como receptor de elétrons durante a oxidação do carbono orgânico pelos microorganismos. Hoyt \& Turner (1975) atribuem a redução da acidez do solo ao mecanismo de adsorção de $\mathrm{H}^{+}$e de $\mathrm{Al}^{3+}$ na superficie do material orgânico. De acordo com Hue (1992), a adição de materiais orgânicos aumenta o pH devido às reações de troca entre os ânions orgânicos e hidróxidos terminais dos óxidos de ferro e alumínio.

Berton et al. (1989) observaram, em cinco tipos de solos, que as incorporações de 2 e $4 \%$ de lodo de esgoto elevaram o pH dos solos pela liberação da amônia, resultante da decomposição dos compostos orgânicos presentes no lodo. Essa elevação do pH, por sua vez, pode ser temporária, quando as taxas de oxidação da amônia se assemelham às quantidades de amônia liberadas (Albregts \& Howard, 1981) ou se o solo possuir alto poder tampão, pode não haver alterações nos valores de $\mathrm{pH}$ do solo durante a decomposição dos resíduos orgânicos.

Por outro lado, a incorporação de materiais orgânicos pode elevar o pH e mantêlo por tempo mais longo, através da presença de substâncias alcalinizantes nestes materiais, que apresentam poder de neutralização (Lund \& Doss, 1980). Asiegbu \& 
Oikeh (1995) concluíram que os incrementos no pH do solo, após 52 dias das adições de 10,20 e $30 \mathrm{Mg} \mathrm{ha}^{-1}$ de esterco de coelho ou de galinha, foram devido aos conteúdos elevados de cálcio nestes materiais. Entretanto, cabe ressaltar, que este cátion por si só não pode incrementar o $\mathrm{pH}$ do solo e sim os ânions acompanhantes como os óxidos, hidróxidos, carbonatos e silicatos. Dessa forma, o cálcio nestes materiais orgânicos deveria estar presente em alguma forma alcalinizante responsável pelo efeito sobre o $\mathrm{pH}$.

Decréscimos no $\mathrm{pH}$ do solo pelos processos de nitrificação do $\mathrm{N}$ amoniacal e orgânico e oxidação de sulfetos também podem ocorrer pela adição de resíduos orgânicos (King \& Morris, 1972). Chang et al. (1991) obtiveram reduções no pH de 0,3 a 0,7 unidades após onze aplicações anuais de 30,60 e $90 \mathrm{Mg} \mathrm{ha}^{-1}$ de esterco de curral, devido à nitrificação do amônio e produção de ácidos orgânicos durante a decomposição do adubo.

\subsection{Efeitos da adição de resíduos orgânicos em atributos físicos do solo}

A matéria orgânica é considerada de grande importância para a formação e estabilidade de agregados do solo pois atua como agente cimentante das partículas. Ela influencia diretamente na retenção de água em decorrência de sua elevada superficie específica e capacidade de absorção, principalmente em altos potenciais hídricos, sendo que na faixa de baixos potenciais hídricos a matéria orgânica tem um efeito indireto, pois a retenção de água depende de alterações de outras propriedades fisicas, como a densidade do solo, porosidade e distribuição de tamanho de poros (Metzger \& Yaron, 1987).

Aumentos na capacidade de retenção de água na capacidade de campo e no ponto de murcha permanente, devido à adição de resíduos orgânicos, são relatados na literatura (Chang et al., 1983; Hall \& Coker, 1983; Wei et al., 1985). Khaleel et al. (1981) estudaram resultados experimentais obtidos em uma ampla variação de solos, com a adição de vários materiais orgânicos e observaram que a retenção de água nestes potenciais aumentou, cujos incrementos foram superiores para solos de textura grosseira em relação aos de textura fina. De acordo com estes autores, aproximadamente $80 \%$ das variações na retenção de água foram explicadas pela textura do solo e aumento no 
conteúdo de carbono do solo após a aplicação de resíduo.

${ }^{b}$ Em um solo arenoso, as adições de $0,112,225$ e $450 \mathrm{Mg} \mathrm{ha}^{-1}$ de lodo de esgoto ( $240 \mathrm{~g} \mathrm{~kg}^{-1}$ de matéria orgânica) promoveram decréscimos na densidade do solo, sendo que a quantidade de água retida a -15 bar aumentou linearmente com o aumento das doses (Gupta \& Larson, 1977). Jacobowitz \& Steenhuis (1984) obtiveram reduções na densidade do solo com as aplicações de 200 e $500 \mathrm{Mg} \mathrm{ha}^{-1}$ de composto de lodo, e aumentos no conteúdo de água do solo na capacidade de campo e no ponto de murcha permanente, entretanto, somente quando se empregou $500 \mathrm{Mg} \mathrm{ha}^{-1}$ deste material.

O conteúdo de água "disponível", definido pela diferença entre a quantidade de água retida na capacidade de campo e no ponto de murcha permanente, também pode ser incrementado pela aplicação de materiais orgânicos no solo. Epstein et al. (1976) observaram que as aplicações de $240 \mathrm{Mg} \mathrm{ha}^{-1}$ de lodo de esgoto e de composto de lodo aumentaram em 48 e 13,8\%, respectivamente, o conteúdo de água "disponível" no solo. Entretanto, segundo Khaleel et al. (1981) o conteúdo de água "disponível” pode não ser muito afetado, uma vez que decréscimos na densidade do solo pela incorporação de resíduos orgânicos, podem contrabalançar qualquer aumento no conteúdo de água "disponivel" em unidade de peso.

As reduções na densidade do solo com a aplicação de resíduos se deve ao efeito de diluição da fração mineral mais densa do solo com a matéria orgânica adicionada, que é menos densa. Segundo Kiehl (1985), há correlação negativa entre o teor de matéria orgânica do solo e sua densidade. Ao se elevar o teor de carbono orgânico de 10 para 30 $\mathrm{g} \mathrm{kg}^{-1}$, a densidade do solo foi reduzida de 1,54 para $1 \mathrm{~g} \mathrm{~cm}^{-3}$. Em solos de textura fina, decréscimos na densidade podem ser atribuídos aos aumentos na porosidade resultante da maior agregação do solo. Seis meses após a aplicação de lodo de esgoto, em um solo argilo-arenoso, a porosidade total alcançou valores entre 24 e $31 \%$ comparados com $17,5 \%$ da testemunha (Pagliai et al., 1981).

Wei et al. (1985) observaram, em um solo de textura média, que as aplicações de 112 e 134,4 $\mathrm{Mg} \mathrm{ha}^{-1}$ de lodo de esgoto (em base seca) reduziram a densidade do solo de $1,44 \mathrm{~g} \mathrm{~cm}^{-3}$ para $1,32 \mathrm{e} 1,35 \mathrm{~g} \mathrm{~cm}^{-3}$, respectivamente.

As adições de 52 e $105 \mathrm{Mg} \mathrm{ha}^{-1}$ de esterco de suíno proporcionaram incrementos 
no teor de carbono orgânico de 0,09 e 0,19 \%, na porosidade total de 1,1 e 3,8 \% e na capacidade de retenção de água de 2,49 e $4,24 \%$, respectivamente, sendo que a densidade do solo foi 0,03 e $0,1 \mathrm{~g} \mathrm{~cm}^{-3}$ menor em relação à inicial (Zeng et al., 1992).

Em experimento conduzido em solo arenoso, as aplicações de 60, 120 e $240 \mathrm{Mg}$ $\mathrm{ha}^{-1}$ de composto de lodo de esgoto reduziram a densidade do solo, cujo decréscimo foi de $45 \%$ para a adição da maior dose. Paralelo a estes resultados, houve incrementos no conteúdo de água do solo (Tester, 1990). A adição de $110 \mathrm{Mg} \mathrm{ha}^{-1}$ de esterco de aves reduziu em $27 \%$ a densidade do solo, resultante do aumento no conteúdo de matéria orgânica e área superficial do solo (Weil \& Kroontje, 1979).

Giusquiani et al. (1995) observaram decréscimos de 5,8 e 10,9\% na densidade do solo e aumentos de 8 e 29,6 \% no conteúdo de água "disponível" e de 4,3 e 23,4\% na retenção de água na capacidade de campo, com adições anuais de 10 e $90 \mathrm{Mg} \mathrm{ha}^{-1}$ de composto de lixo urbano, respectivamente, por um período de quatro anos. Segundo estes autores, os aumentos na retenção de água foram atribuídos à capacidade da matéria orgânica em absorver água e ao aumento da porosidade total do solo. Em área de Latossolo Amarelo textura argilosa cultivada com maracujá amarelo, a umidade do solo aumentou para 25,1 \% após quatro aplicações de $10 \mathrm{Mg} \mathrm{ha}^{-1}$ de esterco de galinha em relação à área não adubada $(7,54 \%$ de umidade), devido também a maior retenção de água no solo pela matéria orgânica (Luizão, 1985).

Aplicações por três anos de $45 \mathrm{Mg} \mathrm{ha}^{-1}$ de composto de lixo urbano aumentaram em $26,9 \%$ o conteúdo médio de água no solo por ano até a profundidade de $60 \mathrm{~cm}$ (Aguilar - Torres et al., 1996). A adição de $10 \mathrm{Mg} \mathrm{ha}^{-1}$ de adubo agrícola (esterco de curral com restos de feno) proporcionou a maior porcentagem de umidade, em torno de $19,19 \%$ na profundidade de 0-15 cm (Gupta, 1995). Adições de lodo de esgoto decomposto anaerobicamente $\left(155,6 \mathrm{~g} \mathrm{~kg}^{-1}\right.$ de $\left.\mathrm{N}\right)$ nas doses equivalentes a 6370, $12770 \mathrm{e}$ $25200 \mathrm{~kg} \mathrm{ha}^{-1}$ de $\mathrm{N}$, lodo decomposto aerobicamente $\left(54,9 \mathrm{~g} \mathrm{~kg}^{-1}\right.$ de $\left.\mathrm{N}\right)$ em quantidade de $12540 \mathrm{~kg} \mathrm{ha}^{-1}$ de $\mathrm{N}$ e lodo ativado $\left(51,2 \mathrm{~g} \mathrm{~kg}^{-1}\right.$ de $\mathrm{N}$ ) em dose correspondente a 24500 $\mathrm{kg} \mathrm{ha}^{-1}$ de $\mathrm{N}$, aumentaram o $\mathrm{pH}$ e diminuiram a densidade do solo em relação à aplicação de $250 \mathrm{~kg} \mathrm{ha}^{-1}$ de $\mathrm{N}, 112 \mathrm{~kg} \mathrm{ha}^{-1}$ de $\mathrm{P}$ e $224 \mathrm{~kg} \mathrm{ha}^{-1}$ de $\mathrm{K}$ na forma de adubo mineral (Harding et al., 1985). 


\subsection{Nutrição e adubação orgânica do tomateiro}

O tomateiro (Lycopersicon esculentum Mill.) está entre as hortaliças mais intensamente adubadas em virtude do seu elevado requerimento por nutrientes para alcançar altas produtividades. Segundo Gargantini \& Blanco (1963) a época de maior demanda de nutrientes coincide com o período de maior desenvolvimento dos frutos, ou seja, do nonagésimo ao centésimo vigésimo dias. $\mathrm{O}$ nitrogênio, potássio, magnésio e enxofre apresentam maior intensidade de absorção entre 100 e 120 dias após a semeadura, sendo que o cálcio e o fósforo são absorvidos continuamente do início até o final do ciclo, alcançando o máximo aos 140 dias após a germinação.

Entre os macronutrientes, o $\mathrm{N}$ e o $\mathrm{K}$ são os mais extraídos do solo pela planta e encontram-se em maiores quantidades nas folhas. Para uma produção correspondente a $76 \mathrm{Mg} \mathrm{ha}^{-1}$ de tomate cv. Extase produzido em estufa, Maher (1976) encontrou os seguintes teores foliares de $\mathrm{N}, \mathrm{P}, \mathrm{K}, \mathrm{Ca}$ e $\mathrm{Mg}$, respectivamente: $36,5,52,33 \mathrm{e} 10 \mathrm{~g} \mathrm{~kg}^{-1}$.

Por ser uma cultura muito exigente em nutrientes em tempo relativamente curto, os adubos orgânicos tem sido normalmente empregados como fonte complementar de elementos essenciais às plantas. Em virtude da composição química variável destes materiais orgânicos, os efeitos de suas aplicações sobre a nutrição e o rendimento do tomateiro, encontrados na literatura também são variáveis (Salek et al., 1981; Murillo et al., 1989; Chu \&Wong, 1987; Asiegbu \& Oikeh, 1995).

Em dois tipos de solos, um argilo-siltoso e outro argilo-arenoso, com 6,7 e 7,6 g $\mathrm{kg}^{-1}$ de matéria orgânica, respectivamente, foram aplicados $50,100,125,150,200$ e 250 $\mathrm{m}^{3} \mathrm{ha}^{-1}$ de esterco semi-sólido de suíno, por dois anos, num total de oito aplicações. A produção de frutos de tomate no solo argilo-arenoso aumentou até $100 \mathrm{~m}^{3} \mathrm{ha}^{-1}$, sendo que no outro solo a produção foi irregular com o aumento das doses. Em ambos os solos, houve incrementos nos teores de $\mathrm{N}$ e $\mathrm{P}$ nas plantas, que variaram de 18,93 a $24,96 \mathrm{~g} \mathrm{~kg}^{-1}$ e 1,25 a $1,82 \mathrm{~g} \mathrm{~kg}^{-1}$, respectivamente, com a aplicação do esterco. Os teores de $\mathrm{K}$ nas plantas, no solo argilo-siltoso, aumentaram com as adições de 200 e $250 \mathrm{~m}^{3} \mathrm{ha}^{-1}$ do esterco. No solo argilo-arenoso o teor de $\mathrm{K}$ nas plantas correspondente à adição de 250 $\mathrm{m}^{3} \mathrm{ha}^{-1}$ foi superior aos demais (Bernal \& Roig, 1993). 
Aplicações de lodo de esgoto em quantidades de até $200 \mathrm{Mg} \mathrm{ha}^{-1}$ proporcionaram aumentos nos pesos de plantas secas de tomate (Vlamis \& Williams, 1972). Incremento de $25,5 \%$ foi obtido na produção de tomate com a aplicação de lodo de esgoto em quantidade equivalente a $112 \mathrm{~kg} \mathrm{ha}^{-1}$ de $\mathrm{N}$, em relação à adição de $112-67-67 \mathrm{~kg} \mathrm{ha}^{-1}$ de $\mathrm{N}, \mathrm{P}_{2} \mathrm{O}_{5}$ e $\mathrm{K}_{2} \mathrm{O}$ como fertilizante mineral (Gerber et al., 1981). Por outro lado, redução de $43,8 \%$ na produção de tomate C-28 foi obtida com a aplicação de $13,4 \mathrm{Mg} \mathrm{ha}^{-1}$ de lodo de esgoto $\left(1-1-0,1 \%\right.$ de $\left.\mathrm{N}, \mathrm{P}_{2} \mathrm{O}_{5}, \mathrm{~K}_{2} \mathrm{O}\right)$ em relação à aplicação de $1117 \mathrm{~kg} \mathrm{ha}^{-1}$ da fórmula 12-12-12 (Hashim et al., 1978).

Aumentos nos pesos de plantas verdes de tomate, após sete semanas do transplante das mudas, também foram constatados com as aplicações de 2 a $10 \%$ em peso seco de lodo de esgoto, atribuídos à presença de $\mathrm{N}$ no material. Os teores foliares de $\mathrm{Ca}$ e $\mathrm{Mg}$ aumentaram com a adição deste material. Os teores de $\mathrm{Cu}, \mathrm{Fe}$ e $\mathrm{Zn}$, de maneira geral, foram reduzidos com as doses empregadas, em virtude da elevação do $\mathrm{pH}$ ocasionada pela aplicação do material orgânico. Um outro estudo foi realizado para comprovar a resposta ao $\mathrm{N}$ proveniente do lodo, empregando-se para isso $6 \%$ do lodo de esgoto com ou sem adição de $100 \mathrm{mg} \mathrm{kg}^{-1}$ de $\mathrm{N}$, utilizando a fórmula 20-20-20. O N mais o lodo reduziram o peso da planta verde para $3,40 \mathrm{~g}$ em relação à testemunha $(8,38$ g). Esta diminuição foi acompanhada por decréscimo no teor de fósforo com sintomas de deficiência nas folhas. Este fato foi atribuído à imobilização do $\mathrm{P}$ no solo como $\mathrm{MgNH}_{4} \mathrm{PO}_{4}$ induzida pelas condições alcalinas devido à adição do lodo e pela adição do $\mathrm{N}$ do fertilizante mineral. (Elliott \& Singer, 1988).

Em um Regossolo de textura arenosa, a produção média de oito anos de cultivo de tomate foi aproximadamente $85 \%$ superior com a aplicação de $56 \mathrm{~kg} \mathrm{ha}^{-1} \mathrm{de} \mathrm{N}, 84 \mathrm{~kg}$ $\mathrm{ha}^{-1}$ de $\mathrm{P}_{2} \mathrm{O}_{5}$ e $56 \mathrm{~kg} \mathrm{ha}^{-1}$ de $\mathrm{K}_{2} \mathrm{O}$, juntamente com $10 \mathrm{Mg} \mathrm{ha}^{-1}$ de esterco de curral, em relação à adubação mineral, cuja produção foi de $14,31 \mathrm{Mg} \mathrm{ha}^{-1}$ (Freitas \& Faria, 1981). Acréscimo de $321 \%$ no rendimento de frutos de tomate foi obtido com a aplicação de 10 $\mathrm{Mg} \mathrm{ha}^{-1}$ de esterco de galinha (Salek et al., 1981). Em um solo Gley Pouco Húmico eutrófico, com pH de 5,1 e $17 \mathrm{~g} \mathrm{~kg}^{-1}$ de matéria orgânica, a maior produção de frutos de tomate (53 $\mathrm{Mg} \mathrm{ha}^{-1}$ ) foi obtida com $104 \mathrm{~kg} \mathrm{ha}^{-1}$ de $\mathrm{N}, 259 \mathrm{~kg} \mathrm{ha}^{-1}$ de $\mathrm{P}_{2} \mathrm{O}_{5}$ e $104 \mathrm{~kg} \mathrm{ha}^{-1}$ de $\mathrm{K}_{2} \mathrm{O}$ e $20 \mathrm{Mg} \mathrm{ha}^{-1}$ de esterco de aves. Com as aplicações de $180 \mathrm{~kg} \mathrm{ha}^{-1}$ de N, $450 \mathrm{~kg}$ 
ha ${ }^{-1}$ de $\mathrm{P}_{2} \mathrm{O}_{\mathrm{S}}$ e $180 \mathrm{~kg} \mathrm{ha}^{-1}$ de $\mathrm{K}_{2} \mathrm{O}$ e $30 \mathrm{Mg} \mathrm{ha}^{-1}$ do adubo orgânico houve redução na produção, atribuída à salinização do solo e antagonismo entre nutrientes (Silva Jr. \& Vizzotto, 1990).

Plantas de tomate cv. Scotia tratadas com $30 \mathrm{Mg} \mathrm{ha}^{-1}$ esterco de gado leiteiro apresentaram a maior produção de frutos, que foi de $1,56 \mathrm{~kg} \mathrm{planta}^{-1}$ (Warman, 1990). Em um solo argilo-arenoso com pH de 4,67, as maiores produções de matéria seca de plantas de tomate foram obtidas após as aplicações de $10 \mathrm{Mg} \mathrm{ha}^{-1}$ de esterco de suíno, 20 $\mathrm{Mg} \mathrm{ha}^{-1}$ de lodo de esgoto ou de $10 \mathrm{a} 20 \mathrm{Mg} \mathrm{ha}^{-1}$ de esterco de coelho ou de galinha. Os teores foliares de $\mathrm{P}, \mathrm{K}, \mathrm{Ca}, \mathrm{Mg}, \mathrm{Cu}$ e $\mathrm{Zn}$ aumentaram com as doses do lodo de esgoto e do esterco de suíno. Com exceção do $\mathrm{P}$, resultados semelhantes foram obtidos com a adição do esterco de coelho. Os teores de $\mathrm{Mg}$ e de $\mathrm{Zn}$ nas folhas aumentaram após a aplicação de esterco de galinha (Asiegbu \& Oikeh, 1995).

Três resíduos sólidos foram estudados por dois anos na cultura do tomate, o composto Agrisoil (lixo compostado), Eweson (lodo de esgoto e lixo compostado) e composto Daorganite (lodo de esgoto tratado quimicamente e com calor). O composto Daorganite possibilitou o maior peso total de frutos (182 $\left.\mathrm{g} \mathrm{planta}^{-1}\right)$ em relação ao Agrisoil, no primeiro ano de cultivo, e maior produção de frutos comercializáveis, no segundo ano. As concentrações de $\mathrm{Ca}$ nas plantas foram reduzidas com a adição do Agrisoil (35 $\mathrm{g} \mathrm{kg}^{-1}$ de Ca) em relação ao controle ( $40 \mathrm{~g} \mathrm{~kg}^{-1} \mathrm{de} \mathrm{Ca}$ ), sendo que para os demais tratamentos tal efeito não foi constatado. No segundo ano, o teor de $\mathrm{Zn}$ aumentou de 16,4 $\mathrm{mg} \mathrm{kg}^{-1}$ para 25,7 $\mathrm{mg} \mathrm{kg}^{-1}$ com a aplicação do Agrisoil (Hampton et al., 1994).

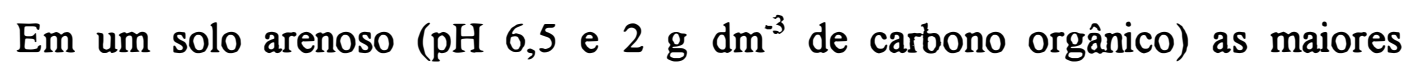
produções de frutos de tomate, em ordem decrescente foram alcançadas com $2 \mathrm{Mg} \mathrm{ha}^{-1}$ da fórmula 15:9:15, seguido da aplicação de $150 \mathrm{Mg} \mathrm{ha}^{-1}$ de lodo ativado e $125 \mathrm{Mg} \mathrm{ha}^{-1}$ de composto de lixo (Chu \& Wong, 1987).

Murillo et al. (1989) estudando os efeitos da adição de composto de lixo urbano no tomateiro, observaram acréscimos de $223 \%$ e $78 \%$ na produção de frutos, devido à incorporação de $400 \mathrm{Mg} \mathrm{ha}^{-1}$ e $150 \mathrm{Mg} \mathrm{ha}^{-1}$, respectivamente, em relação à aplicação de $1,2 \mathrm{Mg} \mathrm{ha}^{-1}$ da fórmula 8-15-15. Entretanto, em três tipos de solos (arenoso, argiloso e 
orgânico) as aplicações de 2,5; 5; 10 e $20 \%$ de composto de lixo urbano diminuiram a produção de frutos de tomate, em decorrência do acúmulo de sais e metais pesados (Fritz \& Venter, 1988). 


\section{EFEITOS DE RESÍDUOS ORGÂNICOS NO DESENVOLVIMENTO DO TOMATEIRO E NOS ATRIBUTOS QUÍMICOS DO SOLO, SOB CONDIÇÕES DE ESTUFA}

\section{Resumo}

O experimento foi conduzido de 8/02/97 a 6/08/97 no município de Piracicaba (SP), a fim de avaliar os efeitos de tipos e doses de resíduos orgânicos no desenvolvimento do tomateiro (Lycopersicon esculentum Mill) cultivado em estufa e nos atributos químicos do solo, classificado como Podzólico Vermelho-Amarelo abrupto A moderado textura arenosa/média. O delineamento experimental foi o de blocos casualizados no esquema fatorial $3 \times 4$, sendo três resíduos orgânicos (composto de lodo de cervejaria + cavaco de eucalipto, composto de lixo e cama de frango) e quatro doses equivalentes a $0,100,150$ e $200 \mathrm{~kg} \mathrm{ha}^{-1}$ de $\mathrm{N}$, com quatro repetições. Quando se empregou a maior dose, a cama de frango proporcionou a maior produção de frutos comercializáveis em relação ao composto de lodo de cervejaria + cavaco de eucalipto. Os valores de $\mathrm{pH}$, de cálcio e da capacidade de troca de cátions ao $\mathrm{pH} \mathrm{7,0}$ do solo foram maiores com o emprego do composto de lodo de cervejaria + cavaco de eucalipto em relação aos demais materiais, nas doses equivalentes a 150 e $200 \mathrm{~kg} \mathrm{ha}^{-1}$ de $\mathrm{N}$. A aplicação de $150 \mathrm{~kg} \mathrm{ha}^{-1}$ de $\mathrm{N}$ como composto de lodo de cervejaria + cavaco de eucalipto aumentou o $\mathrm{pH}$ e os teores de $\mathrm{P}$ disponível, $\mathrm{K}$ e $\mathrm{Mg}$ trocáveis, sendo que os valores de cálcio trocável e da CTC ao pH 7,0 foram incrementados com a adição das doses mais elevadas. A adição de cama de frango em quantidade equivalente a $150 \mathrm{~kg} \mathrm{ha}$

${ }^{1}$ de $\mathrm{N}$ aumentou o teor de $\mathrm{P}$ disponível no solo. As maiores doses do composto de lixo aumentaram os teores de $\mathrm{P}$ disponivel e de $\mathrm{Ca}$ trocável no solo.

Palavras-chave: tomate; composto orgânico; cama de frango; composto de lixo; solo. 


\section{EFFECTS OF ORGANIC MATERIALS ON THE DEVELOPMENT OF TOMATO PLANTS IN GREENHOUSE AND ON THE CHEMICAL PROPERTIES OF SOIL}

\section{Summary}

An experiment was carried out during the period of February to August 1997 to evaluate the effects of different organic wastes on the growth of tomato (Lycopersicon esculentum Mill) plants and on the chemical properties of an Ultisol. The experimental design consisted of complete randomized blocks, with four replicates and treatments disposed in a factorial design $3 \times 4$ : three organic wastes (beershop sludge + eucalyptus chip compost, urban solid waste compost and chicken litter) and four application rates equivalent to $0,100,150$ and $200 \mathrm{~kg} \mathrm{ha}^{-1}$ of nitrogen. At the high rate of chicken litter, the tomato plants had greater marketable yield than the beershop sludge + eucalyptus chip compost. The rates of beershop sludge + eucalyptus chip compost equivalent to 150 and $200 \mathrm{~kg} \mathrm{ha}^{-1}$ of $\mathrm{N}$ provided higher levels of soil $\mathrm{pH}$, calcium and cation exchange capacity, with respect to other organic materials. The rate of beershop sludge + eucalyptus chip compost equivalent to $150 \mathrm{~kg} \mathrm{ha}^{-1}$ of $\mathrm{N}$ increased the soil $\mathrm{pH}$ and $\mathrm{P}, \mathrm{K}$ and $\mathrm{Mg}$ levels. The contents of calcium and cation exchange capacity were larger with the addition of higher rates of this compost. The rate of chicken litter equivalent to $150 \mathrm{~kg}$ $\mathrm{ha}^{-1}$ of $\mathrm{N}$ increased the content of $\mathrm{P}$ of the soil. The higher rates of urban solid waste compost increased the $\mathrm{P}$ and $\mathrm{Ca}$ levels of the soil.

Key-words: tomato; organic compost; chicken litter; urban solid waste compost; soil.

\subsection{Introdução}

O manejo eficiente dos resíduos orgânicos, visando a manutenção e aumento da fertilidade do solo e o incremento da produção vegetal, vem adquirindo grande importância devido aos custos e riscos de poluição associados aos métodos alternativos de descarte desses resíduos e aos beneficios advindos da reciclagem dos nutrientes neles contidos. 
Para espécies olerícolas, dentre elas o tomateiro, que apresentam alto requerimento por nutrientes em tempo relativamente curto, os materiais orgânicos são normalmente empregados como complemento da adubação mineral. Vários trabalhos citados na literatura comprovam a eficiência dos resíduos orgânicos no incremento da produção de tomate (Gerber et al., 1981; Freitas \& Faria, 1981; Warman, 1990).

Nos atributos químicos do solo, a adição de materiais orgânicos pode alterar o $\mathrm{pH}$, a capacidade de troca de cátions e o teor de nutrientes do solo. Incrementos nestas propriedades químicas do solo foram constatados por Mazur et al. (1983), Ndayegamiye \& Côté (1989) e Lund \& Doss (1980). Entretanto, em virtude da grande diversidade de materiais orgânicos existentes, os efeitos de suas aplicações no solo são variáveis, o que infere a necessidade de novas pesquisas, visando principalmente aqueles pouco estudados, dentre os quais pode-se citar os materiais derivados do lodo produzido pelas indústrias de cervejarias.

Dessa forma, este trabalho teve por objetivo verificar os efeitos da aplicação de composto de lodo de cervejaria + cavaco de eucalipto, composto de lixo e cama de frango no desenvolvimento do tomateiro e nas propriedades químicas de um Podzólico Vermelho-Amarelo abrupto A moderado textura arenosa/média do município de Piracicaba (SP).

\subsection{Material e Métodos}

O experimento foi conduzido de 8 de fevereiro a 6 de agosto de 1997, em solo classificado como Podzólico Vermelho-Amarelo abrupto A moderado textura arenosa/média, cultivado com tomate cv. Carmem em estufa, no município de Piracicaba (SP).

Os resíduos orgânicos utilizados neste experimento foram obtidos de acordo com as descrições a seguir. O composto de lodo de cervejaria + cavaco de eucalipto foi proveniente da unidade de Guarulhos (SP) das Cervejarias Reunidas Skol Caracu S/A, constituído da mistura de lodo mais terra infusória e cavacos de eucalipto, na proporção de 1:2, respectivamente. $O$ material foi compostado por cerca de 20 dias em pátio a céu aberto, através de um sistema de leiras estáticas, com aeração forçada, sendo que as leiras foram cobertas com plástico. Após este período, obtido o composto final, realizou-se a 
separação por peneiramento, do material que não havia sido decomposto totalmente, do composto orgânico curado. O composto de lixo foi preparado na usina de tratamento de Santo André (SP), através da permanência em biodigestor por 60 horas. Após esta etapa, o material foi disposto em leiras a céu aberto, as quais foram revolvidas com o auxílio de pá carregadeira a cada 8 dias, a fím de finalizar o processo de decomposição. Posteriormente foi peneirado em malha de $11 \mathrm{~mm}$, para ser comercializado. A cama de frango foi obtida no sítio Asa Branca localizado na estrada Piracicaba - Anhembi, em Piracicaba (SP), sendo constituído da mistura de serragem de pinus com esterco de frango, depositado durante 45 dias.

Amostras representativas de cada resíduo foram coletadas para a realização da análise química, sendo os resultados apresentados na Tabela 1 .

Tabela 1. Propriedades químicas, em base seca, dos resíduos orgânicos empregados.

\begin{tabular}{|c|c|c|c|}
\hline Característica química & CLC & $\mathbf{C L}$ & $\mathbf{C F}$ \\
\hline Umidade total $\left(\mathrm{g} \mathrm{kg}^{-1}\right)$ & 775,8 & 493,0 & 194,9 \\
\hline $\mathrm{pH}$ em $\mathrm{CaCl}_{2} 0,01 \mathrm{M}$ & 7,8 & 8,3 & 8,2 \\
\hline Inertes $\left(\mathrm{g} \mathrm{kg}^{-1}\right)$ & 0,00 & 44,38 & 0,00 \\
\hline Matéria orgânica total $\left(\mathrm{g} \mathrm{kg}^{-1}\right)$ & 500,45 & 692,90 & 862,75 \\
\hline Matéria orgânica compostável $\left(\mathrm{g} \mathrm{kg}^{-1}\right)$ & 479,93 & 496,06 & 713,20 \\
\hline Matéria orgânica resistente à compos. $\left(\mathrm{g} \mathrm{kg}^{-1}\right)$ & 20,52 & 196,84 & 149,55 \\
\hline Carbono total $\left(\mathrm{g} \mathrm{kg}^{-1}\right)$ & 277,88 & 385,01 & 479,32 \\
\hline Carbono orgânico $\left(\mathrm{g} \mathrm{kg}^{-1}\right)$ & 266,73 & 275,54 & 396,22 \\
\hline Resíduo mineral total $\left(\mathrm{g} \mathrm{kg}^{-1}\right)$ & 499,55 & 262,72 & 137,25 \\
\hline Resíduo mineral insolúvel $\left(\mathrm{g} \mathrm{kg}^{-1}\right)$ & 418,82 & 156,80 & 7,83 \\
\hline Resíduo mineral solúvel $\left(\mathrm{g} \mathrm{kg}^{-1}\right)$ & 80,73 & 105,92 & 129,42 \\
\hline $\mathrm{N}$ total $\left(\mathrm{g} \mathrm{kg}^{-1}\right)$ & 14,27 & 12,23 & 33,78 \\
\hline$P$ total $\left(\mathrm{g} \mathrm{kg}^{-1}\right)$ & 2,92 & 1,72 & 9,98 \\
\hline $\mathrm{K}$ total $\left(\mathrm{g} \mathrm{kg}^{-1}\right)$ & 1,11 & 3,60 & 27,00 \\
\hline Ca total $\left(\mathrm{g} \mathrm{kg}^{-1}\right)$ & 55,31 & 14,99 & 21,24 \\
\hline $\mathrm{Mg}$ total $\left(\mathrm{g} \mathrm{kg}^{-1}\right)$ & 1,78 & 7,69 & 5,34 \\
\hline $\mathrm{S}$ total $\left(\mathrm{g} \mathrm{kg}^{-1}\right)$ & 1,34 & 2,56 & 2,36 \\
\hline $\mathrm{Cu}$ total $\left(\mathrm{mg} \mathrm{kg}^{-1}\right)$ & 111,51 & 197,24 & 186,31 \\
\hline Mn total $\left(\mathrm{mg} \mathrm{kg}^{-1}\right)$ & 535,24 & 108,48 & 322,94 \\
\hline $\mathrm{Zn}$ total $\left(\mathrm{mg} \mathrm{kg}^{-1}\right)$ & 156,11 & 364,89 & 365,17 \\
\hline Fe total $\left(\mathrm{mg} \mathrm{kg}^{-1}\right)$ & 18443,35 & 10927,02 & 787,48 \\
\hline $\mathrm{Na}$ total $\left(\mathrm{mg} \mathrm{kg}^{-1}\right)$ & 3822,48 & 3909,27 & 4193,27 \\
\hline Relação C/N (C total e N total) & $19 / 1$ & $31 / 1$ & $14 / 1$ \\
\hline
\end{tabular}

$\mathrm{CLC}=$ composto de lodo de cervejaria + cavaco de eucalipto; $\mathrm{CL}=$ composto de lixo; $\mathrm{CF}=$ cama de frango. 
A área experimental foi amostrada trinta dias antes do plantio, coletando-se 15 sub-amostras à profundidade de $0-20 \mathrm{~cm}$ de terra para constituir uma amostra composta, que foi analisada em laboratórios do Departamento de Ciência do Solo da ESALQ/USP, sendo os resultados apresentados na Tabela 2. Baseado nestes resultados, dispensou-se a calagem e realizou-se a adubação de plantio empregando-se $300 \mathrm{~kg} \mathrm{ha}^{-1}$ de $\mathrm{P}_{2} \mathrm{O}_{5}$ como superfosfato simples ( $18 \%$ de $\left.\mathrm{P}_{2} \mathrm{O}_{5}\right)$ em área total. $\mathrm{O}$ nitrogênio e o potássio foram fornecidos, durante o ciclo da cultura, via fertirrigação, totalizando $380 \mathrm{~kg} \mathrm{ha}^{-1}$ de N e $450 \mathrm{~kg} \mathrm{ha}^{-1}$ de $\mathrm{K}_{2} \mathrm{O}$, conforme indicações de Vivancos (1993). Foram empregadas as fontes nitrato de potássio ( $\left.13 \% \mathrm{~N} \mathrm{e} 44 \% \mathrm{~K}_{2} \mathrm{O}\right)$ e uréia $(45 \% \mathrm{~N})$.

Tabela 2. Propriedades químicas do Podzólico Vermelho-Amarelo no local do experimento à profundidade de $0-20 \mathrm{~cm}$.

\begin{tabular}{|c|c|c|c|c|c|c|c|c|c|}
\hline $\mathrm{pH}$ & M.O. & $\mathrm{P}$ (resina) & $\mathrm{K}$ & $\mathrm{Ca}$ & $\mathrm{Mg}$ & $\mathrm{H}+\mathrm{Al}$ & SB & $\mathrm{T}$ & $\overline{\mathrm{V}}$ \\
\hline $\mathrm{CaCl}_{2}$ & $\mathrm{~g} \mathrm{dm}^{-3}$ & $\mathrm{mg} \mathrm{dm}{ }^{-3}$ & & & $\mathrm{mmol}$ & & & & $\%$ \\
\hline 5,1 & 17 & 64 & 4,6 & 52 & 23 & 15 & 79,6 & 94,6 & 84 \\
\hline
\end{tabular}

As mudas de tomate cv. Carmem foram produzidas em bandejas, em casa-devegetação, e transplantadas para o local definitivo no espaçamento de $50 \mathrm{~cm}$ entre plantas e 1,0 m entre fileiras. A estufa foi do tipo em arco de madeira, coberta com filme de polietileno aditivado, onde as plantas foram conduzidas com fitilho, conforme ilustra a Figura 1. A irrigação, feita por gotejamento, as desbrotas e o controle fitossanitário foram efetuados de acordo com as necessidades da cultura. Pulverizações preventivas com $\mathrm{Ca}$ foram feitas semanalmente, a partir do início do florescimento das plantas, dirigida para os frutos, com uma solução de cloreto de cálcio a 0,6 \% acompanhada de espalhante adesivo (Castellane, 1988).

O delineamento experimental foi o de blocos casualizados com quatro repetições, no esquema fatorial $3 \times 4$, constituído de três resíduos orgânicos (composto de lodo de cervejaria + cavaco de eucalipto, composto de lixo e cama de frango) e quatro doses, equivalentes a $0,100,150$ e $200 \mathrm{~kg} \mathrm{ha}^{-1}$ de nitrogênio. Cada parcela foi composta por 16 
plantas com plantio em linha dupla, ou seja, 8 plantas por linha, totalizando uma área de $7,0 \mathrm{~m}^{2}$.

Foram amostradas cinco plantas tomadas ao acaso por parcela, aos 30,45 e 55 dias após o transplante das mudas para a avaliação da sua altura.

Para as determinações dos teores totais dos nutrientes foram coletadas 5 folhas por parcela, na época do florescimento, tomando-se a quarta folha a partir do ápice (Malavolta et al., 1997). Também foram determinados os teores de $\mathrm{N}-\mathrm{NO}_{3}{ }^{-}, \mathrm{P}^{-} \mathrm{H}_{2} \mathrm{PO}_{4}{ }^{-}$e $\mathrm{K}-\mathrm{K}^{+}$nos peciolos da quarta folha a partir do ápice da planta, nas épocas do florescimento e do aparecimento dos primeiros frutos com alterações de cor (University of California, 1979).

Os teores totais dos nutrientes, de potássio solúvel em água e de fósforo solúvel em ácido acético foram determinados conforme metodologia descrita a seguir por Malavolta et al. (1997): nitrogênio pelo método semi-micro Kjeldahl; fósforo total por colorimetria do metavanadato; fósforo solúvel $\left(\mathrm{P}_{-} \mathrm{H}_{2} \mathrm{PO}_{4}{ }^{-}\right)$por colorimetria do azul de molibdênio; potássio, cálcio, magnésio, cobre, ferro, manganês e zinco por espectrofotometria de absorção atômica; enxofre por turbidimetria do sulfato de bário; boro por colorimetria da azometina $\mathrm{H}$. As determinações de nitrato foram feitas segundo metodologia de Tedesco et al. (1985).

A colheita dos frutos iniciou-se em 12/05/97 e se estendeu até 07/07/97. A produção total, a produção de frutos comercializáveis (frutos com diâmetro maior que $5,5 \mathrm{~cm}$ ), o peso médio de frutos e o número de frutos por planta foram avaliados tomando-se as 16 plantas da parcela.

Em 06/08/97, vinte amostras simples de terra foram coletadas por parcela para formar uma amostra composta, para as determinações do $\mathrm{pH}\left(\mathrm{em} \mathrm{CaCl}_{2}\right)$, matéria orgânica (método colorimétrico), fósforo disponivel (extraído por resina trocadora de ions e determinado por método colorimétrico), potássio, cálcio e magnésio trocáveis (extraídos do solo por resina trocadora de íons e determinados por espectrofotometria de absorção atômica ) e acidez potencial (método tampão SMP). A capacidade de troca de cátions foi calculada através da soma de bases $\left(\mathrm{K}^{+}, \mathrm{Ca}^{++}\right.$e $\left.\mathrm{Mg}^{++}\right)$com a acidez potencial $\left(\mathrm{H}^{+}+\mathrm{Al}^{3+}\right)$. 
Os dados obtidos foram submetidos à análise de variância pelo teste $\mathrm{F}$ e a comparação entre médias feita pelo teste $t$ de Student, ao nível de $5 \%$ de probabilidade. Os dados da altura das plantas, aos 55 dias após o transplante, dos teores foliares de B e dos teores de $\mathrm{Mg}$ no solo foram transformados $\mathrm{em} \mathrm{x}^{1 / 2}, \log 10 \mathrm{e} \mathrm{x}^{0,4}$, respectivamente. Para o efeito de doses efetuou-se a análise de regressão polinomial.

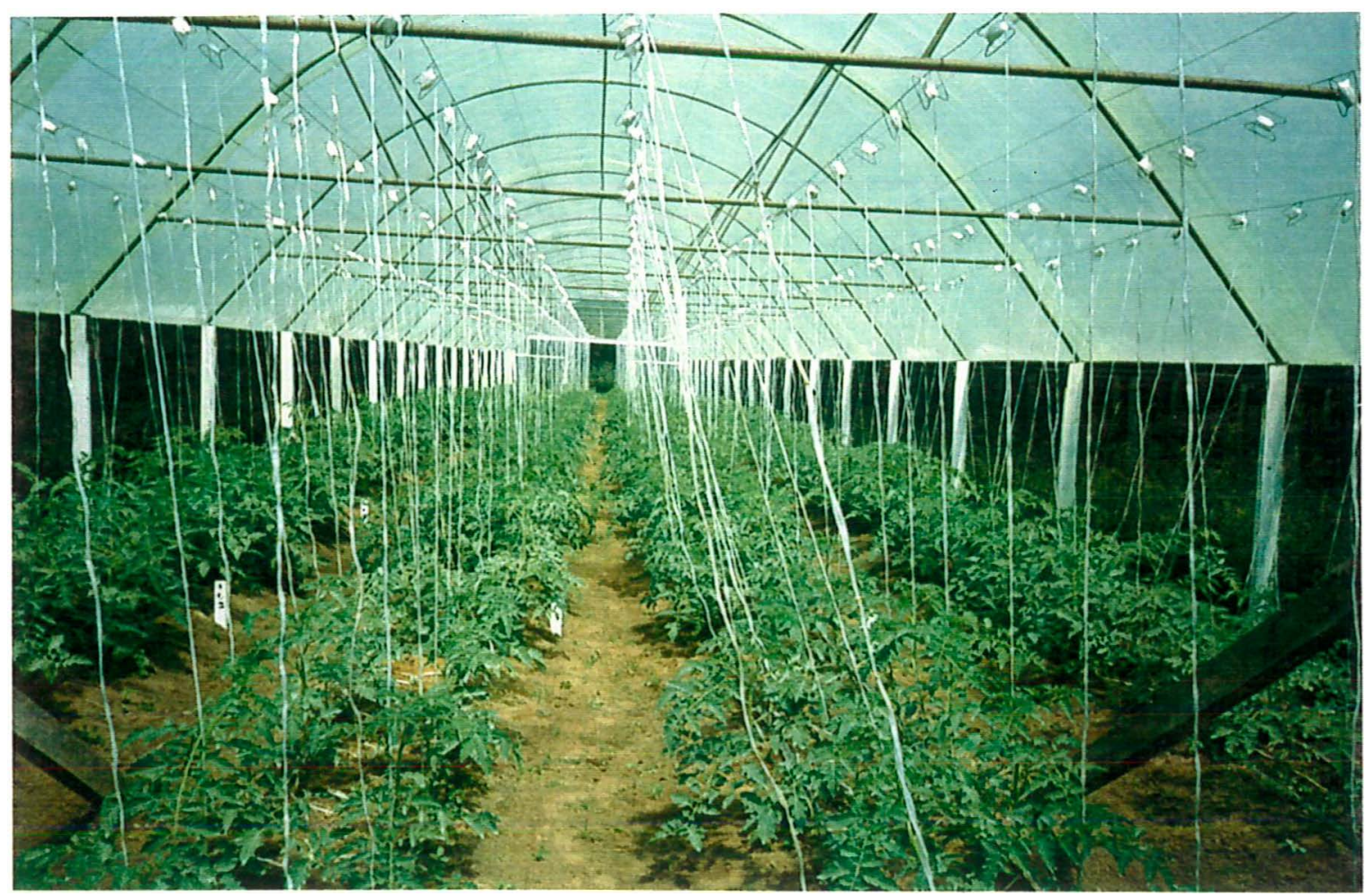

Figura 1. Vista geral das plantas de tomate cv. Carmem cultivadas em estufa do tipo em arco. Piracicaba (SP). 


\subsection{Resultados e Discussão}

A altura das plantas sofreu influência dos tipos de resíduos orgânicos aplicados (Tabela 3). Verificou-se que o composto de lixo, na dose equivalente a $100 \mathrm{~kg} \mathrm{ha}^{-1} \mathrm{de} \mathrm{N}$, proporcionou a menor altura das plantas, em todas as épocas de amostragem. Quando se empregou a maior dose, este resíduo também correspondeu ao menor valor de altura, aos 30 e 55 dias após o transplante. Possivelmente a relação $\mathrm{C} / \mathrm{N}$ maior deste composto (Tabela 1) proporcionou menor taxa de mineralização do $\mathrm{N}$, consequentemente menor disponibilidade deste elemento no solo, o que refletiu no crescimento das plantas. Resultados concordantes foram obtidos por Hampton et al. (1994), os quais observaram diferenças no crescimento das plantas de tomate, após a adição de compostos derivados de residuo sólido urbano, devido às taxas de mineralização distintas entre os materiais orgânicos. Em todas as épocas de amostragem, houve aumento linear na altura das plantas em função das doses do composto de lodo de cervejaria + cavaco de eucalipto e da cama de frango (Figuras 2 e 3), provavelmente, em resposta ao $\mathrm{N}$ fornecido por esses materiais.

Os valores do número de frutos por planta, do peso médio de frutos, da produção total e da produção de frutos comercializáveis, constam da Tabela 4 . Ao contrário do que foi constatado para a altura das plantas, o composto de lixo promoveu o maior peso médio de frutos em relação à cama de frango e ao composto de lodo de cervejaria + cavaco de eucalipto nas doses equivalentes a 100 e $200 \mathrm{~kg} \mathrm{ha}^{-1}$ de $\mathrm{N}$, respectivamente. $\mathrm{O}$ número de frutos por planta e a produção total, por sua vez, não foram afetados pelos tratamentos empregados. Embora não tenha ocorrido diferença significativa entre os tratamentos para a produção total, a cama de frango proporcionou a maior produção de frutos comercializáveis em relação ao composto de lodo de cervejaria + cavaco de eucalipto, não diferindo significativamente do composto de lixo, quando se empregou a maior dose. Considerando-se as concentrações de $\mathrm{P}$ e $\mathrm{K}$ nos materiais orgânicos, a maior dose de cama de frango apresentava $44 \%$ de $\mathrm{P}$ e $925 \%$ de $\mathrm{K}$ a mais em relação ao composto de lodo de cervejaria + cavaco de eucalipto, que possivelmente contribuíram para a maior produção de frutos comercializáveis, ou seja, maior produção de frutos com diâmetro superior a $5,5 \mathrm{~cm}$. Além disso, a menor relação $\mathrm{C} / \mathrm{N}$ da cama de frango pode ter 
resultado em maior disponibilidade de $\mathrm{N}$ durante o ciclo de desenvolvimento da cultura. Asiegbu \& Oikeh (1995) também constataram maior produção, neste caso, de matéria seca de plantas de tomate, com a aplicação de $20 \mathrm{Mg} \mathrm{ha}^{-1}$ de esterco de coelho em relação ao esterco de suíno e ao esterco de galinha, por apresentar em sua composição concentrações maiores de $\mathrm{N}, \mathrm{P}$ e $\mathrm{K}$ e menor relação $\mathrm{C} / \mathrm{N}$.

Com exceção da produção de frutos comercializáveis, as variáveis não foram afetadas com a adição dos materiais orgânicos empregados, provavelmente devido às baixas quantidades aplicadas. Hampton et al. (1994) também não observaram incrementos na produção de tomate com a aplicação de 16 a $48 \mathrm{Mg} \mathrm{ha}^{-1}$ de materiais derivados de resíduo sólido urbano, em solo adubado com $240 \mathrm{~kg} \mathrm{ha}^{-1}$ de $\mathrm{N}$; atribuíram esse resultado às baixas doses adicionadas ou ao fertilizante inorgânico aplicado em todos os tratamentos, o qual pode ter mascarado os efeitos do $\mathrm{N}$ proveniente dos resíduos orgânicos.

A produção de frutos comercializáveis sofreu influência apenas das doses de cama de frango, sendo que a sua aplicação em quantidade equivalente a $200 \mathrm{~kg} \mathrm{ha}^{-1} \mathrm{de} \mathrm{N}$ aumentou a produção de frutos comercializáveis em relação à aplicação de $150 \mathrm{~kg} \mathrm{ha}^{-1} \mathrm{de}$ $\mathrm{N}$, provavelmente devido ao aumento do fornecimento de $\mathrm{N}$ e dos outros nutrientes provenientes desse material orgânico para as plantas. 
Tabela 3. Efeitos de tipos de residuos orgânicos sobre a altura das plantas de tomate cv. Carmen.

\begin{tabular}{|c|c|c|c|c|}
\hline \multirow{2}{*}{$\begin{array}{l}\text { Resíduos } \\
\text { orgânicos }\end{array}$} & \multicolumn{4}{|c|}{ - } \\
\hline & $\mathbf{0}$ & 100 & 150 & 200 \\
\hline & \multicolumn{4}{|c|}{ - } \\
\hline & \multicolumn{4}{|c|}{30 dias após o transplante } \\
\hline CLC & $74,50 \mathrm{ab}$ & 81,42 a & $87,92 \mathrm{a}$ & $89,50 \mathrm{a}$ \\
\hline $\mathrm{CF}$ & $69,00 \mathrm{~b}$ & $81,42 \mathrm{a}$ & $91,25 \mathrm{a}$ & 89,17 a \\
\hline $\mathrm{CL}$ & $82,75 \mathrm{a}$ & $68,83 \mathrm{~b}$ & $83,08 \mathrm{a}$ & $79,08 \mathrm{~b}$ \\
\hline \multirow[t]{2}{*}{ C.V. $(\%)$} & 14,16 & & & \\
\hline & \multicolumn{4}{|c|}{45 dias após o transplante } \\
\hline CLC & $131,50 \mathrm{ab}$ & $141,00 \mathrm{a}$ & $148,67 \mathrm{a}$ & $150,67 \mathrm{a}$ \\
\hline $\mathrm{CF}$ & $126,42 \mathrm{~b}$ & $141,58 \mathrm{a}$ & $152,42 \mathrm{a}$ & $145,67 \mathrm{a}$ \\
\hline $\mathrm{CL}$ & $144,75 \mathrm{a}$ & $126,42 \mathrm{~b}$ & $143,50 \mathrm{a}$ & $140,42 \mathrm{a}$ \\
\hline \multirow[t]{2}{*}{ C.V. $(\%)$} & 9,27 & & & \\
\hline & \multicolumn{4}{|c|}{55 dias após o transplante } \\
\hline CLC & $172,39 a b$ & $180,63 \mathrm{a}$ & $191,27 \mathrm{a}$ & 192,93 a \\
\hline $\mathrm{CF}$ & $168,48 \mathrm{~b}$ & $180,36 \mathrm{a}$ & $192,93 \mathrm{a}$ & $186,05 \mathrm{ab}$ \\
\hline $\mathrm{CL}$ & $186,05 \mathrm{a}$ & $166,93 \mathrm{~b}$ & $184,14 \mathrm{a}$ & $179,02 \mathrm{~b}$ \\
\hline C.V. $(\%)$ & 4,01 & & & \\
\hline
\end{tabular}

* Dados originais

Médias seguidas pela mesma letra não diferem entre si pelo teste $t$ de Student a $5 \%$. $\mathrm{CLC}=$ composto de lodo de cervejaria + cavaco de eucalipto; $\mathrm{C}=$ cama de frango; $\mathrm{CL}$ $=$ composto de lixo. 


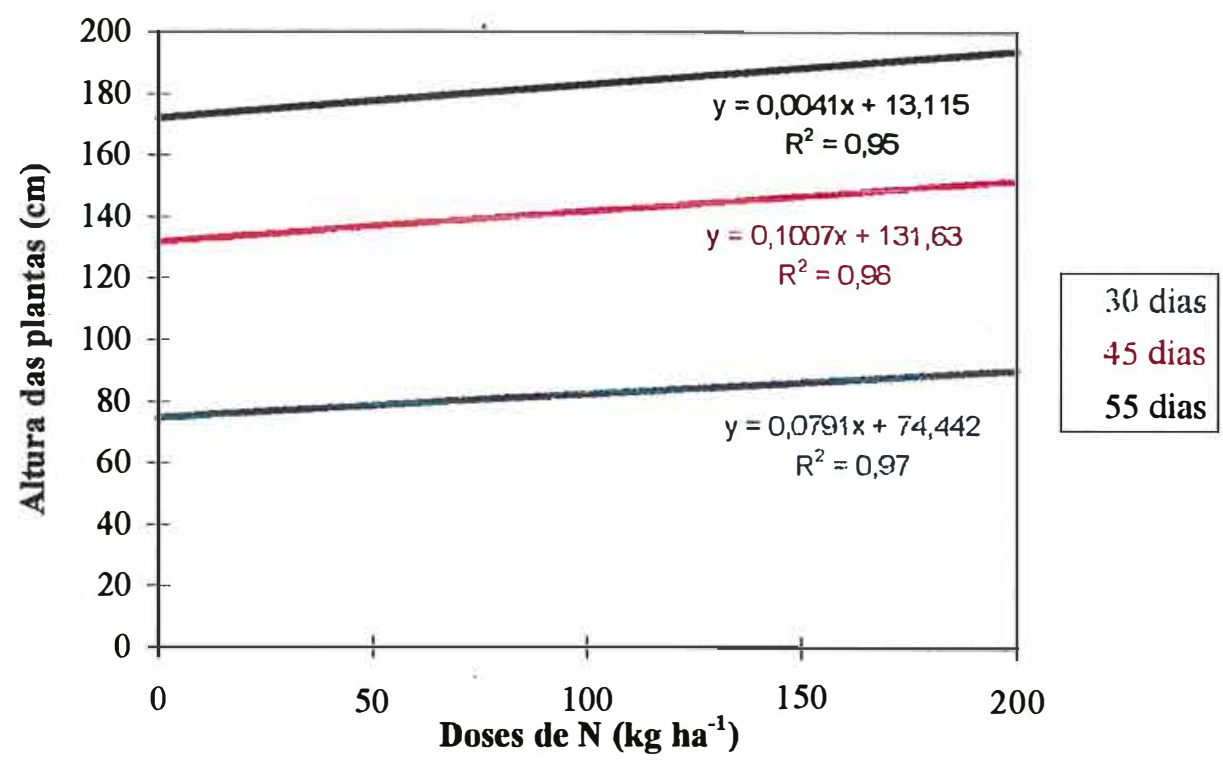

Figura 2. Efeito da adição do composto de lodo de cervejaria + cavaco de eucalipto sobre a altura das plantas, aos 30, 45 e 55 dias após o transplante.

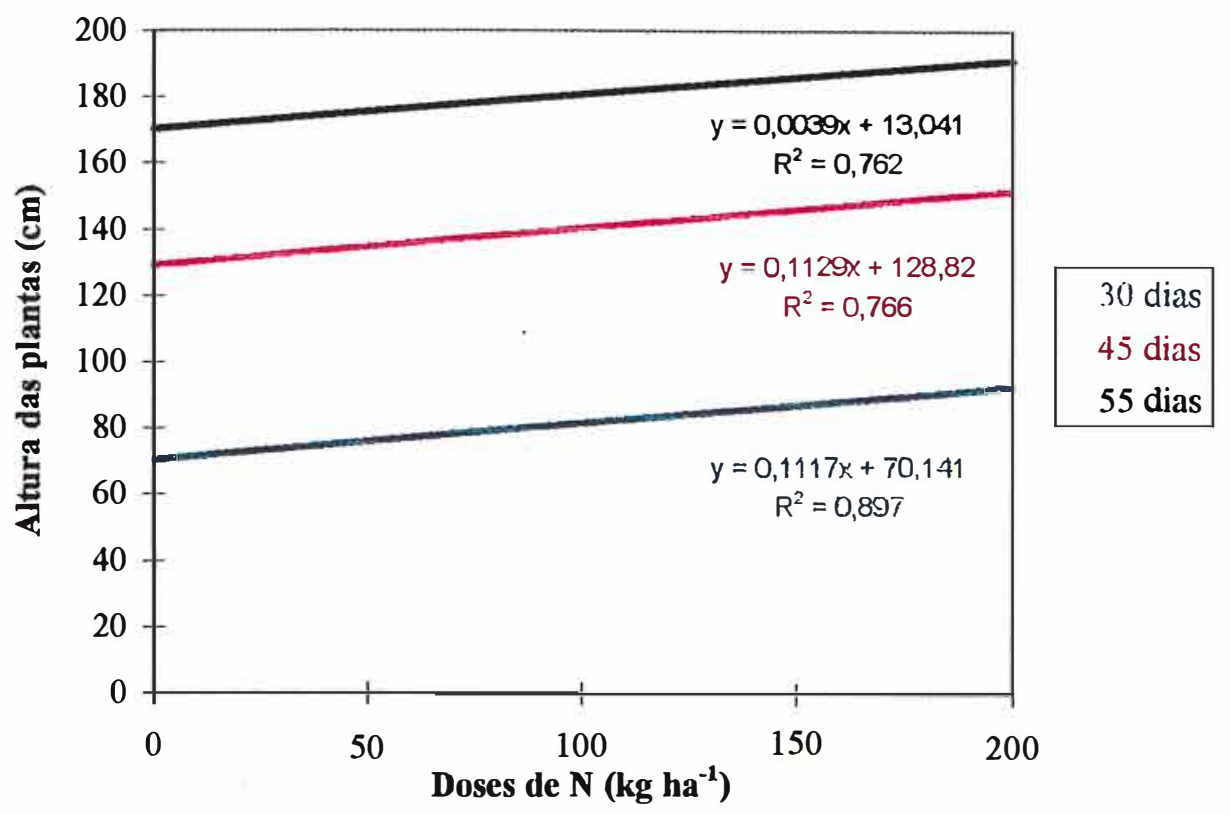

Figura 3. Efeito da adição da cama de frango sobre a altura das plantas, aos 30, 45 e 55 dias após o transplante. 
Tabela 4. Efeitos de tipos e doses de resíduos orgânicos no peso médio de frutos, no número de frutos por planta, na produção total e na produção de frutos comercializáveis de tomate cv. Carmem.

\begin{tabular}{|c|c|c|c|c|}
\hline \multirow[t]{2}{*}{ Resíduos orgânicos } & \multicolumn{4}{|c|}{-Doses de N $\left(\mathrm{kg} \mathrm{ha}^{-1}\right)$} \\
\hline & $\mathbf{0}$ & 100 & 150 & 200 \\
\hline \multicolumn{5}{|l|}{$\begin{array}{l}\text { Peso médio de frutos } \\
\text { (g/fruto) }\end{array}$} \\
\hline CLC & 121,51 a $\mathrm{A}$ & $123,31 \mathrm{ab} \mathrm{A}$ & 122,19 a A & $115,81 \mathrm{~b} \mathrm{~A}$ \\
\hline CF & 121,83 a $\mathrm{A}$ & 120,46 b A & 117,02 a $\mathrm{A}$ & 126,11 ab A \\
\hline $\mathrm{CL}$ & 123,43 a $\mathrm{A}$ & 133,32 a A & 118,28 a $\mathrm{A}$ & 128,05 a A \\
\hline C.V. $(\%)$ & 6,93 & & & \\
\hline \multicolumn{5}{|c|}{ Número de frutos/planta } \\
\hline CLC & 42,00 a $\mathrm{A}$ & 40,25 a $\mathrm{A}$ & 37,20 a A & 38,85 a A \\
\hline $\mathrm{CF}$ & 39,03 a $\mathrm{A}$ & 37,57 a $\mathrm{A}$ & 37,80 a $\mathrm{A}$ & 42,50 a A \\
\hline $\mathrm{CL}$ & 42,20 a A & 33,23 a A & 41,17 a A & 39,08 a A \\
\hline C.V. (\%) & 13,58 & & & \\
\hline \multicolumn{5}{|c|}{ Produção total $\left(\mathrm{Mg} \mathrm{ha}^{-1}\right)$} \\
\hline CLC & 116,99 a A & 113,14 a A & 102,96 a A & 102,65 a $\mathrm{A}$ \\
\hline $\mathrm{CF}$ & 108,36 a A & 106,76 a A & 100,50 a A & 122,45 a $\mathrm{A}$ \\
\hline CL & 106,90 a $\mathrm{A}$ & 100,29 a A & 111,18 a $\mathrm{A}$ & 115,48 a $\mathrm{A}$ \\
\hline C.V. $(\%)$ & 13,02 & & & \\
\hline \multicolumn{5}{|c|}{$\begin{array}{l}\text { Produção de frutos } \\
\text { comercializáveis }\left(\mathrm{Mg} \mathrm{ha}^{-1}\right)\end{array}$} \\
\hline CLC & 109,83 a $\mathrm{A}$ & 105,82 a $\mathrm{A}$ & 95,08 a $\mathrm{A}$ & 93,61 b A \\
\hline $\mathrm{CF}$ & $100,61 \mathrm{a} A B$ & $100,51 \mathrm{a} \mathrm{AB}$ & 90,43 a B & 116,64 a A \\
\hline $\begin{array}{c}\text { CL } \\
\text { C.V. }(\%)\end{array}$ & $\begin{array}{l}99,35 \text { a A } \\
15,03\end{array}$ & 93,65 a A & 105,33 a $\mathrm{A}$ & $109,51 \mathrm{ab} A$ \\
\hline
\end{tabular}

Médias seguidas pela mesma letra, minúscula na coluna e maiúscula na linha, não diferem entre si pelo teste t de Student a $5 \%$.

$\mathrm{CLC}=$ composto de lodo de cervejaria + cavaco de eucalipto; $\mathrm{CF}=$ cama de frango; $\mathrm{CL}$ = composto de lixo.

Os teores de macronutrientes nas folhas estão apresentados na Tabela 5. Com exceção do $\mathrm{Mg}$, os teores de nutrientes não sofreram influência do tipo de resíduo. $\mathrm{O}$ maior teor de $\mathrm{Mg}$ foi obtido com a adição do composto de lixo, na dose equivalente a $150 \mathrm{~kg} \mathrm{ha}^{-1}$ de $\mathrm{N}$, concordando com a maior quantidade de $\mathrm{Mg}$ presente neste material em relação aos demais. 
Os teores foliares de fósforo foram afetados somente com a adição da cama de frango, sendo que sua aplicação em quantidade equivalente a $100 \mathrm{~kg} \mathrm{ha}^{-1}$ de $\mathrm{N}$ aumentou o teor desse elemento nas folhas. As concentrações foliares de potássio aumentaram em torno de 10 a $20 \%$ com a adição dos três materiais orgânicos, provavelmente devido ao fornecimento desse elemento pelos materiais orgânicos. Os teores de $\mathrm{Mg}$ nas folhas foram influenciados pela adição da cama de frango e do composto de lixo, sendo que para o primeiro resíduo as doses mais elevadas reduziram os teores foliares de $\mathrm{Mg}$, o que parcialmente está de acordo com os resultados obtidos para o conteúdo desse elemento no solo (Tabela 8). A aplicação de $150 \mathrm{~kg} \mathrm{ha}^{-1}$ de $\mathrm{N}$ como composto de lixo aumentou a concentração de $\mathrm{Mg}$ nas folhas. Resultados concordantes foram obtidos por Asiegbu \& Oikeh (1995), os quais observaram acréscimos nos teores foliares de $\mathrm{P}, \mathrm{K}$ e $\mathrm{Mg}$ após a adição de esterco de suíno ou lodo de esgoto em quantidades que variaram de 10 a 30 $\mathrm{Mg} \mathrm{ha}^{-1}$.

Os resultados dos teores foliares de micronutrientes estão descritos na Tabela 6. Com exceção do $\mathrm{B}$, os teores de nutrientes não foram afetados pelos tratamentos empregados. A aplicação do composto de lixo em quantidade equivalente a $150 \mathrm{~kg} \mathrm{ha}^{-1}$ de $\mathrm{N}$ reduziu em $5 \%$ o teor de $\mathrm{B}$ nas folhas.

A análise de regressão dos teores foliares de nutrientes em função das quantidades dos materiais orgânicos empregados mostraram efeito significativo da cama de frango sobre o teor de zinco (Figura 4) e do composto de lixo sobre o teor de cobre (Figura 5). Os teores de $\mathrm{Zn}$ nas folhas aumentaram com o aumento das doses da cama de frango. Este comportamento não foi observado para o $\mathrm{Cu}$ quando se empregou o composto de lixo, pois os teores deste elemento nas folhas diminuiram até a dose equivalente a $150 \mathrm{~kg}$ $\mathrm{ha}^{-1}$ de $\mathrm{N}$, aumentando posteriormente. Fritz \& Venter (1988) obtiveram resultados semelhantes para o teor foliar de $\mathrm{Zn}$ com o aumento das doses de composto de lixo. Para o cobre, eles verificaram o mesmo comportamento obtido neste experimento, entretanto, para os teores de $\mathrm{Cu}$ nos frutos de tomate, onde a adição de $50 \mathrm{Mg} \mathrm{ha}^{-1}$ do composto diminuiu o conteúdo deste micronutriente, que posteriormente aumentou com a aplicação de $100 \mathrm{Mg} \mathrm{ha}^{-1}$. Para este fato os autores não encontraram explicação. 
Com exceção do $\mathrm{Cu}$, os teores dos nutrientes encontram-se dentro da faixa considerada adequada, segundo Trani \& Raij (1996). Os teores foliares de N, K e Mg também foram semelhantes aos obtidos por Asiegbu \& Oikeh (1995). Os teores de $\mathrm{Cu}$, por sua vez, foram bem superiores aos encontrados na literatura, provavelmente devido à contaminação por pulverizações foliares com fungicidas cúpricos, realizadas no decorrer do experimento.

Para os teores de nutrientes nos pecíolos do tomate houve interação significativa entre as fontes e as doses dos materiais orgânicos apenas para o potássio, na época do florescimento, e para o nitrato no segundo período de amostragem (Tabela 7). Para o teor solúvel de potássio, os resíduos orgânicos diferiram significativamente entre si na dose equivalente a $150 \mathrm{~kg} \mathrm{ha}^{-1}$ de $\mathrm{N}$, sendo que o composto de lixo proporcionou maior teor de K que o composto de lodo de cervejaria + cavaco de eucalipto. Somente o composto de lixo influenciou nos teores solúveis de potássio, sendo que a adição de 100 $\mathrm{kg} \mathrm{ha}^{-1}$ de $\mathrm{N}$ proporcionou o maior teor deste elemento.

$\mathrm{Na}$ segunda época de amostragem, ou seja, no aparecimento dos primeiros frutos com alteração de cor, houve diferença significativa apenas entre as doses da cama de frango sobre o teor solúvel de nitrato, sendo que a aplicação da dose equivalente a 150 $\mathrm{kg} \mathrm{ha}^{-1}$ de $\mathrm{N}$ reduziu o teor de nitrato, o que está de acordo com a menor produção de frutos comercializáveis (Tabela 7).

Os teores solúveis de nitrato no período do florescimento, de acordo com a classificação da University of California (1979) foram considerados deficientes. Para os demais, os níveis estiveram acima do limite intermediário ou suficiente.

Pode-se concluir que as quantidades maiores dos nutrientes nos materiais orgânicos nem sempre proporcionaram concentrações foliares mais elevadas ou maior produção de frutos, o que está coerente com os resultados obtidos por Asiegbu \& Oikeh (1995), os quais constataram ausência de correlação entre as concentrações de N, P, Ca, $\mathrm{K}, \mathrm{Fe}$ e $\mathrm{Cu}$ nas folhas de tomate e as quantidades desses elementos no esterco de galinha. 
Tabela 5. Efeitos de tipos e doses de resíduos orgânicos nas concentrações de macronutrientes em folhas de tomate cv. Carmem, na época do florescimento.

\begin{tabular}{|c|c|c|c|c|}
\hline \multirow{2}{*}{$\begin{array}{l}\text { Resíduos } \\
\text { orgânicos }\end{array}$} & \multicolumn{4}{|c|}{ Doses de $\mathrm{N}\left(\mathrm{kg} \mathrm{ha}^{-1}\right)$} \\
\hline & 0 & 100 & 150 & 200 \\
\hline \multicolumn{5}{|c|}{ Nitrogênio (N) } \\
\hline CLC & 44,07 a A & 43,30 a $\mathrm{A}$ & 42,83 a $\mathrm{A}$ & 43,05 a $\mathrm{A}$ \\
\hline $\mathrm{CF}$ & 42,45 a $\mathrm{A}$ & 45,68 a $\mathrm{A}$ & 43,65 a A & 44,28 a $\mathrm{A}$ \\
\hline CL & 42,98 a A & 43,20 a A & 42,05 a A & 40,63 a A \\
\hline C.V. (\%) & 6,04 & & & \\
\hline \multicolumn{5}{|l|}{ Fósforo (P) } \\
\hline CLC & 7,28 a A & 7,18 a $\mathrm{A}$ & 7,00 a A & 6,43 a $A$ \\
\hline $\mathrm{CF}$ & 6,10 a B & 7,65 a $\mathrm{A}$ & 7,15 a $\mathrm{AB}$ & 7,25 a $A B$ \\
\hline CL & 6,55 a A & 7,35 a $\mathrm{A}$ & 7,88 a $\mathrm{A}$ & 7,68 a $\mathrm{A}$ \\
\hline C.V. (\%) & 13,16 & & & \\
\hline \multicolumn{5}{|l|}{ Potássio (K) } \\
\hline CLC & 30,30 a B & 31,73 a $A B$ & 32,65 a $A B$ & 33,45 a $\mathrm{A}$ \\
\hline $\mathrm{CF}$ & 28,16 a B & 33,20 a A & 30,95 a $\mathrm{AB}$ & 33,88 a $\mathrm{A}$ \\
\hline CL & 30,48 a B & 31,78 a $\mathrm{AB}$ & 33,63 a $\mathrm{A}$ & 32,65 a $\mathrm{AB}$ \\
\hline C.V. (\%) & 6,21 & & & \\
\hline \multicolumn{5}{|l|}{ Cálcio (Ca) } \\
\hline CLC & 23,45 a $\mathrm{A}$ & 23,63 a $\mathrm{A}$ & 20,10 a $\mathrm{A}$ & 19,88 a A \\
\hline $\mathrm{CF}$ & 24,03 a A & 23,98 a $\mathrm{A}$ & 20,93 a $A$ & 21,80 a A \\
\hline CL & $21,75 \mathrm{a} \mathrm{A}$ & 25,90 a A & $21,50 \mathrm{a} \mathrm{A}$ & 22,58 a A \\
\hline C.V. (\%) & 15,51 & & & \\
\hline \multicolumn{5}{|c|}{ Magnésio (Mg) } \\
\hline CLC & 6,01 a A & 6,60 a A & 6,33 b A & 6,05 a $A$ \\
\hline $\mathrm{CF}$ & 6,38 a $A B$ & 7,05 a $A$ & 6,28 b B & 6,10 a B \\
\hline CL & 6,08 a B & 6,53 a $\mathrm{AB}$ & 7,23 a A & 6,48 a $B$ \\
\hline C.V. (\%) & 7,86 & & & \\
\hline \multicolumn{5}{|l|}{ Enxofre (S) } \\
\hline CLC & 5,35 a A & 5,25 a A & 5,25 a A & 5,15 a A \\
\hline $\mathrm{CF}$ & 5,25 a A & 5,75 a $\mathrm{A}$ & 5,28 a A & 5,23 a A \\
\hline CL & 5,13 a $A$ & 5,08 a A & 5,35 a $\mathrm{A}$ & 5,40 a $\mathrm{A}$ \\
\hline C.V. $(\%)$ & 7,21 & & & \\
\hline
\end{tabular}

Médias seguidas pela mesma letra, minúscula na coluna e maiúscula na linha, não diferem entre si pelo teste $t$ de Student a $5 \%$.

$\mathrm{CLC}=$ composto de lodo de cervejaria + cavaco de eucalipto; $\mathrm{CF}=$ cama de frango; $\mathrm{CL}$ = composto de lixo. 
Tabela 6. Efeitos de tipos e doses de resíduos orgânicos nas concentrações de micronutrientes em folhas de tomate $\mathrm{cv}$. Carmem, na época do florescimento.

\begin{tabular}{|c|c|c|c|c|}
\hline \multirow{2}{*}{$\begin{array}{l}\text { Resíduos } \\
\text { orgânicos }\end{array}$} & \multicolumn{4}{|c|}{ Doses de $N\left(\mathrm{~kg} \mathrm{ha}^{-1}\right)$} \\
\hline & $\mathbf{0}$ & 100 & 150 & 200 \\
\hline & & & $\mathbf{k g}^{-1} \ldots$ & \\
\hline \multicolumn{5}{|l|}{ Boro (B) ${ }^{*}$} \\
\hline CLC & 61,66 a A & 60,26 a $\mathrm{A}$ & 56,23 a $\mathrm{A}$ & 54,95 a $\mathrm{A}$ \\
\hline $\mathrm{CF}$ & 57,54 a $\mathrm{A}$ & 54,95 a $\mathrm{A}$ & $57,54 \mathrm{a} \mathrm{A}$ & 54,95 a $\mathrm{A}$ \\
\hline $\mathrm{CL}$ & 61,66 a A & $57,54 \mathrm{a} A B$ & 50,12 a B & 56,23 a $\mathrm{AB}$ \\
\hline C.V. $(\%)$ & 3,24 & & & \\
\hline \multicolumn{5}{|l|}{ Cobre (Cu) } \\
\hline CLC & 222,75 a $A$ & 214,75 a $\mathrm{A}$ & 214,25 a $\mathrm{A}$ & 213,75 a $\mathrm{A}$ \\
\hline $\mathrm{CF}$ & 247,20 a A & 188,00 a A & 195,75 a $A$ & 222,75 a A \\
\hline $\mathrm{CL}$ & $276,25 \mathrm{a}$ & $189,00 \mathrm{a}$ & $174,00 \mathrm{a}$ & $191,00 \mathrm{a}$ \\
\hline C.V. $(\%)$ & 23,59 & & & \\
\hline \multicolumn{5}{|l|}{ Ferro (Fe) } \\
\hline CLC & 112,75 a $\mathrm{A}$ & 114,25 a $\mathrm{A}$ & 98,75 a $\mathrm{A}$ & 132,50 a $\mathrm{A}$ \\
\hline $\mathrm{CF}$ & 103,50 a $\mathrm{A}$ & 104,32 a $\mathrm{A}$ & 113,00 a $\mathrm{A}$ & 111,23 a $\mathrm{A}$ \\
\hline $\mathrm{CL}$ & 123,25 a $A$ & 102,50 a $\mathrm{A}$ & 96,19 a $A$ & 92,50 a $\mathrm{A}$ \\
\hline C.V. $(\%)$ & 21,80 & & & \\
\hline \multicolumn{5}{|c|}{ Manganês (Mn) } \\
\hline CLC & 87,25 a $\mathrm{A}$ & 95,50 a $\mathrm{A}$ & 117,50 a $\mathrm{A}$ & 89,00 a $\mathrm{A}$ \\
\hline $\mathrm{CF}$ & 128,75 a $A$ & 88,25 a $\mathrm{A}$ & 110,25 a $\mathrm{A}$ & 78,75 a $\mathrm{A}$ \\
\hline $\mathrm{CL}$ & 103,00 a $\mathrm{A}$ & 74,25 a $\mathrm{A}$ & 64,75 a $\mathrm{A}$ & 56,75 a $A$ \\
\hline C.V. $(\%)$ & 46,52 & & & \\
\hline \multicolumn{5}{|l|}{ Zinco (Zn) } \\
\hline CLC & 29,25 a $\mathrm{A}$ & 30,75 a $\mathrm{A}$ & 30,25 a $\mathrm{A}$ & 30,75 a $\mathrm{A}$ \\
\hline $\mathrm{CF}$ & $27,50 \mathrm{a}$ & $31,25 \mathrm{a}$ & $31,50 \mathrm{a}$ & $31,67 \mathrm{a}$ \\
\hline CL & 30,50 a $\mathrm{A}$ & 31,75 a $\mathrm{A}$ & 30,75 a $\mathrm{A}$ & 30,75 a $\mathrm{A}$ \\
\hline C.V. $(\%)$ & 7,78 & & & \\
\hline
\end{tabular}

${ }^{*}$ Dados originais

Médias seguidas pela mesma letra, minúscula na coluna e maiúscula na linha, não diferem entre si pelo teste $t$ de Student a $5 \%$.

$\mathrm{CLC}=$ composto de lodo de cervejaria + cavaco de eucalipto; $\mathrm{CF}=$ cama de frango; $\mathrm{CL}$ = composto de lixo. 


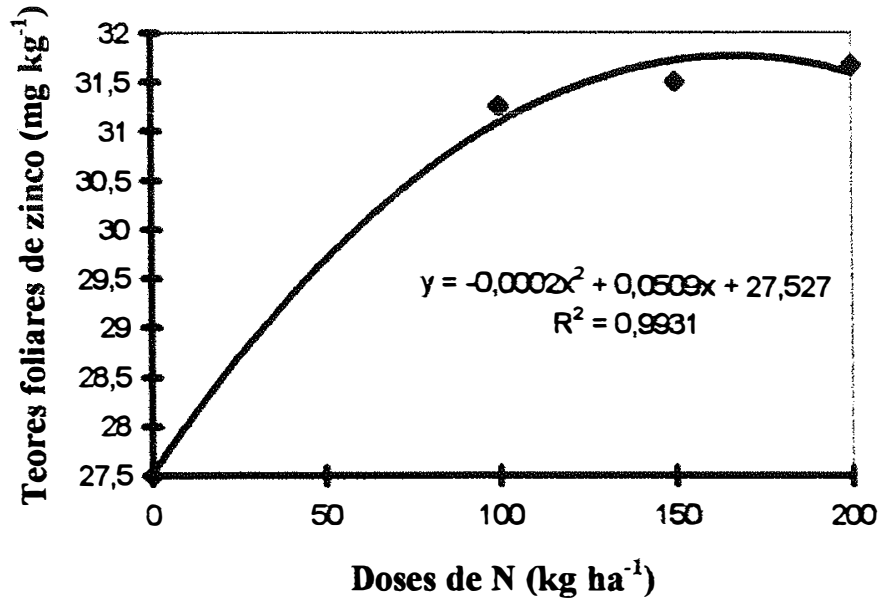

Figura 4. Teores foliares de zinco em função da adição de nitrogênio como cama de frango.

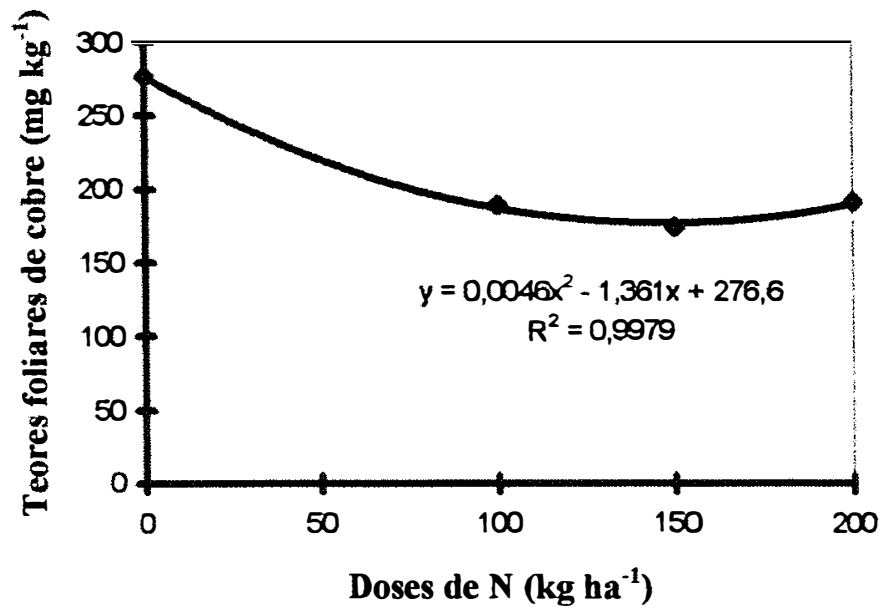

Figura 5. Teores foliares de cobre em função da adição de nitrogênio como composto de lixo. 
Tabela 7. Teores solúveis de potássio, nitrogênio e fósforo nos pecíolos de tomate cv. Carmem.

\begin{tabular}{|c|c|c|c|c|}
\hline \multirow[t]{2}{*}{ Resíduos orgânicos } & \multicolumn{4}{|c|}{ Doses de $N\left(\mathrm{~kg} \mathrm{ha}^{-1}\right)$} \\
\hline & $\mathbf{0}$ & 100 & 150 & 200 \\
\hline & \multicolumn{4}{|c|}{ Epoca do florescimento } \\
\hline \multicolumn{5}{|l|}{ 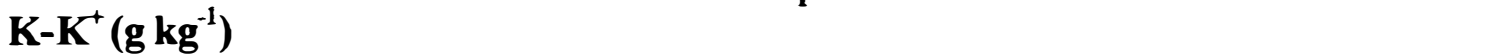 } \\
\hline CLC & 43,5 a $\mathrm{A}$ & 46,7 a $A$ & 43,6 b A & 45,9 a $\mathrm{A}$ \\
\hline $\mathrm{CF}$ & 46,6 a $\mathrm{A}$ & 48,1 a $A$ & $47,1 \mathrm{ab} A$ & 46,5 a $\mathrm{A}$ \\
\hline $\mathrm{CL}$ & 44,8 a B & 49,8 a $\mathrm{A}$ & 48,1 a $A B$ & 48,4 a $A B$ \\
\hline C.V. $(\%)$ & 6,08 & & & \\
\hline \multicolumn{5}{|l|}{$\mathrm{N}-\mathrm{NO}_{3}^{-}\left(\mathrm{mg} \mathrm{kg}^{-1}\right)$} \\
\hline CLC & 3100 a A & 3500 a A & 3500 a A & 3800 a $\mathrm{A}$ \\
\hline $\mathrm{CF}$ & 3400 a A & 3300 a $\mathrm{A}$ & 3500 a A & 3800 a $\mathrm{A}$ \\
\hline $\mathrm{CL}$ & 2800 a $\mathrm{A}$ & 4200 a A & 3800 a A & 3800 a $\mathrm{A}$ \\
\hline C.V. $(\%)$ & 28,53 & & & \\
\hline \multicolumn{5}{|l|}{$\mathrm{P}_{-} \mathrm{H}_{2} \mathrm{PO}_{4}^{-}\left(\mathrm{mg} \mathrm{kg}^{-1}\right)$} \\
\hline CLC & 6687,5 a $A$ & 6812,5 a $A$ & 6687,5 a $A$ & 6187,5 a $A$ \\
\hline $\mathrm{CF}$ & 5875,0 a $\mathrm{A}$ & 6437,5 a A & 6625,0 a $\mathrm{A}$ & 6625,0 a $\mathrm{A}$ \\
\hline $\mathrm{CL}$ & 6375,0 a $\mathrm{A}$ & 6687,5 a $\mathrm{A}$ & 6875,0 a $\mathrm{A}$ & 6875,0 a $A$ \\
\hline \multirow[t]{2}{*}{ C.V. $(\%)$} & 8,28 & & & \\
\hline & \multicolumn{4}{|c|}{ Primeiros frutos com alteração de cor } \\
\hline \multicolumn{5}{|l|}{$K-K^{+}\left(\mathbf{g ~ k g}^{-1}\right)$} \\
\hline CLC & 43,9 a $\mathrm{A}$ & 45,5 a $\mathrm{A}$ & 45,3 a $A$ & 44,4 a $\mathrm{A}$ \\
\hline $\mathrm{CF}$ & 42,8 a $A$ & 42,5 a $A$ & 46,4 a $A$ & 47,1 a $A$ \\
\hline $\mathrm{CL}$ & 46,0 a $\mathrm{A}$ & 46,6 a $\mathrm{A}$ & 45,2 a $\mathrm{A}$ & 49,6 a $\mathrm{A}$ \\
\hline C.V. $(\%)$ & 8,21 & & & \\
\hline \multicolumn{5}{|l|}{$\mathrm{N}-\mathrm{NO}_{3}^{-}\left(\mathrm{mg} \mathrm{kg}^{-1}\right)$} \\
\hline CLC & 3100 a A & 3000 a A & 2900 a A & 2200 a A \\
\hline $\mathrm{CF}$ & 2600 a A & 3500 a A & 1700 a B & 3500 a A \\
\hline $\mathrm{CL}$ & 3200 a A & 2800 a $\mathrm{A}$ & 2600 a A & 2300 a A \\
\hline C.V. $(\%)$ & 32,44 & & & \\
\hline \multicolumn{5}{|l|}{$\mathrm{P}_{-} \mathrm{H}_{2} \mathrm{PO}_{4}^{-}\left(\mathrm{mg} \mathrm{kg}^{-1}\right)$} \\
\hline CLC & 4125,00 a $\mathrm{A}$ & 4062,50 a $A$ & 3625,00 a $\mathrm{A}$ & 3500,00 a $\mathrm{A}$ \\
\hline $\mathrm{CF}$ & 4449,40 a $\mathrm{A}$ & 3472,84 a A & 3437,50 a A & 4250,00 a A \\
\hline $\mathrm{CL}$ & 4562,50 a $\mathrm{A}$ & 4375,00 a A & 4629,68 a A & 4129,68 a A \\
\hline C.V. $(\%)$ & 17,91 & & & \\
\hline
\end{tabular}

Médias seguidas pela mesma letra, minúscula na coluna e maiúscula na linha, não diferem entre si pelo teste $t$ de Student a $5 \%$.

CLC = composto de lodo de cervejaria + cavaco de eucalipto; $\mathrm{CF}=$ cama de frango; $\mathrm{CL}$ = composto de lixo. 
Os valores dos atributos químicos do solo aos seis meses após a incorporação dos materiais orgânicos constam da Tabela 8. Com exceção da matéria orgânica e da acidez potencial, a interação doses e resíduos orgânicos foi significativa para todos os atributos.

A matéria orgânica não sofreu alteração com os tratamentos empregados, provavelmente devido às pequenas quantidades aplicadas dos materiais orgânicos, concordando com Baldock \& Musgrave (1980). Segundo estes autores, normalmente doses baixas de resíduos orgânicos em solos sob intenso cultivo não promovem aumentos significativos no teor de matéria orgânica, onde as condições para a sua decomposição são favoráveis.

O composto de lodo de cervejaria + cavaco de eucalipto proporcionou o maior valor de $\mathrm{pH}$ em relação à cama de frango, sendo que ambos não diferiram significativamente do composto de lixo, nas doses mais elevadas. Resultados concordantes foram obtidos por Braccini et al. (1995), os quais observaram comportamentos distintos entre materiais orgânicos sobre o pH do solo.

Para os teores de fósforo, houve diferença significativa entre os resíduos na dose equivalente a $150 \mathrm{~kg} \mathrm{ha}^{-1}$ de $\mathrm{N}$, onde o composto de lixo foi superior à cama de frango. Este fato não está coerente com a quantidade mais elevada de fósforo adicionada através da cama de frango. Por outro lado, o teor de fósforo mais elevado já existente no solo não tratado com o composto de lixo foi possivelmente responsável por esse resultado.

Os teores de Ca no solo foram superiores com a adição do composto de lodo de cervejaria + cavaco de eucalipto em relação aos outros, nas maiores doses, possivelmente devido à quantidade de $\mathrm{Ca}$ bem superior contida neste material, que foi 3 e 6 vezes maior que aquelas presentes no composto de lixo e na cama de frango, respectivamente. Os teores de potássio e magnésio, por sua vez não foram afetados pelos tipos de resíduos orgânicos.

A capacidade de troca de cátions apresentou o mesmo comportamento obtido para o $\mathrm{Ca}$. Possivelmente, a quantidade mais elevada de matéria orgânica adicionada pelo composto de lodo de cervejaria + cavaco de eucalipto e a sua natureza química contribuíram para o maior valor da CTC ao $\mathrm{pH} 7,0$. 
$\mathrm{O}$ pH aumentou com a aplicação da dose de composto de lodo de cervejaria + cavaco de eucalipto equivalente a $150 \mathrm{~kg} \mathrm{ha}^{-1}$ de $\mathrm{N}$ (Tabela 8). Este fato pode estar relacionado à natureza alcalina e à quantidade elevada de cálcio adicionada pelo composto de lodo de cervejaria + cavaco de eucalipto, os quais sugerem a presença de substâncias alcalinizantes, na forma de óxidos ou hidróxidos de cálcio, responsáveis possivelmente por este efeito. Os demais resíduos não aumentaram o $\mathrm{pH}$ do solo, em virtude talvez das pequenas quantidades adicionadas e da natureza química destes materiais. Holanda et al. (1982) observaram que a aplicação de $12 \mathrm{Mg} \mathrm{ha}^{-1}$ de cama de frango não alterou o $\mathrm{pH}$ em virtude dessa quantidade ser baixa.

$\mathrm{O}$ teor de $\mathrm{P}$ aumentou com a aplicação da dose do composto de lodo de cervejaria + cavaco de eucalipto equivalente a $150 \mathrm{~kg} \mathrm{ha}^{-1} \mathrm{de} \mathrm{N}$ em relação à testemunha, sendo que o mesmo comportamento foi observado quando se aplicou a cama de frango. $O$ composto de lixo na dose equivalente a $150 \mathrm{~kg} \mathrm{ha}^{-1}$ de $\mathrm{N}$ proporcionou incremento no teor de $\mathrm{P}$ quando comparado com a menor dose e com a testemunha. Dentre os processos pelos quais o fósforo pôde tornar-se mais disponível no solo pela adição dos materiais orgânicos, Hue (1992) sugeriu três mecanismos possíveis: (1) o fósforo foi liberado através da mineralização da matéria orgânica; (2) os ânions orgânicos derivados dos materiais orgânicos substituíram o fosfato adsorvido pelos óxidos de ferro e alumínio; (3) e estes ânions orgânicos poderiam ter formado complexos estáveis com os

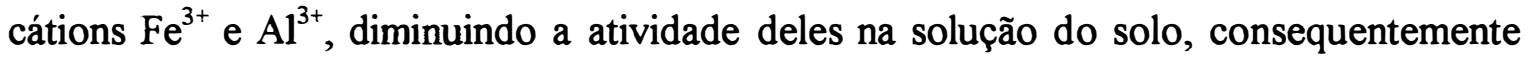
aumentando a atividade do fósforo solúvel.

As maiores doses do composto de lodo de cervejaria + cavaco de eucalipto aumentaram os teores de $\mathrm{Ca}$, sendo que para o $\mathrm{Mg}$ e para o $\mathrm{K}$ os maiores teores foram obtidos com a dose equivalente a $150 \mathrm{~kg} \mathrm{ha}^{-1} \mathrm{de} \mathrm{N}$. Estes resultados podem ser atribuídos ao fornecimento de $\mathrm{K}, \mathrm{Ca}$ e $\mathrm{Mg}$ pelo composto. Somente os teores de $\mathrm{Ca}$ foram afetados pela adição do composto de lixo, sendo que os maiores teores foram obtidos com as doses mais elevadas. Gerber et al. (1981) obtiveram resultados concordantes sobre os teores de $\mathrm{K}, \mathrm{Ca}$ e $\mathrm{Mg}$ no solo após a aplicação de lodo de esgoto em quantidade equivalente a $112 \mathrm{~kg} \mathrm{ha}^{-1}$ de N. A adição de $200 \mathrm{~kg} \mathrm{ha}^{-1}$ de $\mathrm{N}$ como cama de frango reduziu o teor de $\mathrm{Mg}$ no solo. 
A capacidade de troca de cátions ao $\mathrm{pH} 7,0$ aumentou em $49 \%$ com as adições das doses mais elevadas do composto de lodo de cervejaria + cavaco de eucalipto. Este resultado indica em princípio que pode-se incrementar a retenção de cátions com a aplicação de material orgânico em pequenas quantidades, neste caso de 7 e $14 \mathrm{Mg} \mathrm{ha}^{-1}$ do composto, equivalentes a 150 e $200 \mathrm{~kg} \mathrm{ha}^{-1}$ de $\mathrm{N}$.

Embora o conteúdo de matéria orgânica do solo não tenha sido aumentado significativamente com a adição de compostos orgânicos provenientes do composto de lodo de cervejaria + cavaco de eucalipto estes refletiram sobre a CTC ao pH 7,0. Isso é possivel, pois segundo Johnston (1991) mudanças no conteúdo de matéria orgânica do solo ocorrem lentamente e grandes quantidades de materiais orgânicos são necessárias para que o conteúdo da mesma seja aumentado, enquanto que alterações em outras propriedades do solo podem ocorrer de forma mais acentuada e mais rapidamente.

Os demais materiais orgânicos, entretanto, não influenciaram na CTC ao pH 7,0 do solo. Giusquiani et al. (1988) também não observaram alterações na CTC do solo com a adição de $50 \mathrm{Mg} \mathrm{ha}^{-1}$ de composto de lixo. 
Tabela 8 . Atributos químicos do solo em função de tipos e doses de resíduos orgânicos.

\begin{tabular}{|c|c|c|c|c|}
\hline \multirow[t]{2}{*}{ Resíduos orgânicos } & \multicolumn{4}{|c|}{ Doses de N $\left(\mathrm{kg} \mathrm{ha}^{-1}\right)$} \\
\hline & o & 100 & 150 & 200 \\
\hline \multicolumn{5}{|l|}{ pH } \\
\hline CLC & 5,75 a B & 5,73 a $B$ & 6,03 a $\mathrm{A}$ & 5,93 a $\mathrm{AB}$ \\
\hline $\mathrm{CF}$ & 5,83 a $A$ & 5,73 a $A$ & $5,70 \mathrm{~b} \mathrm{~A}$ & 5,58 b A \\
\hline $\mathrm{CL}$ & 5,78 a $A$ & 5,60 a $A$ & $5,80 \mathrm{ab} \mathrm{A}$ & $5,75 \mathrm{ab} A$ \\
\hline C.V. (\%) & 3,65 & & & \\
\hline \multicolumn{5}{|c|}{ Matéria orgânica $\left(\mathrm{g} \mathrm{kg}^{-1}\right)$} \\
\hline CLC & 16,75 a $A$ & 18,50 a $\mathrm{A}$ & 19,25 a $\mathrm{A}$ & 21,25 a $\mathrm{A}$ \\
\hline $\mathrm{CF}$ & 21,00 a $A$ & 21,50 a $\mathrm{A}$ & 18,50 a $\mathrm{A}$ & 20,00 a $\mathrm{A}$ \\
\hline $\mathrm{CL}$ & 21,25 a A & 17,25 a A & 16,25 a $A$ & 17,50 a $\mathrm{A}$ \\
\hline \multicolumn{5}{|l|}{ C.V. (\%) } \\
\hline \multicolumn{5}{|l|}{ Fósforo (mg dm $\left.\mathrm{m}^{-3}\right)$} \\
\hline CLC & 121,50 a B & 171,50 a $A B$ & $198,00 \mathrm{ab} \mathrm{A}$ & 165,50 a $\mathrm{AB}$ \\
\hline $\mathrm{CF}$ & 86,25 a $B$ & 134,75 a $A B$ & 157,44 b A & 136,00 a $\mathrm{AB}$ \\
\hline $\mathrm{CL}$ & 127,50 a $B$ & 106,25 a B & 233,25 a A & $172,00 \mathrm{a} \mathrm{AB}$ \\
\hline C.V. $(\%)$ & 31,32 & & & \\
\hline \multicolumn{5}{|l|}{ Potássio $\left(\mathrm{mmol}_{\mathrm{c}} \mathrm{dm}^{-3}\right)$} \\
\hline CLC & 1,90 a B & 1,78 a B & 2,68 a $A$ & 2,18 a $\mathrm{AB}$ \\
\hline $\mathrm{CF}$ & 2,18 a $\mathrm{A}$ & 2,18 a $\mathrm{A}$ & 2,33 a $\mathrm{A}$ & 1,88 a $\mathrm{A}$ \\
\hline $\mathrm{CL}$ & 1,82 a $A$ & 1,78 a $\mathrm{A}$ & 2,03 a $\mathrm{A}$ & 2,28 a $A$ \\
\hline C.V. $(\%)$ & 23,31 & & & \\
\hline \multicolumn{5}{|l|}{ Cálcio $\left(\mathrm{mmol}_{\mathrm{c}} \mathrm{dm}^{-3}\right)$} \\
\hline CLC & 49,36 a B & 55,25 a B & 71,25 a $\mathrm{A}$ & 77,75 a $\mathrm{A}$ \\
\hline $\mathrm{CF}$ & 56,00 a A & $52,00 \mathrm{ab} \mathrm{A}$ & 52,75 b A & $46,00 \mathrm{~b} \mathrm{~A}$ \\
\hline $\mathrm{CL}$ & 47,75 a $\mathrm{AB}$ & 42,25 b B & $55,50 \mathrm{~b} \mathrm{~A}$ & 52,75 b A \\
\hline C.V. (\%) & 12,74 & & & \\
\hline \multicolumn{5}{|c|}{ Magnésio $\left(\mathrm{mmol}_{\mathrm{c}} \mathrm{dm}^{-3}\right)^{*}$} \\
\hline CLC & 16,75 b B & 17,00 a $\mathrm{AB}$ & 27,75 a A & 22,75 a $\mathrm{AB}$ \\
\hline $\mathrm{CF}$ & 25,75 a $\mathrm{A}$ & 21,75 a $A B$ & 20,56 a $\mathrm{AB}$ & 15,75 a B \\
\hline CL & $18,75 \mathrm{ab} A$ & 14,50 a $\mathrm{A}$ & 20,00 a A & 19,25 a A \\
\hline C.V. (\%) & 12,27 & & & \\
\hline \multicolumn{5}{|l|}{$\mathrm{H}+\mathrm{Al}\left(\mathrm{mmol}_{\mathrm{c}} \mathrm{dm}^{-3}\right)$} \\
\hline CLC & $13,26 \mathrm{aA}$ & $14,50 \mathrm{aA}$ & $13,75 \mathrm{aA}$ & $13,50 \mathrm{aA}$ \\
\hline $\mathrm{CF}$ & $15,00 \mathrm{aA}$ & $16,00 \mathrm{aA}$ & $17,50 \mathrm{aA}$ & $16,50 \mathrm{aA}$ \\
\hline $\mathrm{CL}$ & $16,00 \mathrm{aA}$ & $16,25 \mathrm{aA}$ & $15,25 \mathrm{aA}$ & $15,25 \mathrm{aA}$ \\
\hline C.V. (\%) & 14,64 & & & \\
\hline \multicolumn{5}{|l|}{ CTC $\left(\mathrm{mmol}_{\mathrm{c}} \mathrm{dm}^{-3}\right)$} \\
\hline CLC & 77,65 b B & 88,53 a $\mathrm{B}$ & 115,43 a $\mathrm{A}$ & 116,18 a $\mathrm{A}$ \\
\hline $\mathrm{CF}$ & 98,93 a $\mathrm{A}$ & 91,93 a $\mathrm{A}$ & 93,08 b A & 80,13 b A \\
\hline $\mathrm{CL}$ & $84,33 \mathrm{ab} \mathrm{A}$ & 74,78 a $\mathrm{A}$ & $92,78 \mathrm{~b} \mathrm{~A}$ & 89,53 b A \\
\hline C.V. (\%) & 14,22 & & & \\
\hline
\end{tabular}

* Dados originais

Médias seguidas pela mesma letra, minúscula na coluna e maiúscula na linha, não diferem entre si pelo teste t de Student a $5 \%$.

CLC = composto de lodo de cervejaria + cavaco de eucalipto; $\mathrm{CF}=$ cama de frango; $\mathrm{CL}=$ composto de lixo. 


\subsection{Conclusões}

O menor crescimento das plantas, até os 55 dias após o transplante das mudas, causado pela adição do composto de lixo, não afetou o rendimento final da cultura.

A adição de $200 \mathrm{~kg} \mathrm{ha}^{-1}$ de $\mathrm{N}$ como cama de frango, proporcionou incremento de $24,6 \%$ na produção de frutos comercializáveis de frutos em relação ao composto de lodo de cervejaria + cavaco de eucalipto.

Dentre os materiais orgânicos, o composto de lodo de cervejaria + cavaco de eucalipto foi o responsável pelo maior incremento da fertilidade do solo, sendo o único resíduo que aumentou o $\mathrm{pH}$ e a capacidade de troca de cátions do solo.

É possível melhorar a fertilidade do solo com o emprego de pequenas doses de composto de lodo de cervejaria + cavaco de eucalipto. 


\section{DECOMPOSIÇÃO DE MATERIAIS ORGÂNICOS E EFEITOS DE SUAS APLICAÇÕES NA BIOMASSA MICROBIANA E NOS ATRIBUTOS FÍSICOS DO SOLO}

\section{Resumo}

Para comparar a velocidade de decomposição de materiais orgânicos e avaliar os efeitos de suas aplicações em atributos físicos (capacidade de retenção de água e densidade do solo) e na biomassa microbiana do solo, foi desenvolvido um trabalho em solo Podzólico Vermelho-Amarelo abrupto A moderado textura arenosa/média. O delineamento experimental foi o de blocos ao acaso no esquema fatorial $3 \times 4$, sendo três materiais orgânicos (composto de lodo de cervejaria + cavaco de eucalipto, composto de lixo e cama de frango) e quatro doses equivalentes a $0,100,150$ e $200 \mathrm{~kg} \mathrm{ha}^{-1} \mathrm{de} \mathrm{N}$, com quatro repetições. A velocidade de decomposição dos materiais orgânicos se apresentou na seguinte ordem: cama de frango $\approx$ composto de lixo $>$ composto de lodo de cervejaria + cavaco de eucalipto. Os maiores valores de biomassa microbiana foram obtidos com o composto de lodo de cervejaria + cavaco de eucalipto em relação aos demais. A adição da cama de frango em quantidade equivalente a $150 \mathrm{~kg} \mathrm{ha}^{-1} \mathrm{de} \mathrm{N}$ e as doses do composto de lixo aumentaram a biomassa microbiana do solo. Quando se empregou a dose equivalente a $200 \mathrm{~kg} \mathrm{ha}^{-1}$ de $\mathrm{N}$, o composto de lodo de cervejaria + cavaco de eucalipto proporcionou os maiores valores de retenção de água na capacidade de campo e no ponto de murcha permanente em relação à cama de frango. A adição de $200 \mathrm{~kg} \mathrm{ha}^{-1}$ de $\mathrm{N}$ como composto de lodo de cervejaria + cavaco de eucalipto elevou a retenção de água, em ambos os valores de potencial mátrico e reduziu a densidade do solo. As doses da cama de frango e do composto de lixo não alteraram estas variáveis fisicas do solo. $\mathrm{O}$ conteúdo de água "disponivel", por sua vez, aumentou com a adição do composto de lixo 
em quantidade equivalente a $100 \mathrm{~kg} \mathrm{ha}^{-1}$ de $\mathrm{N}$.

Palavras-chave: decomposição; solo; biomassa microbiana; retenção de água.

DECOMPOSITION OF ORGANIC MATERIALS AND EFFECTS OF THEIR APPLICATIONS ON THE MICROBIAL BIOMASS AND ON THE PHYSICAL PROPERTIES OF THE SOLL

\section{Summary}

This work compared the decomposition rates of organic materials applied to an Ultisol and evaluated the effects of their application on the physical properties (water retention capacity and bulk density) and on the microbial biomass of the soil. The experimental design consisted of randomized blocks with treatments that were disposed in a factorial design $3 \times 4$ : three organic wastes (beershop sludge + eucalyptus chip compost, urban solid waste compost and chicken litter) and four rates equivalent to 0 , 100,150 and $200 \mathrm{~kg} \mathrm{ha}^{-1}$ of nitrogen, with four replications. The results showed that the decomposition rates followed the order: chicken litter $\approx$ urban solid waste compost $>$ beershop sludge + eucalyptus chip compost. The highest contents of microbial biomass were obtained with the beershop sludge + eucalyptus chip compost. The rate of chicken litter equivalent to $150 \mathrm{~kg} \mathrm{ha}^{-1}$ of $\mathrm{N}$ and all rates of urban solid waste compost increased the microbial biomass of the soil. The beershop sludge + eucalyptus chip compost provided the highest levels of retained water at 0.1 and 15 bar matric potentials, as compared to chicken litter at the rate equivalent to $200 \mathrm{~kg} \mathrm{ha}^{-1}$ of $\mathrm{N}$. The high rate of beershop sludge + eucalyptus chip compost increased the retained water at 0.1 and 15 bar matric potentials and decreased the soil bulk density. The addition of chicken litter and urban solid waste compost did not increase the above mentioned physical variables. The "avaliable water" increased with the addition of urban solid waste compost at the rate equivalent to $100 \mathrm{~kg} \mathrm{ha}^{-1}$ of $\mathrm{N}$.

Key-words: decomposition; soil; microbial biomass; water retention. 


\subsection{Introdução}

Desde os primórdios da agricultura, os resíduos orgânicos são empregados visando o incremento da produção agrícola. Atualmente não há mais dúvidas quanto a necessidade da reciclagem destes materiais, como forma de manter ou aumentar a capacidade produtiva dos solos agricultáveis.

A matéria orgânica contida nos resíduos orgânicos, além de ser uma importante fonte de nutrientes para as plantas, pode melhorar as propriedades fisicas e biológicas do solo. Um dos principais efeitos da adição de resíduos orgânicos nos atributos físicos do solo é o aumento da retenção de água, devido a sua elevada superficie específica e presença de cargas na fração húmica ou de uma forma indireta através de modificações de outros atributos, como a redução na densidade do solo. Vários trabalhos tem mostrado incrementos na retenção de água juntamente com decréscimos na densidade do solo, resultantes da adição de materiais orgânicos. Zeng et al. (1992) constataram aumentos na retenção de água de $2,49 \%$ e diminuição de $0,03 \mathrm{~g} \mathrm{~cm}^{-3}$ na densidade do solo, com a adição de $52 \mathrm{Mg} \mathrm{ha}^{-1}$ de esterco de suíno. Em um solo argilo-arenoso, as adições anuais de $10 \mathrm{e} 90 \mathrm{Mg} \mathrm{ha}^{-1}$ de composto de lixo urbano por um período de 4 anos, promoveram decréscimos na densidade do solo de $1,55 \mathrm{~g} \mathrm{~cm}^{-3}$ para $1,46 \mathrm{e} 1,38 \mathrm{~g} \mathrm{~cm}^{-3}$, respectivamente e aumentos nos conteúdos volumétricos de água retida na capacidade de campo ( 0,33 bar), no ponto de murcha permanente (15 bar) e de água "disponivel", referente à diferença entre o conteúdo de água nesses potenciais mátricos (Giusquiani et al., 1995).

Nas propriedades biológicas do solo, a matéria orgânica exerce influência direta, constituindo-se em substrato indispensável para o metabolismo microbiano. Dessa forma, a aplicação de resíduos orgânicos normalmente aumenta a biomassa microbiana do solo (Goyal et al., 1993), usada como índice de fertilidade do solo. (Ghoshal \& Singh, 1995).

Sendo assim, os objetivos deste trabalho foram avaliar a degradação dos materiais orgânicos em condições de laboratório e avaliar os efeitos de suas aplicações em propriedades fisicas e biológicas do solo, em condições de estufa. 


\subsection{Material e Métodos}

\subsubsection{Características dos materiais orgânicos empregados}

O composto de lodo de cervejaria + cavaco de eucalipto foi proveniente da unidade das Cervejarias Reunidas Skol Caracu S/A Guarulhos (SP), constituído da mistura de lodo mais terra infusória e cavacos de eucalipto, na proporção de 1:2, respectivamente. $\mathrm{O}$ material foi compostado por cerca de 20 dias em leiras estáticas dispostas em pátio a céu aberto, com aeração forçada, sendo as leiras cobertas com plástico. Obtido o composto final foi feita a separação do cavaco de eucalipto que não havia se decomposto totalmente, do composto orgânico curado, pelo processo de peneiramento. O composto de lixo foi adquirido na usina de tratamento de Santo André (SP), que após a permanência em biodigestor por 60 horas, foi disposto em leiras a céu aberto, que foram revolvidas com o auxílio de pá carregadeira a cada 8 dias, com o intuito de finalizar o processo de decomposição. Posteriormente, foi peneirado em malha de $11 \mathrm{~mm}$, para ser comercializado. A cama de frango foi obtida no sítio Asa Branca, localizado na estrada Piracicaba - Anhembi, em Piracicaba (SP), pela mistura de serragem de pinus com esterco de frango, depositado durante 45 dias. Os resíduos orgânicos foram amostrados para a realização da análise química (Tabela 9).

\subsubsection{Experimento em estufa}

O experimento foi instalado no município de Piracicaba (SP), em solo classificado como Podzólico Vermelho-Amarelo abrupto A moderado textura arenosa/média, em condições de estufa, durante o período de 8 de fevereiro a 6 de agosto de 1997.

A amostragem de terra foi feita trinta dias antes da incorporação dos materiais orgânicos ao solo, para a realização da análise química (Tabela 10). Baseado nos resultados obtidos realizou-se a adubação de plantio para o tomate, com a aplicação de $300 \mathrm{~kg} \mathrm{ha}^{-1} \mathrm{de} \mathrm{P}_{2} \mathrm{O}_{5}$ como superfosfato simples $\left(18 \%\right.$ de $\mathrm{P}_{2} \mathrm{O}_{5}$ ). $\mathrm{O}$ nitrogênio e o potássio foram fornecidos via fertirrigação, em quantidades de $380 \mathrm{~kg} \mathrm{ha}^{-1}$ de N e $450 \mathrm{~kg} \mathrm{ha}^{-1}$ de $\mathrm{K}_{2} \mathrm{O}$ (Vivancos, 1993), utilizando as fontes nitrato de potássio (13\% de $\mathrm{N}$ e $44 \%$ de $\mathrm{K}_{2} \mathrm{O}$ ) e uréia $(45 \%$ de $\mathrm{N})$. O transplante das mudas de tomate foi realizado em 8/02/1997 
e a colheita estendeu-se até 07/0797.

O delineamento experimental foi o de blocos casualizados com quatro repetições, no esquema fatorial $3 \times 4$, sendo três resíduos orgânicos (composto de lodo de cervejaria + cavaco de eucalipto, composto de lixo e cama de frango) e quatro doses equivalentes a 0 , 100,150 e $200 \mathrm{~kg} \mathrm{ha}^{-1}$ de $\mathrm{N}$. Cada parcela apresentava uma área de 7,0 $\mathrm{m}^{2}$.

Os dados obtidos foram submetidos à análise de variância pelo teste $\mathrm{F}$, e a comparação de médias foi feita pelo teste $\mathrm{t}$ de Student, ao nível de $5 \%$ de probabilidade.

Uma amostra de solo de cada parcela, empregando-se o amostrador de anel volumétrico, foi retirada em 07/08/97 para a determinação da densidade e retenção de água no solo na capacidade de campo e no ponto de murcha permanente, sendo que para isso os anéis volumétricos foram submetidos às pressões de 0,1 e 15 bar, respectivamente (Kiehl, 1979). O conteúdo de água "disponível” foi calculado pela diferença entre o conteúdo de água retida a 0,1 e 15 bar.

Para as avaliações da biomassa microbiana e do carbono orgânico total, coletaram-se 10 sub-amostras de solo de cada parcela para compor uma amostra representativa, na profundidade de $0-10 \mathrm{~cm}$, com o auxilio de um cilindro com diâmetro de $50 \mathrm{~mm}$, em 08/08/97. As amostras foram acondicionadas em sacos plásticos e armazenadas a $4^{\circ} \mathrm{C}$, a fim de evitar alterações significativas na biomassa microbiana. A técnica usada para a determinação da biomassa microbiana foi o da fumigação-extração (Vance et al., 1987). O carbono orgânico total foi determinado pelo método colorimétrico descrito por Quaggio \& Raij (1979).

$\mathrm{O}$ carbono da biomassa microbiana expresso em $\mu \mathrm{g} \mathrm{C} \mathrm{g}^{-1}$ solo foi calculado de acordo com a seguinte relação:

$\mathrm{C}=(\mathrm{F}-\mathrm{NF}) / 0,37$

$\mathrm{C}=$ carbono da biomassa microbiana em $\mu \mathrm{g} \mathrm{C} \mathrm{g}^{-1}$ de solo.

$\mathrm{F}$ e NF representam o $\mathrm{C}$ total do $\mathrm{CO}_{2}$ que foi liberado das sub-amostras fumigadas e não fumigadas, respectivamente.

0,37 = proporção do $\mathrm{C}$ da biomassa microbiana morta que foi convertida em $\mathrm{CO}_{2}$ durante o período de incubação. 
Tabela 9. Propriedades químicas, em base seca, dos resíduos orgânicos empregados.

\begin{tabular}{llll}
\hline Característica química & CLC & CL & CF \\
\hline Umidade total $\left(\mathrm{g} \mathrm{kg}^{-1}\right)$ & 775,8 & 493,0 & 194,9 \\
$\mathrm{pH}$ em $\mathrm{CaCl}_{2} 0,01 \mathrm{M}$ & 7,8 & 8,3 & 8,2 \\
Inertes $\left(\mathrm{g} \mathrm{kg}^{-1}\right)$ & 0,00 & 44,38 & 0,00 \\
Matéria orgânica total $\left(\mathrm{g} \mathrm{kg}^{-1}\right)$ & 500,45 & 692,90 & 862,75 \\
Matéria orgânica compostável $\left(\mathrm{g} \mathrm{kg}^{-1}\right)$ & 479,93 & 496,06 & 713,20 \\
Matéria orgânica resistente à compos. $\left(\mathrm{g} \mathrm{kg}^{-1}\right)$ & 20,52 & 196,84 & 149,55 \\
Carbono total $\left(\mathrm{g} \mathrm{kg}^{-1}\right)$ & 277,88 & 385,01 & 479,32 \\
Carbono orgânico $\left(\mathrm{g} \mathrm{kg}^{-1}\right)$ & 266,73 & 275,54 & 396,22 \\
Resíduo mineral total $\left(\mathrm{g} \mathrm{kg}^{-1}\right)$ & 499,55 & 262,72 & 137,25 \\
Resíduo mineral insolúvel $\left(\mathrm{g} \mathrm{kg}^{-1}\right)$ & 418,82 & 156,80 & 7,83 \\
Resíduo mineral solúvel $\left(\mathrm{g} \mathrm{kg}^{-1}\right)$ & 80,73 & 105,92 & 129,42 \\
$\mathrm{~N}$ total $\left(\mathrm{g} \mathrm{kg}^{-1}\right)$ & 14,27 & 12,23 & 33,78 \\
$\mathrm{P}$ total $\left(\mathrm{g} \mathrm{kg}^{-1}\right)$ & 2,92 & 1,72 & 9,98 \\
$\mathrm{~K}$ total $\left(\mathrm{g} \mathrm{kg}^{-1}\right)$ & 1,11 & 3,60 & 27,00 \\
Ca total $\left(\mathrm{g} \mathrm{kg}^{-1}\right)$ & 55,31 & 14,99 & 21,24 \\
$\mathrm{Mg}$ total $\left(\mathrm{g} \mathrm{kg}^{-1}\right)$ & 1,78 & 7,69 & 5,34 \\
$\mathrm{~S}$ total $\left(\mathrm{g} \mathrm{kg}^{-1}\right)$ & 1,34 & 2,56 & 2,36 \\
Cu total $\left(\mathrm{mg} \mathrm{kg}^{-1}\right)$ & 111,51 & 197,24 & 186,31 \\
$\mathrm{Mn}$ total $\left(\mathrm{mg} \mathrm{kg}^{-1}\right)$ & 535,24 & 108,48 & 322,94 \\
$\mathrm{Zn}$ total $\left(\mathrm{mg} \mathrm{kg}^{-1}\right)$ & 156,11 & 364,89 & 365,17 \\
Fe total $\left(\mathrm{mg} \mathrm{kg}^{-1}\right)$ & 18443,35 & 10927,02 & 787,48 \\
Na total $\left(\mathrm{mg} \mathrm{kg}^{-1}\right)$ & 3822,48 & 3909,27 & 4193,27 \\
Relação C/N $(\mathrm{C}$ total e N total$)$ & $19 / 1$ & $31 / 1$ & $14 / 1$ \\
\hline
\end{tabular}

$\mathrm{CLC}=$ composto de lodo de cervejaria + cavaco de eucalipto; $\mathrm{CL}=$ composto de lixo; $\mathrm{CF}=$ cama de frango.

Tabela 10. Resultados da análise química do Podzólico Vermelho-Amarelo no local do experimento à profundidade de $0-20 \mathrm{~cm}$.

\begin{tabular}{cccccccccc}
\hline $\mathrm{pH}$ & $\mathrm{M} . \mathrm{O}$ & $\mathrm{P}$ (resina) & $\mathrm{K}$ & $\mathrm{Ca}$ & $\mathrm{Mg}$ & $\mathrm{H}+\mathrm{Al}$ & $\mathrm{SB}$ & $\mathrm{T}$ & $\mathrm{V}$ \\
$\mathrm{CaCl}_{2}$ & $\mathrm{~g} \mathrm{dm}^{-3}$ & $\mathrm{mg} \mathrm{dm}^{-3}$ & $\ldots \ldots \ldots \ldots \ldots \ldots \ldots \ldots \ldots \mathrm{mmol}_{\mathrm{c}} \mathrm{dm}^{3} \ldots \ldots \ldots \ldots \ldots \ldots \ldots \ldots \ldots \ldots \ldots \ldots$ & $\%$ \\
\hline 5,1 & 17 & 64 & 4,6 & 52 & 23 & 15 & 79,6 & 94,6 & 84 \\
\hline
\end{tabular}




\subsubsection{Experimento em laboratório}

Em laboratório, estudou-se a velocidade de degradação dos materiais orgânicos no solo, cujos tratamentos adotados e o delineamento experimental foram descritos no item 4.2.2.

Inicialmente, porções de $50 \mathrm{~g}$ de terra coletada da camada de $0-20 \mathrm{~cm}$ foram misturadas com os materiais orgânicos e em seguida as misturas foram umedecidas a 70 $\%$ da capacidade de campo e colocadas em frascos de vidro. Dentro de cada frasco foi colocado um béquer contendo $10 \mathrm{ml}$ de $\mathrm{NaOH} 1 \mathrm{~N}$ e posteriormente o frasco foi hermeticamente fechado. Os recipientes com as soluções coletoras $(\mathrm{NaOH})$ foram substituídos aos 7, 14 e 21 dias, para a determinação do carbono retido na forma de $\mathrm{CO}_{2}$. Para isso foram adicionados aos béqueres $1 \mathrm{ml}$ de solução de $\mathrm{BaCl}_{2} 50 \%$ mais 2 gotas de fenolftaleína. Em seguida, o excesso de $\mathrm{NaOH}$, ou seja, a fração não consumida na reação com o $\mathrm{CO}_{2}$, foi titulada com $\mathrm{HCl} 1 \mathrm{~N}$. A quantidade de $\mathrm{CO}_{2}$ foi calculada através da seguinte expressão (Anderson, 1982):

mg $\mathrm{CO}_{2} \mathrm{~g}^{-1}$ de solo $=(\mathrm{VB}-\mathrm{VA}) . \mathrm{N} .22 /$ peso do solo seco $(\mathrm{g})$ onde:

$\mathrm{VB}=$ volume de solução de $\mathrm{HCl}$ gasto na titulação da prova em branco (ml);

$\mathrm{VA}=$ volume de solução de $\mathrm{HCl}$ gasto na titulação da amostra (ml);

$\mathrm{N}=$ concentração normal da solução de $\mathrm{HCl}$;

$22=$ massa de $1 / 2$ mmol $_{c}$ de $\mathrm{CO}_{2}$

\subsection{Resultados e Discussão}

\subsubsection{Atributos biológicos}

\subsubsection{Degradação dos resíduos orgânicos}

As taxas de decomposição dos resíduos orgânicos medidas através das emanações de $\mathrm{CO}_{2}$ das amostras de terra incubadas constam das Figuras 6,7 e 8. As perdas diárias de $\mathrm{CO}_{2}$ foram maiores aos 7 dias de incubação do solo com os materiais orgânicos, nas três doses aplicadas, sendo que a partir deste período os valores de respiração do solo diminuíram até os 28 dias. As menores taxas de respiração nos períodos iniciais de incubação corresponderam ao controle (solo sem material orgânico) e ao solo tratado 
com composto de lodo de cervejaria + cavaco de eucalipto, provavelmente por este ser um material de alto grau de estabilização. A cama de frango e o composto de lixo apresentaram os maiores decréscimos nas taxas de respiração, sendo que este comportamento foi mais acentuado, de maneira geral, quando o solo foi tratado com a cama de frango, por ser um material de natureza menos complexa. Barreto (1995) observou comportamentos distintos entre materiais orgânicos quanto a velocidade de degradação, que foi superior para a torta de filtro, de fácil decomposição, em relação aos materiais de natureza mais complexa, cuja ordem decrescente foi: lodo de esgoto $\approx$ composto de lixo > lodo petroquímico.

Aos 7 dias de incubação, a perda de carbono na forma de $\mathrm{CO}_{2}$ variou com as doses aplicadas dos materiais orgânicos (Tabela 11). As maiores doses adicionadas do composto de lodo de cervejaria + cavaco de eucalipto não alteraram as perdas de carbono na forma de $\mathrm{CO}_{2}$. Por ser um material mais estável no solo, as quantidades de carbono adicionadas tornaram-se menos disponiveis, nesta fase inicial de incubação, não resultando, portanto, em perdas maiores e significativas de carbono com o aumento das doses. A adição da cama de frango aumentou a quantidade de $\mathrm{C}$ liberada na forma de $\mathrm{CO}_{2}$, cujos maiores valores foram obtidos com 150 e $200 \mathrm{~kg} \mathrm{ha}^{-1}$ de $\mathrm{N}$. As perdas de carbono na forma de $\mathrm{CO}_{2}$ também aumentaram com a adição do composto de lixo. Estes resultados podem ser explicados pelos incrementos nas quantidades de carbono presentes nestes materiais, que tornaram-se disponiveis para serem utilizados pelos microorganismos decompositores. 


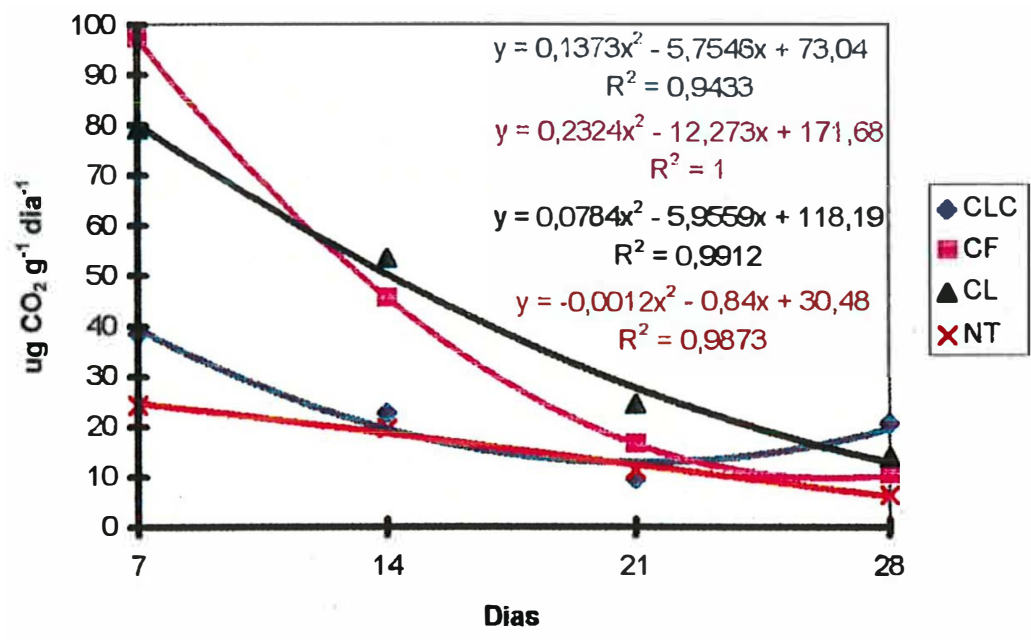

Figura 6 . Perdas diárias de $\mathrm{CO}_{2}$ do solo tratado com materiais orgânicos em quantidade equivalente a $100 \mathrm{~kg} \mathrm{ha}^{-1}$ de $\mathrm{N}$ (CLC=composto de lodo de cervejaria + cavaco de eucalipto; $\mathrm{CL}=$ composto de lixo; $\mathrm{CF}=$ cama de frango; $\mathrm{NT}=$ testemunha).

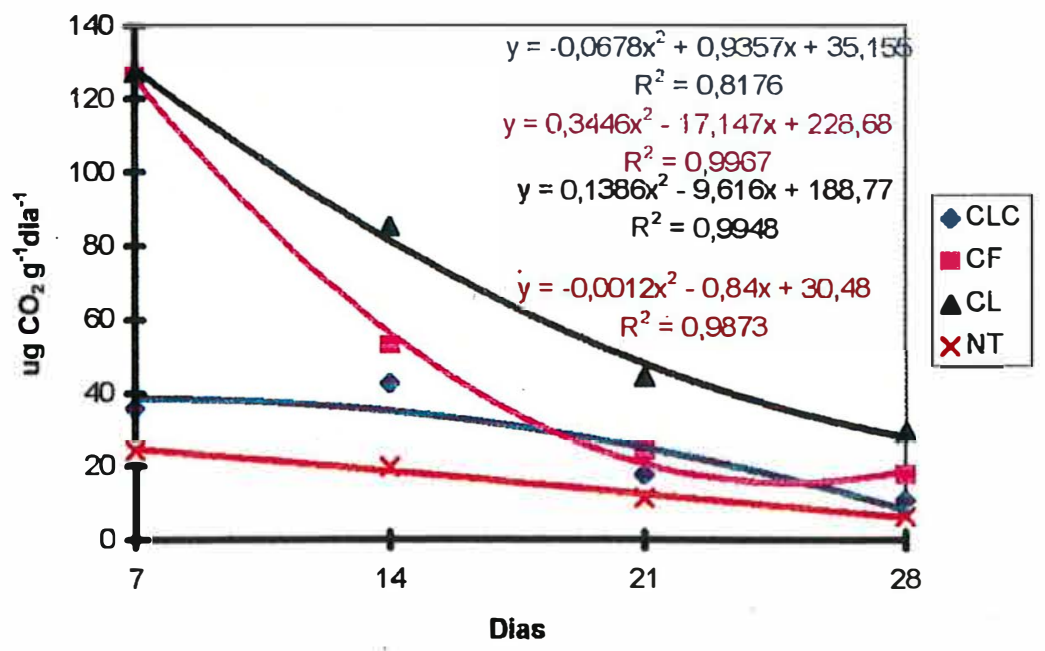

Figura 7. Perdas diárias de $\mathrm{CO}_{2}$ do solo tratado com materiais orgânicos em quantidade equivalente a $150 \mathrm{~kg} \mathrm{ha}^{-1}$ de $\mathrm{N}(\mathrm{CLC}=$ composto de lodo de cervejaria + cavaco de eucalipto; $\mathrm{CL}=$ composto de lixo; $\mathrm{CF}=$ cama de frango; $\mathrm{NT}=$ testemunha). 


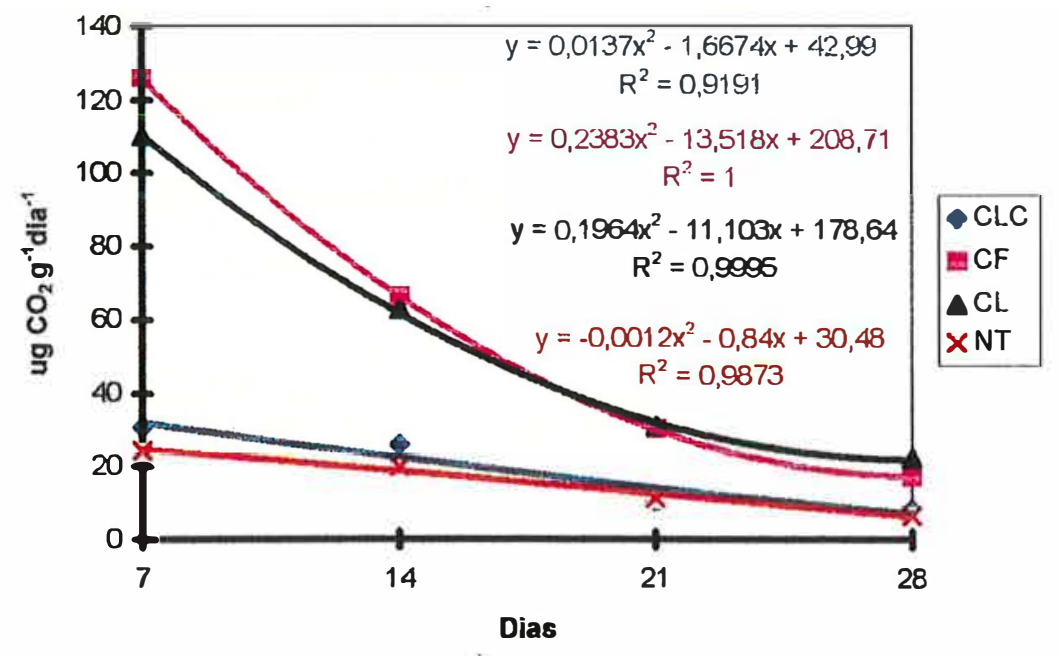

Figura 8. Perdas diárias de $\mathrm{CO}_{2}$ do solo tratado com materiais orgânicos em quantidade equivalente a $200 \mathrm{~kg} \mathrm{ha}^{-1}$ de $\mathrm{N}(\mathrm{CLC}=$ composto de lodo de cervejaria + cavaco de eucalipto; $\mathrm{CL}=$ composto de lixo; $\mathrm{CF}=$ cama de frango; $\mathrm{NT}=$ testemunha).

Tabela 11. Perdas de $\mathrm{C}$ na forma de $\mathrm{CO}_{2}$ aos 7 dias de incubação do solo tratado com os resíduos orgânicos.

\begin{tabular}{|c|c|c|c|c|}
\hline \multirow{2}{*}{$\begin{array}{l}\text { Resíduos } \\
\text { orgânicos }\end{array}$} & \multicolumn{4}{|c|}{ - Doses de N $\left(\mathrm{kg} \mathrm{ha}^{-1}\right)-$} \\
\hline & $\mathbf{0}$ & 100 & 150 & 200 \\
\hline & \multicolumn{4}{|c|}{ 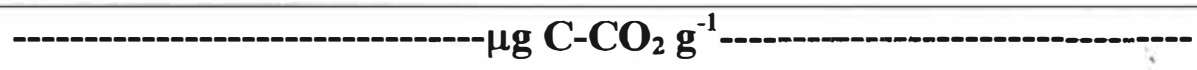 } \\
\hline CLC & $42,62 \mathrm{~A}$ & $69,63 \mathrm{~B}$ & $65,13 \mathrm{AB}$ & $57,98 \mathrm{AB}$ \\
\hline $\mathrm{CF}$ & $47,66 \mathrm{~A}$ & $183,81 \mathrm{~B}$ & $229,68 \mathrm{C}$ & $226,92 \mathrm{C}$ \\
\hline CL & $47,99 \mathrm{~A}$ & $143,77 \mathrm{~B}$ & $230,37 \mathrm{C}$ & $199,88 \mathrm{D}$ \\
\hline $\mathrm{CV} \%$ & $12,4 \%$ & & & \\
\hline
\end{tabular}

Médias seguidas pela mesma letra na linha, não diferem entre si pelo teste t de Student a $5 \%$.

$\mathrm{CLC}=$ composto de lodo de cervejaria + cavaco de eucalipto; $\mathrm{CF}=$ cama de frango; $\mathrm{CL}$ $=$ composto de lixo. 


\subsubsection{Biomassa microbiana do solo}

Os valores de biomassa microbiana e de carbono orgânico total constam da Tabela 12 . Em todas as doses empregadas a biomassa microbiana foi maior com a adição do composto de lixo em relação aos demais, sendo que o composto de lodo de cervejaria + cavaco de eucalipto e a cama de frango não diferiram significativamente entre si. Este fato pode ter sido devido à quantidade maior de carbono orgânico adicionada ao solo através do composto de lixo, que se tornou disponivel para o aumento da biomassa microbiana. Entretanto, o mesmo comportamento não foi constatado para o conteúdo de carbono orgânico total do solo, onde os resíduos orgânicos não diferiram significativamente entre si.

Witter et al. (1993) obtiveram comportamentos distintos de diversos tipos de resíduos orgânicos adicionados ao solo sobre a biomassa microbiana. Estes autores constataram o menor valor da biomassa microbiana com a aplicação de turfa, devido à baixa degradabilidade deste material, quando comparado com o adubo agrícola (mistura de esterco de curral com restos de feno) e com o adubo verde, ambos de fácil decomposição, concordando com os resultados obtidos neste trabalho.

Quando se empregou o composto de lodo de cervejaria + cavaco de eucalipto as doses aplicadas não alteraram a biomassa microbiana. Possivelmente a menor degradabilidade do composto de lodo de cervejaria + cavaco de eucalipto explica a ausência de incrementos significativos na biomassa microbiana com o aumento das doses. Dessa forma o $\mathrm{C}$ adicionado ao solo através deste material tornou-se menos disponivel para a decomposição microbiana e então formação de conteúdos maiores de biomassa microbiana. A adição de $150 \mathrm{~kg} \mathrm{ha}^{-1}$ de $\mathrm{N}$ como cama de frango elevou a biomassa microbiana. As quantidades aplicadas do composto de lixo aumentaram em 75 a 82,8 \% a biomassa microbiana em relação ao solo não tratado, mas não diferiram significativamente entre si. Schnürer et al. (1985) também obtiveram aumento na biomassa microbiana de $67 \%$ com a adição de $80 \mathrm{~kg} \mathrm{~N} \mathrm{ha}^{-1}$ ano $^{-1}$ e $1800 \mathrm{~kg} \mathrm{C} \mathrm{ha}^{-1}$ ano $^{-1}$ como adubo orgânico (esterco de curral com restos de feno). Pode-se inferir que tais incrementos na biomassa microbiana significam maior reciclagem de nutrientes, onde grande parte do $\mathrm{N}$ é armazenado em forma relativamente lábil (Jenkinson \& Ladd, 1981). 
Houve correlação positiva entre a biomassa microbiana (Tabela 12) e a perda de carbono na forma de $\mathrm{CO}_{2}$ aos 7 dias de incubação do solo com os materiais orgânicos (Tabela 11), cujo coeficiente foi de 0,72 (P < 0,02), o que evidenciou que a respiração mais ativa do solo levou a valores maiores de biomassa microbiana (Figura 9). Kanazawa et al. (1988) obtiveram resultados semelhantes, cujo coeficiente de correlação obtido foi de 0,866 entre a evolução do $\mathrm{CO}_{2}$ e a biomassa $\mathrm{C}$ do solo.

O conteúdo de carbono não foi alterado com o aumento das doses dos materiais orgânicos. Segundo Powlson \& Jenkinson (1981), o conteúdo de carbono orgânico total do solo sofre pequenas mudanças, enquanto que alterações na biomassa microbiana normalmente são mais rápidas e mais notáveis, após a adição de materiais orgânicos.

O nível da biomassa microbiana variou de 1,69 a 3,68 \% do carbono orgânico total do solo tratado com os materiais orgânicos. Estes valores foram semelhantes aos obtidos por Goyal et al. (1992), em solo adubado com 15 a $90 \mathrm{Mg} \mathrm{ha}^{-1}$ de adubo orgânico, resultante da compostagem de esterco de curral misturado com restos de feno.

Tabela 12. Efeitos de tipos e doses de resíduos orgânicos sobre a biomassa microbiana e carbono orgânico total do solo.

\begin{tabular}{|c|c|c|c|c|}
\hline \multirow{2}{*}{$\begin{array}{l}\text { Resíduos } \\
\text { orgânicos }\end{array}$} & \multicolumn{4}{|c|}{ - Doses de $\mathrm{N}\left(\mathrm{kg} \mathrm{ha}^{-1}\right)$} \\
\hline & $\mathbf{0}$ & 100 & 150 & 200 \\
\hline & \multicolumn{4}{|c|}{ Biomassa microbiana $\left(\mu \mathrm{g} \mathrm{C} \mathrm{g}^{-1}\right)$} \\
\hline CLC & 184,60 a $\mathrm{A}$ & 201,63 a $\mathrm{A}$ & 224,34 a $\mathrm{A}$ & 228,98 a $\mathrm{A}$ \\
\hline $\mathrm{CF}$ & 195,43 a B & 211,85 a $\mathrm{AB}$ & 260,94 a A & 230,63 a $\mathrm{AB}$ \\
\hline $\mathrm{CL}$ & 190,02 a B & $346,50 \mathrm{~b} \mathrm{~A}$ & $347,40 \mathrm{~b} \mathrm{~A}$ & 333,95 b A \\
\hline \multirow[t]{2}{*}{ C.V. $(\%)$} & 19,16 & & & \\
\hline & \multicolumn{4}{|c|}{ Carbono orgânico total $\left(\mathrm{g} \mathrm{kg}^{-1}\right)$} \\
\hline CLC & 9,72 a $\mathrm{A}$ & 10,73 a $\mathrm{A}$ & 11,17 a A & 12,33 a $\mathrm{A}$ \\
\hline $\mathrm{CF}$ & 12,18 a $\mathrm{A}$ & 12,47 a $\mathrm{A}$ & 10,73 a $\mathrm{A}$ & 11,60 a $\mathrm{A}$ \\
\hline $\mathrm{CL}$ & 12,33 a $\mathrm{A}$ & 10,01 a $\mathrm{A}$ & 9,43 a $\mathrm{A}$ & 10,15 a $\mathrm{A}$ \\
\hline C.V. $(\%)$ & 19,07 & & & \\
\hline
\end{tabular}

Médias seguidas pela mesma letra, maiúscula na linha e minúscula na coluna, não diferem entre si pelo teste $\mathrm{t}$ de Student a $5 \%$.

CLC = composto de lodo de cervejaria + cavaco de eucalipto; $\mathrm{CF}=$ cama de frango; $\mathrm{CL}$ $=$ composto de lixo. 


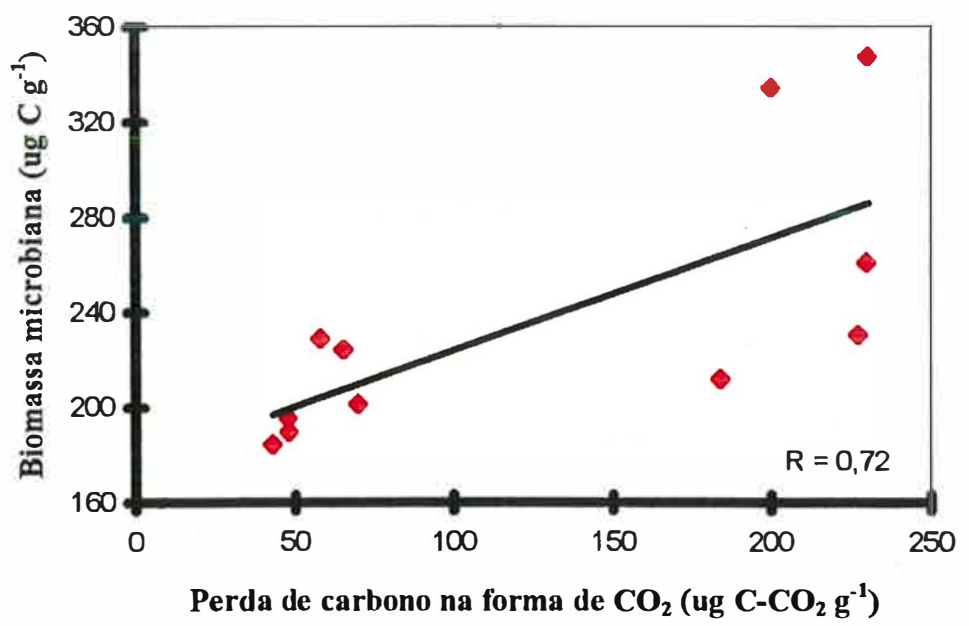

Figura 9. Relação entre a biomassa microbiana e a evolução do dióxido de carbono do solo tratado com materiais orgânicos $(n=11)$.

\subsubsection{Atributos físicos do solo}

Os resultados da densidade do solo, da capacidade de retenção de água na capacidade de campo ( 0,1 bar) e no ponto de murcha permanente ( 15 bar) e do conteúdo de água "disponível" (0,1 - 15 bar) constam da Tabela 13. Entre os resíduos orgânicos, os valores de retenção de água no solo na capacidade de campo foram significativamente distintos somente quando se empregou a dose equivalente a $200 \mathrm{~kg} \mathrm{ha}^{-1} \mathrm{de} \mathrm{N}$, sendo que a retenção de água foi maior com a aplicação do composto de lodo de cervejaria + cavaco de eucalipto em relação à cama de frango. O mesmo comportamento foi constatado para a retenção de água no ponto de murcha permanente, também com a adição de $200 \mathrm{~kg} \mathrm{ha}^{-1}$ de N. Quando se empregou $100 \mathrm{~kg} \mathrm{ha}^{-1}$ de $\mathrm{N}$, o composto de lodo de cervejaria + cavaco de eucalipto foi superior à cama de frango sobre esta característica fisica do solo. Por sua vez, o conteúdo de água "disponível” e a densidade do solo não sofreram influência do tipo de material orgânico empregado.

Considerando as taxas de decomposição dos materiais orgânicos, a menor degradabilidade do composto de lodo de cervejaria + cavaco de eucalipto talvez foi responsável pela maior persistência do carbono orgânico adicionado no solo por este material, que contribuiu para a obtenção dos maiores valores de retenção de água, em 
ambos os potenciais mátricos acima descritos. Além disso, a quantidade 2,4 vezes maior de carbono aplicado pelo composto de lodo de cervejaria + cavaco de eucalipto em relação à cama de frango, também pode ter exercido influência sobre este resultado.

Os valores de retenção de água na capacidade de campo e no ponto de murcha permanente aumentaram com a adição de $14 \mathrm{Mg} \mathrm{ha}^{-1}$ do composto de lodo de cervejaria + cavaco de eucalipto, equivalente a $200 \mathrm{~kg} \mathrm{ha}^{-1}$ de $\mathrm{N}$, em virtude possivelmente do aumento no fornecimento de matéria orgânica pelo composto e pelo fato desse material ser menos degradável no solo. O inverso foi constatado para a densidade do solo, concordando com os resultados obtidos na literatura, ou seja, incrementos na retenção de água associados com decréscimos na densidade do solo (Tester, 1990; Zeng et al., $1992 \mathrm{e}$ Giusquiani et al., 1995). Entretanto, os acréscimos na retenção de água em ambos os potenciais mátricos descritos não promoveram aumentos no conteúdo de água "disponivel". Segundo Khaleel et al. (1981) este fato pode ocorrer, pois o decréscimo na densidade do solo pode contrabalançar qualquer aumento no conteúdo de água "disponivel" em unidade de peso.

Quando se adicionou $100 \mathrm{~kg} \mathrm{ha}^{-1}$ de $\mathrm{N}$ como composto de lixo, a retenção de água a 15 bar foi reduzida, sendo que o inverso foi verificado para o conteúdo de água "disponivel", indicando que a quantidade de água mais fracamente retida aumentou nesta dose empregada, facilitando o consumo de água pelas plantas. O conteúdo de água retida na capacidade de campo e a densidade do solo não foram alterados com as doses aplicadas deste material.

Para a cama de frango, as doses empregadas não alteraram os atributos fisicos avaliados, provavelmente por serem muito baixas as quantidades de matéria orgânica adicionadas através deste material. De acordo com Khaleel et al. (1981) torna-se dificil verificar qualquer mudança nas propriedades fisicas quando as taxas de aplicação de materiais orgânicos no solo são muito pequenas. Stewart \& Webber (1976) também constataram ausência de resposta na capacidade de retenção de água com a aplicação de pequenas quantidades de lodo de esgoto, que variaram de 12 a $46 \mathrm{Mg} \mathrm{ha}^{-1}$. 
Tabela 13. Efeitos de tipos e doses de resíduos orgânicos sobre a densidade do solo, retenção de água na capacidade de campo $(0,1$ bar $)$ e no ponto de murcha permanente ( 15 bar ) e conteúdo de água "disponivel" $(0,1-15$ bar $)$.

\begin{tabular}{|c|c|c|c|c|}
\hline \multirow[t]{2}{*}{ Resíduos orgânicos } & \multicolumn{4}{|c|}{ Doses de $\mathrm{N}\left(\mathrm{kg} \mathrm{ha}^{-1}\right)$} \\
\hline & $\mathbf{0}$ & 100 & 150 & 200 \\
\hline \multicolumn{5}{|l|}{ Densidade $\left(\mathrm{g} \mathrm{cm}^{-3}\right)$} \\
\hline CLC & 1,34 a $\mathrm{A}$ & $1,29 \mathrm{a} A \mathrm{~B}$ & 1,30 a $\mathrm{AB}$ & 1,25 a B \\
\hline $\mathrm{CF}$ & 1,36 a $\mathrm{A}$ & 1,36 a A & 1,29 a A & 1,33 a $\mathrm{A}$ \\
\hline $\mathrm{CL}$ & 1,37 a $\mathrm{A}$ & 1,39 a $\mathrm{A}$ & 1,42 a $\mathrm{A}$ & 1,34 a $\mathrm{A}$ \\
\hline C.V. $(\%)$ & 7,35 & & & \\
\hline \multicolumn{5}{|c|}{ Retenção de água a 0,1 bar $\left(\mathrm{g} \mathrm{g}^{-1}\right)$} \\
\hline CLC & 0,2140 a B & 0,2376 a $A B$ & 0,2288 a AB & 0,2600 a $\mathrm{A}$ \\
\hline CF & 0,2191 a $\mathrm{A}$ & 0,2202 a A & 0,2135 a $\mathrm{A}$ & 0,2227 b A \\
\hline $\mathrm{CL}$ & 0,2231 a $\mathrm{A}$ & 0,2103 a $\mathrm{A}$ & 0,2135 a A & $0,2350 \mathrm{ab} \mathrm{A}$ \\
\hline C.V. (\%) & 10,40 & & & \\
\hline \multicolumn{5}{|c|}{ Retenção de água a 15 bar $\left(\mathrm{g} \mathrm{g}^{-1}\right)$} \\
\hline CLC & 0,1097 a $B$ & 0,1477 a $A B$ & 0,1573 a $A B$ & 0,1710 a $\mathrm{A}$ \\
\hline CF & 0,1357 a $\mathrm{A}$ & $0,1308 \mathrm{ab} A$ & 0,1235 a $\mathrm{A}$ & 0,1074 b A \\
\hline $\mathrm{CL}$ & 0,1541 a $\mathrm{A}$ & 0,0784 b B & 0,1151 a $A B$ & $0,1324 \mathrm{ab} A B$ \\
\hline C.V. (\%) & 17,01 & & & \\
\hline \multicolumn{5}{|c|}{ Água "disponível" $\left(\mathrm{g} \mathrm{g}^{-1}\right)$} \\
\hline CLC & 0,1043 a $\mathrm{A}$ & 0,0899 a $\mathrm{A}$ & 0,0715 a $\mathrm{A}$ & 0,0899 a A \\
\hline $\mathrm{CF}$ & 0,0834 a $\mathrm{A}$ & 0,0894 a A & 0,0899 a $\mathrm{A}$ & 0,1154 a $\mathrm{A}$ \\
\hline $\mathrm{CL}$ & 0,0691 a $B$ & 0,1318 a $\mathrm{A}$ & 0,0984 a $\mathrm{AB}$ & 0,1026 a $A B$ \\
\hline C.V. (\%) & 35,37 & & & \\
\hline
\end{tabular}

Médias seguidas pela mesma letra, maiúscula na linha e minúscula na coluna, não diferem entre si pelo teste $\mathrm{t}$ de Student a $5 \%$.

CLC = composto de lodo de cervejaria + cavaco de eucalipto; $C F=$ cama de frango; $\mathrm{CL}=$ composto de lixo. 


\subsection{Conclusões}

As propriedades físicas e biológicas do solo foram influenciadas pelo natureza química e quantidade do material orgânico empregado.

O composto de lodo de cervejaria + cavaco de eucalipto foi considerado o menos degradável no solo, em virtude da sua maior estabilidade.

A adição de $200 \mathrm{~kg} \mathrm{ha}^{-1}$ de $\mathrm{N}$ como composto de lodo de cervejaria + cavaco de eucalipto melhorou as propriedades fisicas do solo, através do aumento na retenção de água a 0,1 e 15 bar e redução da densidade do solo.

A biomassa microbiana aumentou com as aplicações do composto de lixo e da cama de frango. 


\section{INFLUÊNCIA DE MATERIAIS ORGÂNICOS NO DESENVOLVIMENTO DO TOMATEIRO E NAS CARACTERÍSTICAS QUIMICAS DO SOLO EM AMBIENTE PROTEGIDO}

\section{Resumo}

Foram avaliadas as influências da adição de cama de frango, de composto de lixo e de composto de lodo de cervejaria + cavaco de eucalipto no desenvolvimento do tomateiro (Lycopersicon esculentum Mill.) cultivado em estufa e nas propriedades químicas do solo, classificado como Latossolo Vermelho-Amarelo álico A moderado textura média, em Limeira (SP), de 5 de maio a 5 de novembro de 1997. As doses dos materiais orgânicos empregadas foram equivalentes a 0,100, 150 e $200 \mathrm{~kg} \mathrm{ha}^{-1} \mathrm{de} \mathrm{N}$. A produção total de frutos não aumentou com a adição dos materiais orgânicos. $\mathrm{Na}$ dose mais elevada, o composto de lodo de cervejaria + cavaco de eucalipto foi superior à cama de frango e proporcionou os maiores valores de $\mathrm{pH}$, de cálcio e da capacidade de troca de cátions ao $\mathrm{pH} 7,0$ do solo. A aplicação de $150 \mathrm{~kg} \mathrm{ha}^{-1}$ de $\mathrm{N}$ como cama de frango elevou o teor de $\mathrm{K}$ no solo. O composto de lixo, por sua vez, não alterou as características químicas do solo.

Palavras-chave: tomate; composto; capacidade de troca de cátions. 


\section{EFFECTS OF ORGANIC MATERIALS ON THE DEVELOPMENT OF THE TOMATO PLANTS AND ON SOIL CHEMICAL CARACTHERISTICS IN GREENHOUSE}

\section{Summary}

To evaluate the effects of the aplicattion of chicken litter, urban solid waste compost and beershop sludge + eucalyptus chip compost on tomato growth, cultivated in greenhouse, and on chemical properties of an Oxisol, an experiment was carried out in Limeira (SP), during the period of May to November 1997. The rates of organic materials were equivalent to $0,100,150$ e $200 \mathrm{~kg} \mathrm{ha}^{-1}$ of $\mathrm{N}$. The fruit yield did not increase with the application of the organic materials. The high rate of the beershop sludge + eucalyptus chip compost provided the highest leves of $\mathrm{pH}$, calcium and cation exchange capacity as compared to chicken litter. The addition of the chicken litter at the rate equivalent to $150 \mathrm{~kg} \mathrm{ha}^{-1}$ of $\mathrm{N}$ increased the potassium content of the soil. The rates of application of the urban solid waste compost did not change the chemical properties of the soil.

Key-words: tomato; compost; cation exchange capacity.

\subsection{Introdução}

$\mathrm{O}$ aumento do custo dos fertilizantes minerais e a tendência em utilizar recursos sustentáveis tem possibilitado ,cada vez mais, o emprego de materiais orgânicos na agricultura.

Como fonte de nutrientes ao tomateiro (Lycopersicon esculentum Mill), a adubação orgânica tem sido normalmente praticada visando suprir parte das necessidades nutricionais desta espécie. Na literatura, diversos trabalhos comprovam a eficiência da aplicação de materiais orgânicos no rendimento do tomateiro (Freitas \& Faria, 1981; Salek et al., 1981; Silva Jr. \& Vizzotto, 1990). Além de fornecer nutrientes às plantas, os materiais orgânicos podem incrementar a fertilidade do solo. Dentre os beneficios gerados pela adição desses materiais nos atributos químicos do solo, o aumento do $\mathrm{pH} \mathrm{e}$ da capacidade de troca de cátions são muito relevantes. Essas alterações dependem, 
dentre outros fatores, da quantidade e do tipo de adubo orgânico empregado no solo.

Incrementos de 7,6 e 15,2\% na capacidade de troca de cátions foram obtidos com as aplicações de 40 e $60 \mathrm{Mg} \mathrm{ha}^{-1}$ de adubo orgânico, respectivamente (Ndayegamiye \& Coté, 1989). Melo et al. (1994) constataram aumento da capacidade de troca de cátions do solo com a adição de $32 \mathrm{Mg} \mathrm{ha}^{-1}$ de lodo de esgoto, enquanto que as aplicações de 4,8 e $16 \mathrm{Mg} \mathrm{ha}^{-1}$ do material não afetaram esta propriedade química do solo. Em um Oxisol, a adição de $10 \mathrm{Mg} \mathrm{ha}^{-1}$ de esterco de curral elevou o $\mathrm{pH}$ de 5,8 para 6,1, após um período de 60 dias (Tiwari, 1993). Por outro lado, onze aplicações de 30, $60 \mathrm{e} 90 \mathrm{Mg} \mathrm{ha}^{-1}$ deste mesmo adubo orgânico reduziram o pH do solo.

Portanto, como a resposta do sistema solo-planta à aplicação de materiais orgânicos é variável, há a necessidade de se realizar outras pesquisas incluindo materiais pouco estudados, como aqueles derivados do lodo produzido pelas indústrias de cervejarias. Dessa forma, este trabalho teve por objetivo avaliar os efeitos da adição de cama de frango, de composto de lixo e de composto de lodo de cervejaria + cavaco de eucalipto sobre o desenvolvimento do tomateiro e em propriedades químicas do solo, em condições de estufa.

\subsection{Material e Métodos}

O experimento foi conduzido na região de Limeira (SP), durante o período de 5 de maio a 5 de novembro de 1997, em um solo classificado como Latossolo VermelhoAmarelo álico A moderado textura média. A descrição dos materiais orgânicos empregados e suas respectivas análises químicas constam no ítem 3.2.

O solo foi amostrado 30 dias antes do plantio para a realização da análise química, cujos resultados foram: $\mathrm{pH}\left(\mathrm{CaCl}_{2}\right) 4,9 ; 26 \mathrm{~g} \mathrm{dm}^{-3}$ de matéria orgânica; $274 \mathrm{mg} \mathrm{dm}^{-3}$ de $\mathrm{P}$ (resina); 6,5, 87 e $50 \mathrm{mmol}_{\mathrm{c}} \mathrm{dm}^{-3}$ de $\mathrm{K}, \mathrm{Ca}$ e $\mathrm{Mg}$, respectivamente; acidez potencial 42 $\mathrm{mmol}_{\mathrm{c}} \mathrm{dm}^{-3}$; capacidade de troca de cátions $185,5 \mathrm{mmol}_{\mathrm{c}} \mathrm{dm}^{-3}$; saturação por bases $77 \%$. Baseado nestes resultados não foi necessária a aplicação de calcário (Trani et al., 1996) e dispensou-se a adição de fósforo no plantio. $O$ nitrogênio e o potássio foram fornecidos desde o transplante das mudas até 15 dias antes da última colheita via fertirrigação, num total de $380 \mathrm{~kg} \mathrm{ha}^{-1}$ de $\mathrm{Ne} 450 \mathrm{~kg} \mathrm{ha}^{-1}$ de $\mathrm{K}_{2} \mathrm{O}$ (Vivancos, 1993). 
O plantio das mudas de tomate cv. Débora Plus foi feito em $5 / 5 / 97$, no espaçamento de $50 \mathrm{~cm}$ entre plantas e 1,0 m entre fileiras. As plantas foram conduzidas com fitilho em uma estufa do tipo em arco, coberta com filme de polietileno aditivado. A irrigação, pelo sistema de gotejamento, as desbrotas e o controle fitossanitário foram efetuados conforme as exigências da cultura.

O delineamento experimental foi o de blocos casualizados com quatro repetições, no esquema fatorial $3 \times 4$, com três materiais orgânicos (composto de lodo de cervejaria + cavaco de eucalipto, composto de lixo e cama de frango) e quatro doses $(0,100,150 \mathrm{e}$ $200 \mathrm{~kg} \mathrm{ha}^{-1} \mathrm{de} \mathrm{N}$ ). Cada parcela continha 16 plantas, sendo 8 plantas por linha, numa área de $7,0 \mathrm{~m}^{2}$.

Aos 52, 62 e 72 dias após o transplante das mudas foram amostradas cinco plantas ao acaso por parcela, para a determinação da sua altura. No período do florescimento, aos 52 dias após o transplante, coletaram-se cinco folhas por parcela, tomando-se a quarta folha a partir do ápice, para a determinação dos teores totais de nutrientes. Foram analisados também os níveis de $\mathrm{N}-\mathrm{NO}_{3}{ }^{-}, \mathrm{P}_{-}-\mathrm{H}_{2} \mathrm{PO}_{4}{ }^{-}$e $\mathrm{K}-\mathrm{K}^{+}$nos pecíolos destas folhas e nos pecíolos daquelas coletadas na época do aparecimento dos primeiros frutos com alteração de cor.

Os frutos foram colhidos de 20/08/97 a 27/10/97 para as determinações do número de frutos por planta, peso médio dos frutos e produção total. Para isso, utilizaram-se as 16 plantas da parcela.

Foram coletadas 10 amostras simples por parcela para formar uma amostra composta, em 5 de novembro de 1997, para as determinações do $\mathrm{pH}$ em $\mathrm{CaCl}_{2}$, da matéria orgânica (método colorimétrico), do fósforo disponível (extraído por resina trocadora de íons e determinado por método colorimétrico), potássio, cálcio e magnésio trocáveis ( extraídos por resina trocadora de íons e determinados por espectrofotometria de absorção atômica) e acidez potencial (método tampão SMP). A capacidade de troca de cátions ao $\mathrm{pH} 7,0$ foi obtida através da soma de bases com a acidez potencial.

Os resultados obtidos foram submetidos à análise de variância pelo teste $\mathrm{F}$, e a comparação entre médias foi feita pelo teste $t$ de Student, a $5 \%$ de probabilidade. 


\subsection{Resultados e Discussão}

Os resultados da altura das plantas, aos 52,62 e 72 dias após o transplante, constam da Tabela 14. Houve diferença significativa entre os materiais orgânicos somente na terceira amostragem. Neste período de avaliação, o composto de lodo de cervejaria + cavaco de eucalipto proporcionou a maior altura das plantas, na dose equivalente a 100 $\mathrm{kg} \mathrm{ha}^{-1}$ de N. Entretanto, na dose equivalente a $150 \mathrm{~kg} \mathrm{ha}^{-1}$ de N, a altura das plantas foi superior com a adição da cama de frango em relação ao composto de lodo de cervejaria + cavaco de eucalipto. A relação $\mathrm{C} / \mathrm{N}$ menor da cama de frango indica que a taxa de mineralização do $\mathrm{N}$ pode ter sido maior, o que possibilitou maior disponibilidade deste elemento, responsável possivelmente por este efeito sobre o crescimento das plantas.

Aos 52 e 72 dias após o transplante, a adição de $200 \mathrm{~kg} \mathrm{ha}^{-1}$ de $\mathrm{N}$ como composto de lodo de cervejaria + cavaco de eucalipto reduziu a altura das plantas. $\mathrm{O}$ mesmo fato foi constatado com a aplicação do composto de lixo, aos 52 dias após o transplante das mudas. Entretanto, cabe ressaltar que a redução na altura das plantas foi pequena, em torno de 4 a $8 \%$, o que não afetou a produção total (Tabela 14). As doses de cama de frango influenciaram na altura das plantas na terceira amostragem, onde o maior valor foi obtido com a aplicação de $150 \mathrm{~kg} \mathrm{ha}^{-1}$ de $\mathrm{N}$ em relação às doses equivalentes a $100 \mathrm{e} 200$ $\mathrm{kg} \mathrm{ha}^{-1}$ de $\mathrm{N}$.

Os valores do número de frutos por planta, da produção total e do peso médio de frutos estão apresentados na Tabela 15 . Estas características sofreram influência do tipo de material orgânico quando se empregou $150 \mathrm{~kg} \mathrm{ha}^{-1}$ de $\mathrm{N}$. O composto de lodo de cervejaria + cavaco de eucalipto proporcionou o maior peso médio de frutos em relação ao composto de lixo, sendo que ambos não diferiram significativamente da cama de frango. A produção total e o número de frutos por planta foram maiores com a adição do composto de lodo de cervejaria + cavaco de eucalipto e da cama de frango.

$\mathrm{O}$ peso médio, o número de frutos por planta e a produção total não aumentaram com as doses aplicadas dos materiais orgânicos, possivelmente por estas serem pequenas. Resultados semelhantes foram obtidos por Hampton et al. (1994), onde as adições de 16 a $48 \mathrm{Mg} \mathrm{ha}^{-1}$ de materiais derivados de resíduo sólido urbano, em solo adubado com 240 $\mathrm{kg} \mathrm{ha}^{-1}$ de $\mathrm{N}$, não promoveram aumentos na produção de tomate. 
Tabela 14. Efeitos de tipos e doses de resíduos orgânicos sobre a altura das plantas de tomate cv. Débora Plus.

\begin{tabular}{|c|c|c|c|c|}
\hline \multirow{2}{*}{$\begin{array}{l}\text { Resíduos } \\
\text { orgânicos }\end{array}$} & \multicolumn{4}{|c|}{ Doses de $\mathrm{N}\left(\mathrm{kg} \mathrm{ha}^{-1}\right)$} \\
\hline & $\mathbf{0}$ & 100 & 150 & 200 \\
\hline & \multicolumn{4}{|c|}{52 dias após o transplante } \\
\hline CLC & 74,00 a $\mathrm{AB}$ & 75,56 a $\mathrm{A}$ & $71,25 \mathrm{a} A B$ & 70,44 a B \\
\hline $\mathrm{CF}$ & 73,81 a $\mathrm{A}$ & 71,50 a $\mathrm{A}$ & 77,25 a A & 73,31 a $\mathrm{A}$ \\
\hline $\mathrm{CL}$ & 71,75 a $A B$ & 72,00 a $A B$ & 75,94 a A & 69,75 a $B$ \\
\hline \multirow[t]{2}{*}{ C.V. $(\%)$} & 10,12 & & & \\
\hline & \multicolumn{4}{|c|}{62 dias após o transplante } \\
\hline CLC & 100,63 a $\mathrm{A}$ & 98,47 a $A$ & 102,69 a A & 99,54 a $\mathrm{A}$ \\
\hline $\mathrm{CF}$ & 100,75 a A & 93,01 a $\mathrm{A}$ & 104,31 a $\mathrm{A}$ & 98,21 a $\mathrm{A}$ \\
\hline $\mathrm{CL}$ & 100,56 a A & 96,16 a $\mathrm{A}$ & 101,13 a $\mathrm{A}$ & 96,38 a $\mathrm{A}$ \\
\hline \multirow[t]{2}{*}{ C.V. $(\%)$} & 8,35 & & & \\
\hline & \multicolumn{4}{|c|}{72 dias após o transplante } \\
\hline CLC & 124,81 a $A B$ & 127,19 a $\mathrm{A}$ & $120,44 \mathrm{~b} \mathrm{AB}$ & 118,46 a B \\
\hline $\mathrm{CF}$ & 122,44 a $A B$ & 118,85 b B & 128,73 a $\mathrm{A}$ & 119,61 a B \\
\hline $\mathrm{CL}$ & 125,57 a A & $118,86 \mathrm{~b} \mathrm{~A}$ & $122,92 \mathrm{ab} \mathrm{A}$ & 123,75 a $\mathrm{A}$ \\
\hline C.V. $(\%)$ & 8,97 & & & \\
\hline
\end{tabular}

Médias seguidas pela mesma letra, minúscula na coluna e maiúscula na linha, não diferem entre si pelo teste $t$ de Student a $5 \%$.

$\mathrm{CLC}=$ composto de lodo de cervejaria + cavaco de eucalipto; $\mathrm{CF}=$ cama de frango; $\mathrm{CL}$ = composto de lixo.

Os teores foliares de macronutrientes estão descritos na Tabela 16. As concentrações de $\mathrm{N}, \mathrm{Ca}$ e $\mathrm{S}$ não foram afetadas pelo tipo de material orgânico. Houve diferença significativa entre os resíduos orgânicos sobre os teores foliares de $\mathrm{P}$ e de $\mathrm{K}$ na dosagem de $100 \mathrm{~kg} \mathrm{ha}^{-1}$ de $\mathrm{N}$. $\mathrm{O}$ teor de $\mathrm{P}$ foi superior para o composto de lodo de cervejaria + cavaco de eucalipto em relação ao composto de lixo, provavelmente em virtude da maior quantidade deste elemento presente no composto de lodo de cervejaria + cavaco de eucalipto, que tornou-se disponível para as plantas. $\mathrm{O}$ maior valor de $\mathrm{K}$ foi obtido com a adição da cama de frango comparado ao composto de lodo de cervejaria + cavaco de eucalipto, cuja explicação também baseia-se na quantidade mais elevada de $\mathrm{K}$ adicionada através do primeiro material orgânico. Para as concentrações de $\mathrm{Mg}$ nas folhas o maior valor foi obtido com a adição de $150 \mathrm{~kg} \mathrm{ha}^{-1}$ de $\mathrm{N}$ como composto de lixo em relação ao composto de lodo de cervejaria + cavaco de eucalipto, o que está de 
acordo com a maior quantidade de $\mathrm{Mg}$ no composto de lixo, em torno de cinco vezes superior.

Com exceção do $\mathrm{K}$ e do $\mathrm{Mg}$, os teores dos nutrientes nas folhas não foram afetados pelas doses dos materiais orgânicos (Tabela 16). O teor foliar de $\mathrm{K}$ aumentou em $11 \%$ com a adição de $150 \mathrm{~kg} \mathrm{ha}^{-1}$ de $\mathrm{N}$ na forma de composto de lixo. Bernal \& Roig (1993) também constataram aumento no teor foliar de $\mathrm{K}$ em plantas de tomate com a aplicação de $250 \mathrm{~m}^{3} \mathrm{ha}^{-1}$ de esterco de suíno em solo argilo-arenoso. Os teores foliares de $\mathrm{Mg}$, por sua vez, foram reduzidos pelas aplicações de 150 e $200 \mathrm{~kg} \mathrm{ha}^{-1}$ de $\mathrm{N}$ como composto de lodo de cervejaria + cavaco de eucalipto e como composto de lixo, respectivamente, sem refletir, contudo, em queda de produção.

As concentrações foliares de micronutrientes constam da Tabela 17. Entre os materiais orgânicos, o teor foliar de boro foi superior para o composto de lodo de cervejaria + cavaco de eucalipto com a aplicação de $150 \mathrm{~kg} \mathrm{ha}^{-1}$ de $\mathrm{N}$, sendo que nas demais doses, os materiais orgânicos não diferiram significativamente entre si. Para os teores foliares de cobre, foram constatados comportamentos variáveis entre os resíduos orgânicos. $\mathrm{Na}$ dosagem de $100 \mathrm{~kg} \mathrm{ha}^{-1}$ de $\mathrm{N}$, o maior teor de $\mathrm{Cu}$ foi obtido com a cama de frango em relação ao composto de lodo de cervejaria + cavaco de eucalipto, enquanto que para a adição de $150 \mathrm{~kg} \mathrm{ha}^{-1}$ de $\mathrm{N}$, a concentração mais elevada deste micronutriente correspondeu ao composto de lixo, o que está coerente com a quantidade mais elevada de $\mathrm{Cu}$, cerca de duas vezes superior, neste composto. A maior concentração de $\mathrm{Mn}$ foi obtida com a cama de frango em quantidade equivalente a $100 \mathrm{~kg} \mathrm{ha}^{-1}$ de $\mathrm{N}$. Os teores foliares de $\mathrm{Fe}$ e de $\mathrm{Zn}$ não sofreram influência do tipo de resíduo orgânico.

Somente os teores foliares de $\mathrm{B}$ e de $\mathrm{Cu}$ foram afetados pelas doses adicionadas dos materiais orgânicos (Tabela 17). A adição de $150 \mathrm{~kg} \mathrm{ha}^{-1}$ de $\mathrm{N}$ como composto de lodo de cervejaria + cavaco de eucalipto aumentou o teor de $\mathrm{B}$ em relação às aplicações de 100 e $200 \mathrm{~kg} \mathrm{ha}^{-1}$ de $\mathrm{N}$. A aplicação de $200 \mathrm{~kg} \mathrm{ha}^{-1}$ de $\mathrm{N}$ como cama de frango reduziu o teor de $\mathrm{B}$ nas folhas. Os teores de $\mathrm{Cu}$ aumentaram com a adição de 100 e $200 \mathrm{~kg} \mathrm{ha}^{-1}$ de $\mathrm{N}$ como cama de frango e como composto de lodo de cervejaria + cavaco de eucalipto, respectivamente. Entretanto, a aplicação de $200 \mathrm{~kg} \mathrm{ha}^{-1}$ de $\mathrm{N}$ na forma de composto de lixo, reduziu o teor foliar deste micronutriente, o que indica que a maior 
quantidade de matéria orgânica adicionada e a natureza deste composto podem ter sido responsáveis pela menor disponibilidade de $\mathrm{Cu}$ para as plantas, através possivelmente da complexação desse metal em formas orgânicas. Elliott \& Singer (1988) constataram reduções nos teores de $\mathrm{Cu}$ nas folhas de tomate com a adição de 2 a $10 \%$ de lodo de esgoto, neste caso, devido ao aumento do $\mathrm{pH}$ após a adição do material orgânico, que proporcionou precipitação do $\mathrm{Cu}$, tornando-o menos disponivel para as plantas.

Com exceção do $\mathrm{Cu}$, os teores foliares dos nutrientes foram considerados adequados por Trani \& Raij (1996). Os teores de Cu, por sua vez, estão acima da faixa considerada adequada, descrita por estes autores, em virtude provavelmente da contaminação por $\mathrm{Cu}$ através de pulverizações foliares com fungicidas cúpricos praticadas na cultura.

Os teores solúveis de potássio, nitrogênio e fósforo nos pecíolos das folhas no período do florescimento e do aparecimento dos primeiros frutos com alteração de cor, constam da Tabela 18. No período do florescimento, os teores solúveis destes nutrientes sofreram influência dos materiais orgânicos na dosagem de $150 \mathrm{~kg} \mathrm{ha}^{-1}$ de $\mathrm{N}$. O maior teor de potássio solúvel foi obtido com a cama de frango em relação ao composto de lodo de cervejaria + cavaco de eucalipto, o que correspondeu a maior quantidade deste elemento presente na cama de frango. $\mathrm{O}$ composto de lixo proporcionou o maior teor de nitrato que o composto de lodo de cervejaria + cavaco de eucalipto. A concentração de fosfato foi inferior com a adição do composto de lixo, o que está coerente também com o menor conteúdo de fósforo presente no composto de lixo. Na época do aparecimento dos primeiros frutos com alteração de cor, houve diferença significativa entre os materiais orgânicos, na dose equivalente a $200 \mathrm{~kg} \mathrm{ha}^{-1} \mathrm{de} \mathrm{N}$, sobre os teores de nitrato, onde o maior valor foi obtido com o composto de lodo de cervejaria + cavaco de eucalipto comparado com a cama de frango.

As concentrações de potássio e nitrogênio solúveis em ambos os períodos de amostragem estão acima dos níveis considerados suficientes pela University of California (1979). Os teores de fósforo solúvel no período do florescimento estão entre os limites intermediário e suficiente, sendo que na época do aparecimento dos primeiros frutos com alteração de cor, as concentrações deste elemento encontram-se entre os limites 
deficiente e intermediário.

Através dos resultados obtidos, pode-se inferir que os maiores conteúdos dos nutrientes nos materiais orgânicos nem sempre refletiram na concentração foliar ou na produção, o que está de acordo com Asiegbu \& Oikeh (1995), os quais verificaram ausência de correlação entre as concentrações de $\mathrm{N}, \mathrm{P}, \mathrm{Ca}, \mathrm{K}, \mathrm{Fe}$ e $\mathrm{Cu}$ nas folhas e as quantidades totais dos mesmos no esterco de galinha.

Tabela 15. Efeitos de tipos e doses de resíduos orgânicos no peso médio de frutos, no número de frutos por planta e na produção total de tomate cv. Débora Plus.

\begin{tabular}{|c|c|c|c|c|}
\hline \multirow[t]{2}{*}{ Resíduos orgânicos } & \multicolumn{4}{|c|}{-Doses de $\mathrm{N}\left(\mathrm{kg} \mathrm{ha}^{-1}\right)-$} \\
\hline & $\mathbf{0}$ & 100 & 150 & 200 \\
\hline \multicolumn{5}{|l|}{$\begin{array}{l}\text { Peso médio de frutos } \\
\text { (g/fruto) }\end{array}$} \\
\hline CLC & 123,82 a $\mathrm{A}$ & 113,67 a $\mathrm{A}$ & 122,90 a A & 125,03 a $\mathrm{A}$ \\
\hline $\mathrm{CF}$ & 114,94 a A & 108,70 a $\mathrm{A}$ & $117,70 \mathrm{ab} A$ & 111,90 a $\mathrm{A}$ \\
\hline CL & 105,53 a $\mathrm{AB}$ & 121,67 a $\mathrm{A}$ & 92,89 b B & 129,99 a A \\
\hline C.V. (\%) & 15,17 & & & \\
\hline \multicolumn{5}{|c|}{ Número de frutos/planta } \\
\hline CLC & 22,20 a A & 19,03 a $\mathrm{A}$ & 21,48 a $\mathrm{A}$ & 21,57 a A \\
\hline $\mathrm{CF}$ & 19,69 a A & 19,81 a $\mathrm{A}$ & 20,43 a $\mathrm{A}$ & 18,69 a A \\
\hline $\mathrm{CL}$ & 20,21 a $\mathrm{AB}$ & 21,29 a A & $15,81 \mathrm{~b} \mathrm{~B}$ & 19,69 a $\mathrm{AB}$ \\
\hline C.V. (\%) & 16,08 & & & \\
\hline \multicolumn{5}{|c|}{ Produção total $\left(\mathrm{Mg} \mathrm{ha}^{-1}\right)$} \\
\hline CLC & 62,30 a A & 49,97 a A & 60,41 a A & 61,14 a $\mathrm{A}$ \\
\hline $\mathrm{CF}$ & 50,54 a A & 49,73 a A & 55,41 a A & 46,73 a A \\
\hline CL & 49,19 a $\mathrm{AB}$ & 59,75 a $\mathrm{A}$ & 33,88 b B & 58,50 a $\mathrm{A}$ \\
\hline C.V. $(\%)$ & 23,03 & & & \\
\hline
\end{tabular}

Médias seguidas pela mesma letra, minúscula na coluna e maiúscula na linha, não diferem entre si pelo teste $t$ de Student a $5 \%$.

$\mathrm{CLC}=$ composto de lodo de cervejaria + cavaco de eucalipto; $\mathrm{CF}=$ cama de frango; $\mathrm{CL}$ = composto de lixo. 
Tabela 16. Efeitos de tipos e doses de resíduos orgânicos nas concentrações de macronutrientes em folhas de tomate cv. Débora Plus, na época do florescimento.

\begin{tabular}{|c|c|c|c|c|}
\hline \multirow{2}{*}{$\begin{array}{l}\text { Resíduos } \\
\text { orgânicos }\end{array}$} & \multicolumn{4}{|c|}{ Doses de $\mathrm{N}\left(\mathrm{kg} \mathrm{ha}^{-1}\right)$} \\
\hline & $\mathbf{0}$ & 100 & 150 & 200 \\
\hline \multicolumn{5}{|c|}{ Nitrogênio (N) } \\
\hline CLC & 52,43 a A & 52,45 a A & 53,33 a A & 54,60 a $\mathrm{A}$ \\
\hline $\mathrm{CF}$ & 51,70 a A & 49,98 a $\mathrm{A}$ & 52,45 a $\mathrm{A}$ & 50,75 a A \\
\hline $\mathrm{CL}$ & 51,20 a A & 50,74 a A & 51,48 a $\mathrm{A}$ & 53,40 a $\mathrm{A}$ \\
\hline C.V. (\%) & 5,98 & & & \\
\hline \multicolumn{5}{|l|}{ Fósforo (P) } \\
\hline CLC & 6,10 a $\mathrm{A}$ & 6,40 a A & 6,18 a $\mathrm{A}$ & 6,15 a $\mathrm{A}$ \\
\hline $\mathrm{CF}$ & 6,08 a $\mathrm{A}$ & $5,70 \mathrm{ab} A$ & 6,13 a $A$ & 5,85 a $\mathrm{A}$ \\
\hline $\mathrm{CL}$ & 6,28 a A & $5,63 \mathrm{~b} \mathrm{~A}$ & 5,93 a A & 6,13 a $\mathrm{A}$ \\
\hline C.V. (\%) & 8,01 & & & \\
\hline \multicolumn{5}{|l|}{ Potássio (K) } \\
\hline CLC & 39,88 ab A & $38,55 \mathrm{~b} \mathrm{~A}$ & 41,60 a $\mathrm{A}$ & 41,28 a $\mathrm{A}$ \\
\hline $\mathrm{CF}$ & 42,95 a $\mathrm{A}$ & 43,58 a $\mathrm{A}$ & 40,75 a A & 40,75 a $\mathrm{A}$ \\
\hline $\mathrm{CL}$ & 38,65 b B & $40,98 \mathrm{ab} \mathrm{AB}$ & 42,93 a A & 39,15 a $\mathrm{AB}$ \\
\hline C.V. (\%) & 7,06 & & & \\
\hline \multicolumn{5}{|l|}{ Cálcio (Ca) } \\
\hline CLC & 26,60 a $A$ & 27,88 a $A$ & 25,50 a $\mathrm{A}$ & 26,05 a $\mathrm{A}$ \\
\hline $\mathrm{CF}$ & 26,85 a $A$ & 27,73 a $\mathrm{A}$ & 25,20 a A & 26,30 a A \\
\hline $\mathrm{CL}$ & 26,43 a $\mathrm{A}$ & 26,05 a $\mathrm{A}$ & 25,95 a A & 24,68 a A \\
\hline C.V. (\%) & 8,44 & & & \\
\hline \multicolumn{5}{|c|}{ Magnésio (Mg) } \\
\hline CLC & $9,60 \mathrm{~b} A B$ & 9,95 a $\mathrm{A}$ & 9,00 b B & 9,90 a $\mathrm{AB}$ \\
\hline $\mathrm{CF}$ & $9,97 \mathrm{ab} A$ & 10,30 a $A$ & $9,45 \mathrm{ab} \mathrm{A}$ & 10,25 a A \\
\hline CL & 10,80 a A & $10,10 \mathrm{a} A \mathrm{AB}$ & 9,98 a $\mathrm{AB}$ & 9,45 a B \\
\hline C.V. (\%) & 6,53 & & & \\
\hline \multicolumn{5}{|c|}{ Enxofre (S) } \\
\hline CLC & 4,63 a $A$ & 4,55 a $\mathrm{A}$ & 4,88 a $\mathrm{A}$ & 4,75 a $\mathrm{A}$ \\
\hline $\mathrm{CF}$ & 4,50 a A & 4,70 a $\mathrm{A}$ & 4,53 a $\mathrm{A}$ & 4,88 a $\mathrm{A}$ \\
\hline $\mathrm{CL}$ & 4,53 a $\mathrm{A}$ & 4,17 a $\mathrm{A}$ & 4,70 a $\mathrm{A}$ & 4,10 a $\mathrm{A}$ \\
\hline C.V. (\%) & 10,31 & & & \\
\hline
\end{tabular}

Médias seguidas pela mesma letra, minúscula na coluna e maiúscula na linha, não diferem entre si pelo teste $t$ de Student a $5 \%$.

$\mathrm{CLC}=$ composto de lodo de cervejaria + cavaco de eucalipto; $\mathrm{CF}=$ cama de frango; $\mathrm{CL}$ $=$ composto de lixo. 
Tabela 17. Efeitos de tipos e doses de resíduos orgânicos nas concentrações de micronutrientes em folhas de tomate cv. Débora Plus, na época do florescimento.

\begin{tabular}{|c|c|c|c|c|}
\hline \multirow{2}{*}{$\begin{array}{l}\text { Resíduos } \\
\text { orgânicos }\end{array}$} & \multicolumn{4}{|c|}{-Doses de $\mathrm{N}\left(\mathrm{kg} \mathrm{ha}^{-1}\right)$} \\
\hline & $\mathbf{0}$ & 100 & 150 & 200 \\
\hline & & (- & $\mathrm{kg}^{-1} \ldots$ & \\
\hline \multicolumn{5}{|l|}{ Boro (B) } \\
\hline CLC & $38,50 \mathrm{a} A B$ & 35,50 a B & 40,50 a $\mathrm{A}$ & 36,75 a $B$ \\
\hline $\mathrm{CF}$ & 39,50 a $\mathrm{A}$ & 36,25 a $\mathrm{AB}$ & $36,25 \mathrm{~b} \mathrm{AB}$ & 34,25 a B \\
\hline $\mathrm{CL}$ & 36,00 a $\mathrm{A}$ & 36,75 a $A$ & $35,25 \mathrm{~b} \mathrm{~A}$ & 34,50 a $\mathrm{A}$ \\
\hline C.V. $(\%)$ & 6,85 & & & \\
\hline \multicolumn{5}{|l|}{ Cobre (Cu) } \\
\hline CLC & 48,25 a B & $51,25 \mathrm{~b} \mathrm{AB}$ & 50,75 b B & 66,75 a $A$ \\
\hline $\mathrm{CF}$ & 53,50 a B & 75,75 a $\mathrm{A}$ & $55,59 \mathrm{ab} \mathrm{AB}$ & 61,50 a $A B$ \\
\hline $\mathrm{CL}$ & 63,75 a $\mathrm{AB}$ & $63,25 \mathrm{ab} A B$ & 74,00 a $\mathrm{A}$ & $47,50 \mathrm{~b} \mathrm{~B}$ \\
\hline C.V. $(\%)$ & 22,81 & & & \\
\hline \multicolumn{5}{|l|}{ Ferro (Fe) } \\
\hline CLC & 147,25 a $\mathrm{A}$ & 160,00 a $\mathrm{A}$ & 161,50 a $A$ & 156,75 a $A$ \\
\hline $\mathrm{CF}$ & 150,50 a $\mathrm{A}$ & 146,25 a A & 158,25 a A & 156,00 a $A$ \\
\hline $\mathrm{CL}$ & 156,25 a $A$ & 162,50 a $\mathrm{A}$ & 152,50 a $\mathrm{A}$ & 150,25 a $\mathrm{A}$ \\
\hline C.V. $(\%)$ & 9,59 & & & \\
\hline \multicolumn{5}{|c|}{ Manganês (Mn) } \\
\hline CLC & 115,25 a A & $102,50 \mathrm{~b} \mathrm{~A}$ & 119,25 a A & 128,25 a $A$ \\
\hline $\mathrm{CF}$ & 120,50 a $\mathrm{A}$ & 142,00 a A & 131,75 a $\mathrm{A}$ & 128,00 a $\mathrm{A}$ \\
\hline $\mathrm{CL}$ & 104,00 a A & $130,00 \mathrm{ab} \mathrm{A}$ & 121,25 a A & 118,25 a $A$ \\
\hline C.V. $(\%)$ & 18,00 & & & \\
\hline \multicolumn{5}{|l|}{ Zinco (Zn) } \\
\hline CLC & 38,75 a $\mathrm{A}$ & 39,50 a $\mathrm{A}$ & 41,50 a $\mathrm{A}$ & 43,25 a A \\
\hline $\mathrm{CF}$ & 41,00 a $\mathrm{A}$ & 43,00 a $\mathrm{A}$ & 43,00 a $\mathrm{A}$ & 41,25 a $\mathrm{A}$ \\
\hline $\mathrm{CL}$ & 41,75 a $A$ & 41,75 a $\mathrm{A}$ & 43,50 a $\mathrm{A}$ & 45,75 a $\mathrm{A}$ \\
\hline C.V. $(\%)$ & 7,74 & & & \\
\hline
\end{tabular}

Médias seguidas pela mesma letra, minúscula na coluna e maiúscula na linha, não diferem entre si pelo teste t de Student a $5 \%$.

$\mathrm{CLC}=$ composto de lodo de cervejaria + cavaco de eucalipto; $\mathrm{CF}=$ cama de frango; $\mathrm{CL}$ $=$ composto de lixo. 
Tabela 18. Teores solúveis de potássio, nitrogênio e fósforo nos pecíolos de tomate cv. Débora Plus.

\begin{tabular}{|c|c|c|c|c|}
\hline \multirow[t]{2}{*}{ Resíduos orgânicos } & \multicolumn{4}{|c|}{ Doses de N $\left(\mathrm{kg} \mathrm{ha}^{-1}\right)$} \\
\hline & $\mathbf{0}$ & 100 & 150 & 200 \\
\hline & \multicolumn{4}{|c|}{ Época do florescimento } \\
\hline$K-K^{+}\left(\mathrm{g} \mathrm{kg}^{-1}\right)$ & & & & \\
\hline CLC & 67,6 a $\mathrm{A}$ & 67,2 a $A$ & $65,9 \mathrm{~b} \mathrm{~A}$ & 68,9 a $\mathrm{A}$ \\
\hline $\mathrm{CF}$ & $71,6 \mathrm{~b} \mathrm{~A}$ & 69,2 a $A$ & 69,6 a A & 69,2 a $\mathrm{A}$ \\
\hline $\mathrm{CL}$ & $69,1 \mathrm{ab} A$ & 69,0 a $\mathrm{A}$ & $68,0 \mathrm{ab} A$ & 69,1 a $\mathrm{A}$ \\
\hline C.V. (\%) & 3,12 & & & \\
\hline \multicolumn{5}{|l|}{$\mathrm{N}-\mathrm{NO}_{3}^{-}\left(\mathrm{mg} \mathrm{kg}^{-1}\right)$} \\
\hline CLC & 18800 a A & 19500 a A & 17900 b A & 19900 a A \\
\hline $\mathrm{CF}$ & 18500 a A & 20300 a A & $19400 \mathrm{ab} A$ & 19300 a A \\
\hline $\mathrm{CL}$ & 19100 a A & 19400 a A & 20100 a A & 19000 a A \\
\hline C.V. (\%) & 8,08 & & & \\
\hline \multicolumn{5}{|c|}{$\mathrm{P}-\mathrm{HPO}_{4}^{-2}\left(\mathrm{mg} \mathrm{kg}^{-1}\right)$} \\
\hline CLC & 5562,5 a $\mathrm{A}$ & 5687,5 a $\mathrm{A}$ & 5687,5 a $\mathrm{A}$ & 5875,0 a $\mathrm{A}$ \\
\hline $\mathrm{CF}$ & 5812,5 a $\mathrm{A}$ & 5812,5 a $A$ & 5687,5 a $\mathrm{A}$ & 5687,5 a A \\
\hline $\mathrm{CL}$ & 5625,0 a $\mathrm{A}$ & 5402,5 a A & 5250,0 b A & 5687,5 a A \\
\hline C.V. (\%) & 4,87 & & & \\
\hline & \multicolumn{4}{|c|}{ Primeiros frutos com alteração de cor } \\
\hline $\mathrm{K}-\mathrm{K}^{+}\left(\mathrm{g} \mathrm{kg}^{-1}\right)$ & & & & \\
\hline CLC & 48,4 a $A$ & 45,7 a $A$ & 51,3 a $A$ & 47,2 a $A$ \\
\hline $\mathrm{CF}$ & 44,6 a A & 40,7 a $\mathrm{A}$ & 43,4 a $A$ & 46,8 a $\mathrm{A}$ \\
\hline $\mathrm{CL}$ & 44,3 a $A$ & 42,6 a $A$ & 48,6 a $A$ & 48,4 a $A$ \\
\hline C.V. (\%) & 12.91 & & & \\
\hline \multicolumn{5}{|c|}{$\mathrm{N}-\mathrm{NO}_{3}^{-}\left(\mathrm{mg} \mathrm{kg}^{-1}\right)$} \\
\hline $\mathrm{CLC}$ & 8200 a A & 6000 a A & 8300 a A & 9100 a A \\
\hline $\mathrm{CF}$ & 8600 a A & 6200 a A & 6500 a A & $5700 \mathrm{~b}$ A \\
\hline $\mathrm{CL}$ & 8600 a A & 6200 a A & 6000 a A & $6800 \mathrm{ab} \mathrm{A}$ \\
\hline C.V. (\%) & 30,43 & & & \\
\hline \multicolumn{5}{|c|}{$\mathrm{P}_{-} \mathrm{HPO}_{4}^{-2}\left(\mathrm{mg} \mathrm{kg}^{-1}\right)$} \\
\hline CLC & 2250,0 a $\mathrm{A}$ & 2375,0 a A & 2062,5 a A & 2437,5 a A \\
\hline $\mathrm{CF}$ & 2187,5 a $\mathrm{A}$ & 2250,0 a $A$ & 1932,5 a A & 2437.5 a A \\
\hline $\mathrm{CL}$ & 2062,5 a A & 2062,5 a A & 1875,0 a A & 2472,5 a A \\
\hline C.V. (\%) & 26,47 & & & \\
\hline
\end{tabular}

Médias seguidas pela mesma letra maiúscula na linha e minúscula na coluna não diferem entre si pelo teste $\mathrm{t}$ de Student a $5 \%$.

$\mathrm{CLC}=$ composto de lodo de cervejaria + cavaco de eucalipto; $\mathrm{CF}=$ cama de frango; $\mathrm{CL}=$ composto de lixo. 
As características químicas do solo aos seis meses após a incorporação dos resíduos orgânicos constam da Tabela 19. Com exceção dos conteúdos de matéria orgânica e de magnésio, os atributos químicos foram afetados pelos tratamentos empregados.

O conteúdo de matéria orgânica não sofreu influência da adição dos materiais orgânicos, em virtude possivelmente das pequenas quantidades aplicadas desses materiais. Além disso, o nível relativamente alto de matéria orgânica já presente no solo, pode também ter contribuído para este fato. Na literatura há relatos de que pequenas taxas de adubos orgânicos não promovem aumentos no conteúdo de matéria orgânica (Anderson \& Peterson, 1973; Campbell, 1978).

$\mathrm{O} \mathrm{pH}$ foi menor para a cama de frango em relação aos demais, com as aplicações de 150 e $200 \mathrm{~kg} \mathrm{ha}^{-1}$ de N. Possivelmente as menores quantidades de matéria orgânica adicionadas através da cama de frango e a sua natureza química foram responsáveis por este resultado. Braccini et al. (1995) também encontraram efeito diferenciado entre resíduos orgânicos sobre o $\mathrm{pH}$ do solo. A aplicação de $200 \mathrm{~kg} \mathrm{ha}^{-1}$ de $\mathrm{N}$ como composto de lodo de cervejaria + cavaco de eucalipto aumentou o $\mathrm{pH}$ do solo. A natureza alcalina desse material e a sua quantidade elevada de cálcio sugerem a presença de substâncias alcalinizantes na forma de óxidos ou hidróxidos de cálcio, os quais seriam responsáveis por esse efeito.

As doses de cama de frango e do composto de lixo aplicadas não alteraram o pH. Cabe ressaltar que possíveis incrementos no $\mathrm{pH}$ do solo podem ter ocorrido durante o processo de decomposição destes resíduos orgânicos, mas não foram mantidos após seis meses. Holanda et al. (1982) também obtiveram resultados semelhantes com a adição de $12 \mathrm{Mg} \mathrm{ha}^{-1}$ de esterco de galinha, onde o $\mathrm{pH}$ não aumentou após treze meses da sua aplicação, devido à baixa quantidade aplicada .

$\mathrm{O}$ teor de $\mathrm{P}$ no solo foi maior com a adição do composto de lodo de cervejaria + cavaco de eucalipto em relação aos demais resíduos, em quantidade equivalente a $100 \mathrm{~kg}$ $\mathrm{ha}^{-1}$ de N. Nas demais doses, os materiais orgânicos não diferiram significativamente entre si. Para o efeito de doses, a adição de $100 \mathrm{~kg} \mathrm{ha}^{-1}$ de $\mathrm{N}$ na forma de composto de lodo de cervejaria + cavaco de eucalipto aumentou o teor de $\mathrm{P}$ disponivel em relação à 
testemunha e a dose intermediária. Este fato foi acompanhado por aumento do $\mathrm{pH}$ e redução na acidez potencial do solo, o que permitiu maior disponibilidade de $\mathrm{P}$, em virtude da redução do alumínio no solo, consequentemente da formação de fosfatos de alumínio. Berton et al. (1989) também observaram aumentos do pH e de $\mathrm{P}$ no solo com as adições de 2 e $4 \%$ de lodo de esgoto.

$\mathrm{O}$ teor de $\mathrm{K}$ foi superior com a adição da cama de frango em relação ao composto de lodo de cervejaria + cavaco de eucalipto, na dose equivalente a $150 \mathrm{~kg} \mathrm{ha}^{-1}$ de $\mathrm{N}$, possivelmente pela quantidade mais elevada deste elemento na cama de frango. A aplicação de $150 \mathrm{~kg} \mathrm{ha}^{-1}$ de $\mathrm{N}$ como cama de frango elevou o teor de $\mathrm{K}$, sendo que para os demais resíduos, as doses aplicadas não proporcionaram aumentos significativos nos conteúdos deste nutriente, em relação ao solo não tratado. Os conteúdos de $\mathrm{Ca}$ no solo foram influenciados pelo tipo de resíduo, nas doses equivalentes a 100 e $200 \mathrm{~kg} \mathrm{ha}^{-1}$ de $\mathrm{N}$, onde o composto de lodo de cervejaria + cavaco de eucalipto proporcionou os maiores valores de $\mathrm{Ca}$, também em virtude da quantidade mais elevada de $\mathrm{Ca}$ neste material. Para o conteúdo de $\mathrm{Ca}$, as adições de 100 e $200 \mathrm{~kg} \mathrm{ha}^{-1}$ de $\mathrm{N}$ como composto de lodo de cervejaria + cavaco de eucalipto elevaram os teores dessa base trocável. Holanda et al. (1982) verificaram resultados semelhantes nos níveis de $\mathrm{K}$ e de Ca com a adição de $12 \mathrm{Mg} \mathrm{ha}^{-1}$ de esterco de galinha.

Dentre os resíduos orgânicos, o composto de lodo de cervejaria + cavaco de eucalipto foi responsável pelos menores valores de acidez potencial com a aplicação de 100 e $200 \mathrm{~kg} \mathrm{ha}^{-1}$ de $\mathrm{N}$, sendo que na dose intermediária, o menor valor foi obtido com o composto de lixo. De maneira geral, estes resultados estão coerentes com os constatados para o $\mathrm{pH}$, ou seja, os maiores valores de $\mathrm{pH}$ foram acompanhados por decréscimos na acidez potencial. A adição de $100 \mathrm{~kg} \mathrm{ha}^{-1}$ de $\mathrm{N}$ como composto de lodo de cervejaria + cavaco de eucalipto reduziu a acidez potencial. O mesmo fato foi constatado com a aplicação de composto de lixo em quantidade equivalente a $150 \mathrm{~kg} \mathrm{ha}^{-1}$ de $\mathrm{N}$. Esses resultados podem ser atribuídos ao efeito do $\mathrm{pH}$. Miyazawa et al. (1993) obtiveram redução na acidez potencial após a incorporação de adubo verde, devido ao efeito do $\mathrm{pH}$ nas cargas variáveis do solo. Além disso, pode ter ocorrido complexação do alumínio por moléculas orgânicas, o que contribuiu também para a redução da acidez potencial. Hue 
(1992) observou redução do Al por complexação orgânica após a aplicação de esterco de frango ou de lodo de esgoto.

A capacidade de troca de cátions ao $\mathrm{pH} 7,0$ foi maior para o composto de lodo de cervejaria + cavaco de eucalipto em relação à cama de frango, na dose equivalente a 200 $\mathrm{kg} \mathrm{ha}^{-1}$ de N. A maior quantidade de matéria orgânica adicionada através do primeiro material e a sua composição química podem ter sido responsáveis por esse resultado. A adição da dose mais elevada do composto de lodo de cervejaria + cavaco de eucalipto aumentou a CTC ao $\mathrm{pH}$ 7,0 do solo. Este resultado indica em princípio que pode-se incrementar a retenção de cátions com a aplicação de material orgânico em quantidade pequena, como a utilizada neste experimento.

Embora o conteúdo de matéria orgânica do solo não tenha sido aumentado significativamente com a adição do composto de lodo de cervejaria + cavaco de eucalipto, a matéria orgânica proveniente deste material refletiu sobre a CTC ao pH 7,0. Isso é possivel, pois segundo Johnston (1991) mudanças no conteúdo de matéria orgânica do solo ocorrem lentamente e grandes quantidades de materiais orgânicos são necessárias para que o conteúdo da mesma seja aumentado, enquanto que alterações em outras propriedades do solo podem ocorrer mais rapidamente e de maneira mais acentuada. Este comportamento não foi, entretanto, verificado para os outros materiais orgânicos. Resultados semelhantes foram obtidos por Giusquiani et al. (1988), os quais não observaram alterações na CTC do solo com a adição de $50 \mathrm{Mg} \mathrm{ha}^{-1}$ de composto de lixo. 
Tabela 19. Atributos químicos do solo em função de tipos e doses de resíduos orgânicos.

\begin{tabular}{|c|c|c|c|c|}
\hline \multirow[t]{2}{*}{ Resíduos orgânicos } & \multicolumn{4}{|c|}{ - Doses de $N\left(\mathrm{~kg} \mathrm{ha}^{-1}\right)$} \\
\hline & $\mathbf{0}$ & 100 & 150 & 200 \\
\hline \multicolumn{5}{|l|}{ pH } \\
\hline CLC & 4,96 a $B$ & 5,45 a $\mathrm{A}$ & 5,35 a $\mathrm{A}$ & 5,48 a $\mathrm{A}$ \\
\hline $\mathrm{CF}$ & 5,20 a $\mathrm{A}$ & 5,30 a $\mathrm{A}$ & $5,08 \mathrm{~b} \mathrm{~A}$ & 5,05 b A \\
\hline CL & 5,25 a $\mathrm{A}$ & 5,23 a $\mathrm{A}$ & 5,40 a $\mathrm{A}$ & 5,33 a $\mathrm{A}$ \\
\hline C.V. (\%) & 3,36 & & & \\
\hline \multicolumn{5}{|l|}{ M.O. $\left(\mathrm{g} \mathrm{kg}^{-1}\right)$} \\
\hline CLC & 30,17 a $\mathrm{A}$ & 31,00 a $\mathrm{A}$ & 31,50 a $\mathrm{A}$ & 33,50 a $\mathrm{A}$ \\
\hline $\mathrm{CF}$ & 30,25 a $\mathrm{A}$ & 29,00 a $\mathrm{A}$ & 29,75 a $\mathrm{A}$ & 30,00 a $\mathrm{A}$ \\
\hline CL & 28,50 a $\mathrm{A}$ & 31,50 a $\mathrm{A}$ & 30,25 a $\mathrm{A}$ & 34,00 a $\mathrm{A}$ \\
\hline C.V. (\%) & 13,63 & & & \\
\hline \multicolumn{5}{|l|}{ Fósforo (mg kg $\left.{ }^{-1}\right)$} \\
\hline CLC & 163,89 a B & 248,75 a $A$ & 164,50 a B & 213,25 a $\mathrm{AB}$ \\
\hline $\mathrm{CF}$ & 136,25 a $\mathrm{A}$ & 158,00 b A & 191,25 a $\mathrm{A}$ & 150,50 a $\mathrm{A}$ \\
\hline $\mathrm{CL}$ & 175,00 a $\mathrm{A}$ & $165,50 \mathrm{~b} \mathrm{~A}$ & 160,50 a $\mathrm{A}$ & 173,25 a $\mathrm{A}$ \\
\hline C.V. (\%) & 32,76 & & & \\
\hline \multicolumn{5}{|c|}{ Potássio $\left(\mathrm{mmol}_{\mathrm{c}} \mathrm{dm}^{-3}\right)$} \\
\hline CLC & 7,26 a $A B$ & 7,48 a $A B$ & 5,68 b B & 9,59 a $\mathrm{A}$ \\
\hline $\mathrm{CF}$ & 6,30 a B & 7,63 a $A B$ & 9,08 a $\mathrm{A}$ & 8,25 a $A B$ \\
\hline CL & 7,38 a $\mathrm{A}$ & 8,08 a $\mathrm{A}$ & $6,63 \mathrm{ab} A$ & 7,63 a $A$ \\
\hline C.V. (\%) & 8,33 & & & \\
\hline \multicolumn{5}{|l|}{ Cálcio $\left(\mathrm{mmol}_{\mathrm{c}} \mathrm{dm}^{-3}\right)$} \\
\hline CLC & 62,58 a C & 82,00 a $\mathrm{AB}$ & 73,75 a BC & 92,00 a $\mathrm{A}$ \\
\hline $\mathrm{CF}$ & 58,50 a $A$ & 63,50 b A & 60,50 a $\mathrm{A}$ & 59,00 b A \\
\hline CL & 65,25 a $A$ & $69,00 \mathrm{ab} \mathrm{A}$ & 69,00 a $\mathrm{A}$ & 69,25 b A \\
\hline C.V. (\%) & 16,35 & & & \\
\hline \multicolumn{5}{|c|}{ Magnésio $\left(\mathrm{mmol}_{\mathrm{c}} \mathrm{dm}^{3}\right)$} \\
\hline CLC & 27,67 a $\mathrm{A}$ & 28,50 a $\mathrm{A}$ & 27,50 a $\mathrm{A}$ & 27,00 a $\mathrm{A}$ \\
\hline $\mathrm{CF}$ & 24,25 a $\mathrm{A}$ & 27,00 a $\mathrm{A}$ & 23,50 a $\mathrm{A}$ & 25,75 a $\mathrm{A}$ \\
\hline CL & 25,50 a $A$ & 26,00 a $A$ & 25,00 a $\mathrm{A}$ & 26,00 a $A$ \\
\hline C.V. (\%) & 18,88 & & & \\
\hline \multicolumn{5}{|l|}{$\mathrm{H}+\mathrm{Al}\left(\mathrm{mmol}_{\mathrm{c}} \mathrm{dm}^{-3}\right)$} \\
\hline CLC & 36,78 a $A$ & 28,00 b B & $38,75 \mathrm{ab} A$ & $35,00 \mathrm{~b} A B$ \\
\hline $\mathrm{CF}$ & 43,75 a $A$ & 40,75 a $\mathrm{A}$ & 45,75 a $A$ & 46,25 a $A$ \\
\hline CL & 42,50 a $\mathrm{A}$ & 44,75 a $A$ & 34,25 b B & $42,50 \mathrm{ab} A$ \\
\hline C.V. (\%) & 13,52 & & & \\
\hline \multicolumn{5}{|l|}{$\operatorname{CTC}\left(\mathrm{mmol}_{\mathrm{c}} \mathrm{dm}^{-3}\right)$} \\
\hline CLC & 134,29 a B & 145,98 a $A B$ & 145,68 a $A B$ & 163,58 a $\mathrm{A}$ \\
\hline $\mathrm{CF}$ & 132,80 a $\mathrm{A}$ & 138,88 a A & 138,83 a A & 139,25 b A \\
\hline CL & 140,63 a $\mathrm{A}$ & 147,83 a $A$ & 134,88 a $\mathrm{A}$ & 145,38 ab A \\
\hline C.V. (\%) & 10,37 & & & \\
\hline
\end{tabular}

Médias seguidas pela mesma letra, minúscula na coluna e maiúscula na linha, não diferem entre si pelo teste t de Student a $5 \%$.

$\mathrm{CLC}=$ composto de lodo de cervejaria + cavaco de eucalipto; $\mathrm{CF}=$ cama de frango; $\mathrm{CL}$ = composto de lixo. 


\subsection{Conclusões}

A redução na altura das plantas pela adição de $200 \mathrm{~kg} \mathrm{ha}^{-1}$ de $\mathrm{N}$ como composto de lodo de cervejaria + cavaco de eucalipto não afetou o rendimento final da cultura.

As doses empregadas dos compostos orgânicos não incrementaram a produção total de frutos de tomate.

A adicão de $200 \mathrm{~kg} \mathrm{ha}^{-1}$ de $\mathrm{N}\left(14 \mathrm{Mg} \mathrm{ha}^{-1}\right)$ na forma de composto de lodo de cervejaria + cavaco de eucalipto aumentou o $\mathrm{pH}$, os teores de fósforo e de potássio e a capacidade de troca de cátions do solo. 


\section{DEGRADAÇÃO DE MATERIAIS ORGÂNICOS E EFEITOS DE SUAS}

APLICAÇÕES NA BIOMASSA MICROBIANA E NOS ATRIBUTOS FÍSICOS DE UM LATOSSOLO VERMELHO-AMARELO TEXTURA MÉDIA

\section{Resumo}

Em um experimento conduzido no laboratório comparou-se a velocidade de degradação de três materiais orgânicos (composto de lodo de cervejaria + cavaco de eucalipto, composto de lixo e cama de frango) com quatro doses equivalentes a 0,100 , 150 e $200 \mathrm{~kg} \mathrm{ha}^{-1}$ de $\mathrm{N}$. Em condições de estufa realizou-se outro experimento para avaliar os efeitos dos tratamentos descritos na biomassa microbiana e em atributos físicos do solo, após o cultivo com tomate. A velocidade de decomposição dos materiais orgânicos obedeceu a seguinte ordem: cama de frango $\approx$ composto de lixo $>$ composto de lodo de cervejaria + cavaco de eucalipto. Os maiores valores de biomassa microbiana foram obtidos com o composto de lodo de cervejaria + cavaco de eucalipto em relação aos demais. As quantidades empregadas dos materiais orgânicos não aumentaram a biomassa microbiana e o conteúdo de carbono orgânico total do solo. A adição de $200 \mathrm{~kg}$ $\mathrm{ha}^{-1}$ de $\mathrm{N}$ como composto de lodo de cervejaria + cavaco de eucalipto aumentou em 10,4 e $19,9 \%$ o conteúdo de água retida na capacidade de campo ( 0,1 bar) e no ponto de murcha permanente ( 15 bar), respectivamente e reduziu a densidade do solo de 1,27 para $1,12 \mathrm{~g} \mathrm{~cm}^{-3}$. Os demais resíduos orgânicos não alteraram as propriedades físicas avaliadas.

Palavras-chave: propriedade fisica; biomassa microbiana; residuo orgânico. 


\section{DECOMPOSITION OF ORGANIC MATERIALS AND EFFECTS OF THEIR APPLICATIONS ON THE MICROBIAL BIOMASS AND THE PHYSICAL PROPERTIES OF AN OXISOL}

\section{Summary}

A laboratory experiment was conducted to compare the decomposition of three organic materials (beershop sludge + eucaliptus chip compost, urban solid waste compost and chicken litter) with four rates equivalent to $0,100,150$ and $200 \mathrm{~kg} \mathrm{ha}^{-1}$ of $\mathrm{N}$. A greenhouse experiment was also carried out to evaluate the effects these treatments explained on microbial biomass and the physical properties of the soil cultivated with tomato. The rates of decomposition of the materials in the soil followed the order: chicken litter $\approx$ urban solid waste compost $>$ beershop sludge + eucaliptus chip compost. The highest contents of microbial biomass were obtained with beershop sludge + eucaliptus chip compost as compared to other materials. The rates of organic materials did not increase the microbial biomass and the organic carbon content of the soil. The application of beershop sludge + eucaliptus chip compost at the rate equivalent to $200 \mathrm{~kg}$ $\mathrm{ha}^{-1}$ of $\mathrm{N}$ increased the water contents correponding to the 0.1 and 15 bar potentials by soil, 10.4 and $19.9 \%$, respectively, and the bulk density decreased from 1,27 to $1,12 \mathrm{~g}$ $\mathrm{cm}^{-3}$. The other organic materials did not change the physical properties of soil.

Key-words: physical propertie; microbial biomass; organic waste.

\subsection{Introdução}

Dentre os beneficios gerados pela adição de materiais orgânicos no solo, o aumento da retenção de água consiste num dos principais efeitos sobre as propriedades fisicas do solo. A matéria orgânica presente nestes materiais atua diretamente na retenção de água, através de sua elevada superficie específica e capacidade de absorção ou ainda de forma indireta alterando outras características fisicas, como a densidade do solo. Diversos trabalhos comprovam o aumento da capacidade de retenção de água devido à adição de resíduos orgânicos (Wei et al., 1985; Zeng et al., 1992; Giusquiani et al., 1995). 
A persistência do efeito da aplicação de resíduos orgânicos sobre a capacidade de retenção de água do solo está diretamente relacionada a decomposição do material. Dessa forma, a avaliação da atividade microbiana é de fundamental importância para estabelecer o comportamento destes materiais no solo, que contribuirá para explicar as alterações fisicas decorrentes de sua aplicação. Segundo Metzger \& Yaron (1987) resíduos orgânicos que apresentam parte do carbono orgânico mais resistente à degradação microbiana favorecem a manutenção dos efeitos fisicos por tempo mais longo, quando são adicionados ao solo.

Considerando, portanto, o que foi exposto, os objetivos deste trabalho foram determinar a taxa de degradação de três materiais orgânicos (composto de lixo, composto de lodo de cervejaria + cavaco de eucalipto e cama de frango) e avaliar os efeitos de suas aplicações na biomassa microbiana e em propriedades fisicas do solo.

\subsection{Material e Métodos}

\subsubsection{Experimento em estufa}

O experimento foi conduzido em solo classificado como Latossolo VermelhoAmarelo álico A moderado textura média, da região de Limeira (SP), em condições de estufa. $O$ solo foi amostrado para a realização da análise química, cujos resultados obtidos foram: $\mathrm{pH}\left(\mathrm{CaCl}_{2}\right)$ de 4,9; $26 \mathrm{~g} \mathrm{dm}^{-3}$ de matéria orgânica, $274 \mathrm{mg} \mathrm{dm}^{-3}$ de $\mathrm{P}$ (resina); 6,5, 87 e 50 mmol $_{c} \mathrm{dm}^{-3}$ de $\mathrm{K}, \mathrm{Ca}$ e $\mathrm{Mg}$, respectivamente; acidez potencial 42 $\mathrm{mmol}_{\mathrm{c}} \mathrm{dm}^{-3}$; capacidade de troca de cátions $185,5 \mathrm{mmol}_{\mathrm{c}} \mathrm{dm}^{-3}$; saturação por bases $77 \%$.

$O$ delineamento experimental foi o de blocos casualizados com quatro repetições, no esquema fatorial $3 \times 4$, sendo três materiais orgânicos (composto de lixo, composto de lodo de cervejaria + cavaco de eucalipto e cama de frango) e quatro doses equivalentes a $0,100,150$ e $200 \mathrm{~kg} \mathrm{ha}^{-1}$ de $\mathrm{N}$.

Os materiais orgânicos, cujas descrições e características químicas dos mesmos constam no ítem 4.2.1 e Tabela 9, foram incorporados no solo à profundidade de 0-20 $\mathrm{cm}$, com o auxílio de uma enxada. Posteriormente realizou-se o plantio das mudas de tomate cv. Débora Plus, em parcelas de 7,0 $\mathrm{m}^{2}$, em 5 de maio de 1997. De acordo com os resultados da análise química do solo dispensou-se a calagem e a aplicação de fósforo 
no plantio. As adubações nitrogenada e potássica foram realizadas via fertirrigação, empregando-se $380 \mathrm{~kg} \mathrm{ha}^{-1}$ de $\mathrm{N}$ e $450 \mathrm{~kg} \mathrm{ha}^{-1}$ de $\mathrm{K}_{2} \mathrm{O}$, conforme recomendações de Vivancos (1993).

Após o cultivo do tomate, em 5 de novembro de 1997, ou seja, seis meses após a incorporação dos materiais orgânicos, foi feita a amostragem do solo para as avaliações dos atributos fisicos e biológicos dos solos.

Uma amostra de solo de cada parcela foi retirada com o auxílio de um amostrador de anel volumétrico para as determinações da densidade e da retenção de água na capacidade de campo $(0,1 \mathrm{bar})$ e no ponto de murcha permanente (15 bar), segundo metodologia descrita por Kiehl (1979). A partir dos dados de retenção de água em ambos os potenciais mátricos descritos, calculou-se o conteúdo de água "disponivel", definido como a diferença entre o conteúdo de água retida a 0,1 e 15 bar.

Coletaram-se 10 sub-amostras de solo de cada parcela, na profundidade de 0-10 $\mathrm{cm}$, para formar uma amostra composta, para avaliação da biomassa microbiana e do carbono orgânico total do solo. A biomassa microbiana foi determinada pelo método da fumigação-extração (Vance et al., 1987), sendo que o carbono orgânico total do solo foi determinado pelo método colorimétrico, descrito por Quaggio \& Raij (1979). O carbono presente na biomassa foi calculado através da seguinte expressão:

$\mathrm{C}=(\mathrm{F}-\mathrm{NF}) / 0,37$

$\mathrm{C}=$ carbono da biomassa microbiana em $\mu \mathrm{g} \mathrm{C} \mathrm{g}^{-1}$ de solo.

$\mathrm{F}$ e NF representam o carbono total do $\mathrm{CO}_{2}$ que foi liberado das sub-amostras fumigadas e não fumigadas, respectivamente.

0,37 = proporção do carbono da biomassa microbiana morta que foi convertida em $\mathrm{CO}_{2}$ durante o período de incubação.

\subsubsection{Experimento em laboratório}

Para a avaliação da degradação dos materiais orgânicos no solo foi instalado um experimento em laboratório, incubando amostras de $50 \mathrm{~g}$ de solo com os materiais orgânicos em frascos herméticos. $O$ delineamento experimental foi o de blocos casualizados, com três materiais orgânicos e quatro doses, conforme descrito 
anteriormente. Em cada frasco, contendo a mistura terra + material orgânico, foi colocado um béquer com $10 \mathrm{ml}$ de $\mathrm{NaOH} 1 \mathrm{~N}$ e posteriormente o frasco foi fechado. Após 7 dias, os frascos foram abertos para a adição de $1 \mathrm{ml}$ de solução de cloreto de bário $50 \%$ mais 2 gotas de fenolftaleína em cada béquer, para a determinação do carbono retido na forma de $\mathrm{CO}_{2}$ que reagiu com a $\mathrm{NaOH}$. $\mathrm{O}$ excesso de $\mathrm{NaOH}$, ou seja, a fração não consumida na reação com o $\mathrm{CO}_{2}$ foi titulada com o $\mathrm{HCl} 1 \mathrm{~N}$. Este procedimento foi repetido aos 14 e 21 dias. A quantidade de $\mathrm{CO}_{2}$, que foi liberada durante o período de incubação foi calculada através da seguinte expressão (Anderson, 1982):

$\mathrm{mg} \mathrm{CO} 2 \mathrm{~g}^{-1}$ de solo = (VB - VA).N.22/peso do solo seco $(\mathrm{g})$, onde:

$\mathrm{VB}=$ volume de solução de $\mathrm{HCl}$ gasto na titulação da prova em branco (ml);

$\mathrm{VA}=$ volume de solução de $\mathrm{HCl}$ gasto na titulação da amostra (ml);

$\mathrm{N}=$ concentração normal da solução de $\mathrm{HCl}$;

$22=$ massa de $1 / 2$ mmol $_{c}$ de $\mathrm{CO}_{2}$

\subsection{Resultados e Discussão}

\subsubsection{Degradação dos materiais orgânicos}

As taxas de degradação dos materiais orgânicos nas doses equivalentes a 100, 150 e $200 \mathrm{~kg} \mathrm{ha}^{-1}$ de $\mathrm{N}$ estão apresentadas nas Figuras 10, 11 e 12, respectivamente. A perda diária de $\mathrm{CO}_{2}$ foi máxima aos 7 dias de incubação do solo, confirmando que as maiores taxas de respiração do solo após o tratamento com materiais orgânicos ocorrem nos primeiros dias de incubação (Metzger et al., 1987). Após este período, houve decréscimos na evolução do $\mathrm{CO}_{2}$ até os 28 dias, em todas as doses aplicadas.

A velocidade de decomposição do composto de lodo de cervejaria + cavaco de eucalipto foi menor em relação aos demais nas três doses aplicadas, o que sugere que o método de compostagem empregado para a obtenção deste material e a natureza das matérias-primas que o originou foram responsáveis pela formação de um composto mais estável no solo. A cama de frango e o composto de lixo apresentaram comportamentos semelhantes nas doses inferiores a $200 \mathrm{~kg} \mathrm{ha}^{-1}$ de $\mathrm{N}$, sendo que nesta quantidade mais elevada a velocidade de degradação foi maior para a cama de frango, o que indica que a 
taxa de degradação do material orgânico também sofreu influência da quantidade aplicada. Barreto (1995) constatou diferenças na velocidade de decomposição de tipos distintos de resíduos orgânicos adicionados no solo. Segundo este autor, as menores perdas de carbono na forma de $\mathrm{CO}_{2}$ foram obtidas com o lodo petroquímico, devido a menor degradabilidade deste material em relação à torta de filtro, ao lodo de esgoto e ao composto de lixo.

As perdas de carbono na forma de $\mathrm{CO}_{2}$ aos 7 dias de incubação, aumentaram com a adição da cama de frango e do composto de lixo (Tabela 20). Entretanto, as doses aplicadas do composto de lodo de cervejaria + cavaco de eucalipto não alteraram a respiração do solo, o que está de acordo com a menor degradabilidade deste material.

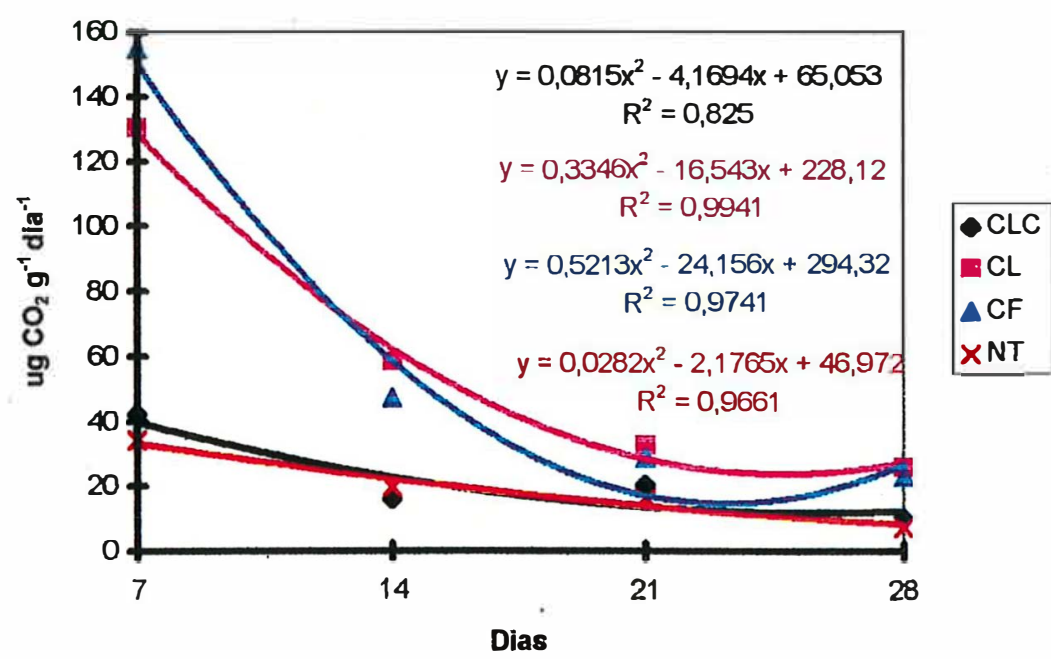

Figura 10. Perdas diárias de $\mathrm{CO}_{2}$ do solo tratado com materiais orgânicos em quantidade equivalente a $100 \mathrm{~kg} \mathrm{ha}^{-1}$ de $\mathrm{N}$ (CLC=composto de lodo de cervejaria + cavaco de eucalipto; $\mathrm{CL}=$ composto de lixo; $\mathrm{CF}=$ cama de frango; $\mathrm{NT}=$ =testemunha). 


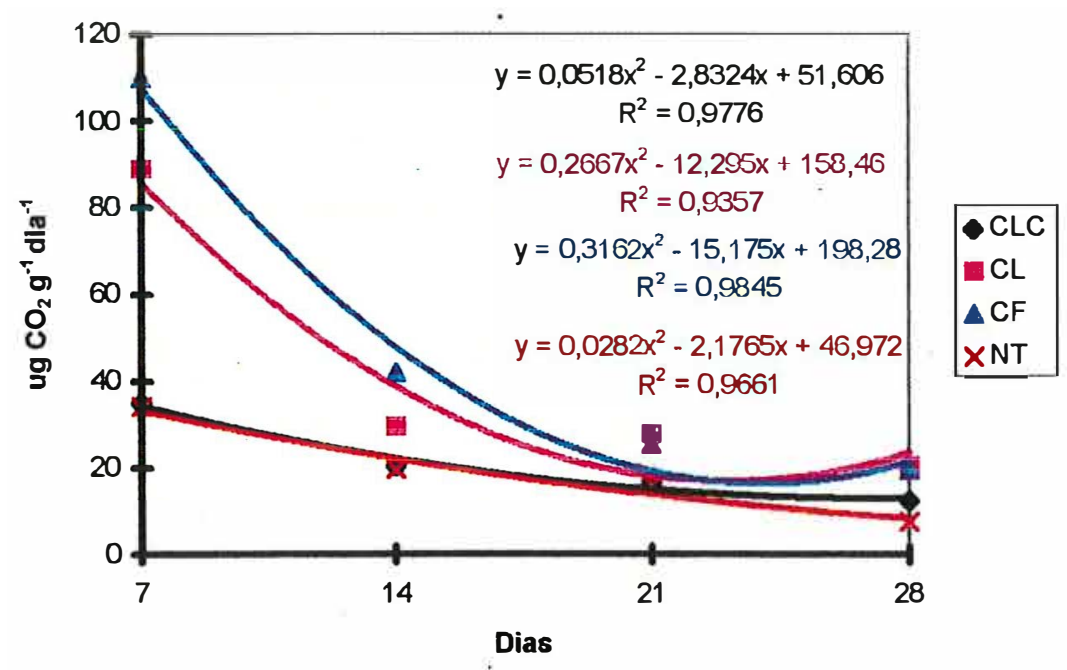

Figura 11. Perdas diárias de $\mathrm{CO}_{2}$ do solo tratado com materiais orgânicos em quantidade equivalente a $150 \mathrm{~kg} \mathrm{ha}^{-1}$ de $\mathrm{N}$ (CLC=composto de lodo de cervejaria + cavaco de eucalipto; $\mathrm{CL}=$ composto de lixo; $\mathrm{CF}=$ cama de frango; $\mathrm{NT}=$ testemunha).

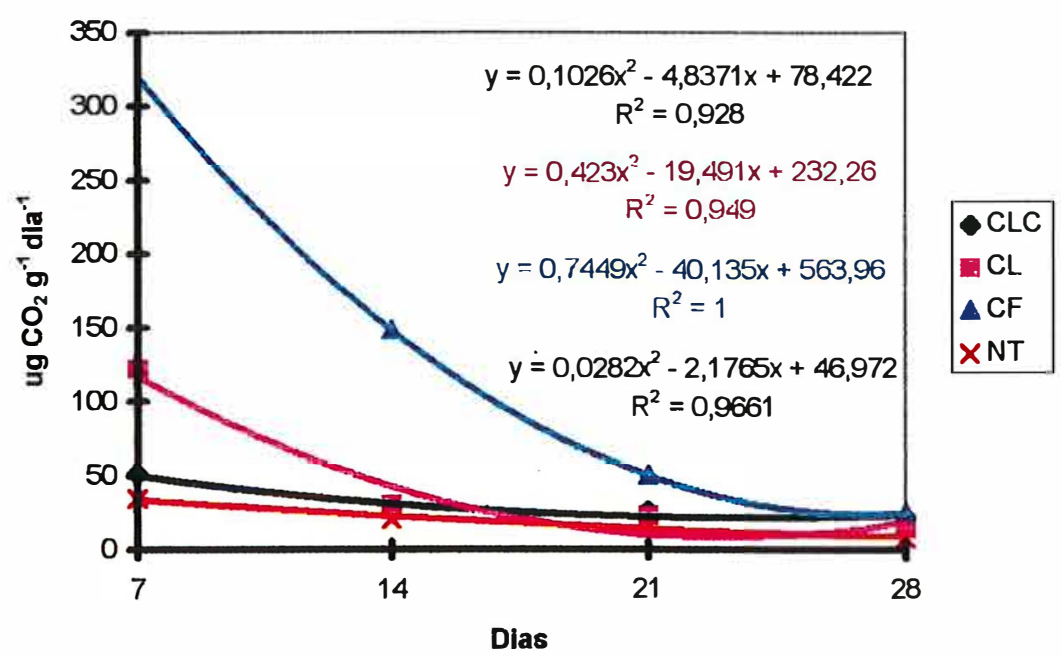

Figura 12. Perdas diárias de $\mathrm{CO}_{2}$ do solo tratado com materiais orgânicos em quantidade equivalente a $200 \mathrm{~kg} \mathrm{ha}^{-1}$ de $\mathrm{N}$ (CLC=composto de lodo de cervejaria + cavaco de eucalipto; $\mathrm{CL}=$ composto de lixo; $\mathrm{CF}=$ cama de frango; $\mathrm{NT}=$ testemunha). 
Tabela 20. Perdas de $\mathrm{C}$ na forma de $\mathrm{CO}_{2}$ aos 7 dias de incubação do solo tratado com resíduos orgânicos.

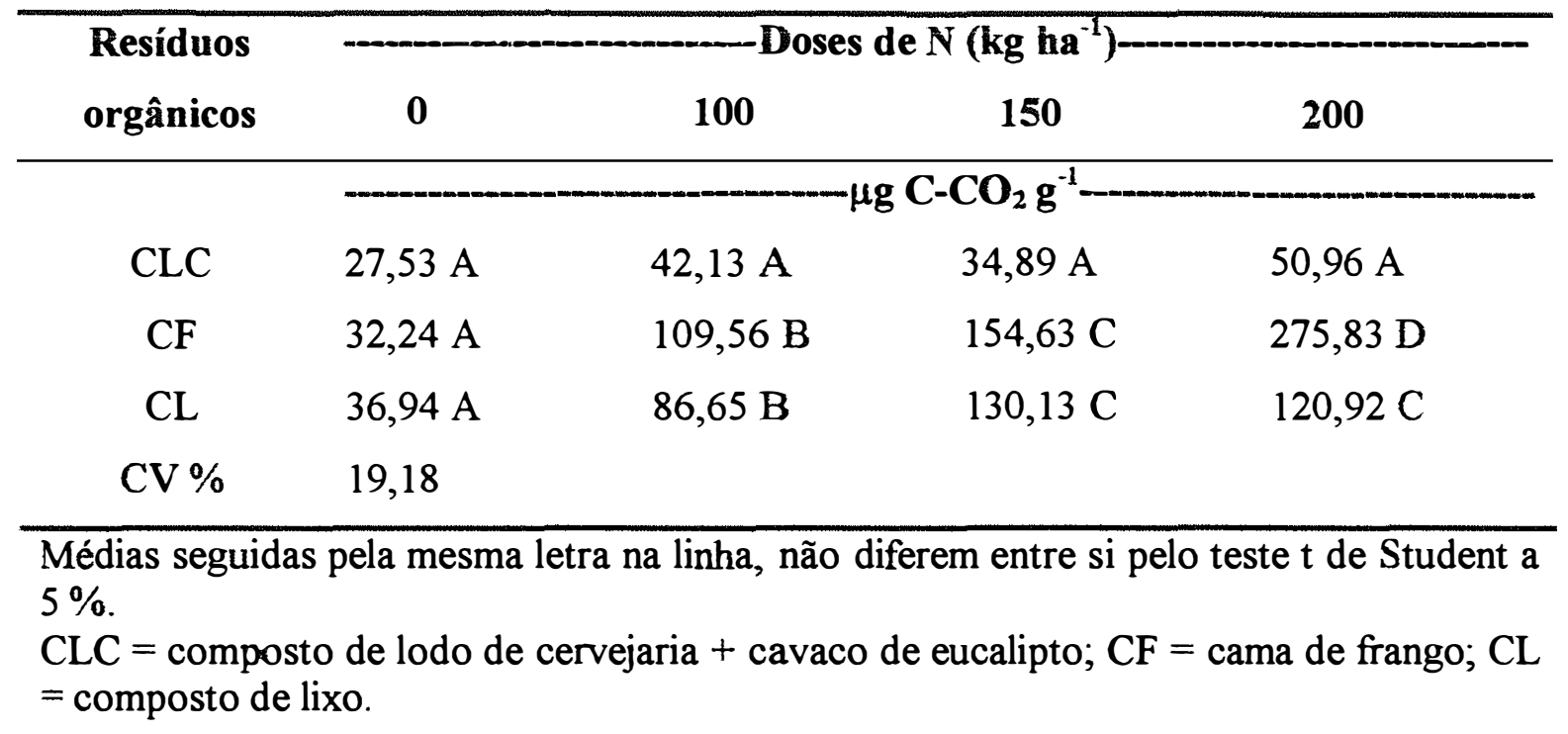

\subsubsection{Biomassa microbiana do solo}

A biomassa microbiana sofreu influência dos tipos de materiais orgânicos em todas as doses empregadas (Tabela 21), onde o composto de lodo de cervejaria + cavaco de eucalipto promoveu os maiores valores de biomassa microbiana em relação aos demais. Por sua vez, era de se esperar que o material menos degradável proporcionasse o menor conteúdo de biomassa, em virtude da menor disponibilidade de carbono orgânico para a sua formação. Witter et al. (1993) observaram menor conteúdo de biomassa microbiana no solo tratado com turfa em relação ao adubo verde e ao adubo agrícola (esterco de curral com restos de feno), devido à menor degradabilidade do primeiro material, discordando, dessa forma, dos resultados obtidos neste experimento. Entretanto, para o conteúdo de carbono orgânico total do solo não se observou o mesmo comportamento obtido para a biomassa microbiana. Este fato é possivel, uma vez que as alterações no conteúdo de carbono são mais lentas e menores do que as mudanças na biomassa microbiana do solo (Anderson \& Domsch, 1989).

Tanto a biomassa microbiana como o conteúdo de carbono orgânico total do solo não sofreram influência das doses adicionadas dos materiais orgânicos, possivelmente por estas serem pequenas e pelo fato do solo ter apresentado um teor inicial relativamente 
alto de matéria orgânica (26 $\left.\mathrm{g} \mathrm{dm}^{-3}\right)$. Mugwira (1979) também obteve resultados semelhantes com a aplicação de esterco de gado, em quantidades inferiores a $45 \mathrm{Mg} \mathrm{ha}^{-1}$.

A biomassa microbiana representou uma pequena fração, em torno de 0,92 a 1,34 \% do carbono orgânico total do solo tratado com os materiais orgânicos, valores estes inferiores aos encontrados por Goyal et al. (1992), cujo intervalo foi de 1,8 a 2,2 \%, depois de doze meses de incubação do solo com 15 a $90 \mathrm{Mg} \mathrm{ha}^{-1}$ de adubo orgânico (esterco de curral misturado com restos de feno). Por outro lado, valores de 0,2 a $5 \%$ foram encontrados na literatura (Houot \& Chaussod, 1995).

Tabela 21. Efeitos de tipos e doses de resíduos orgânicos sobre a biomassa microbiana e carbono orgânico total do solo.

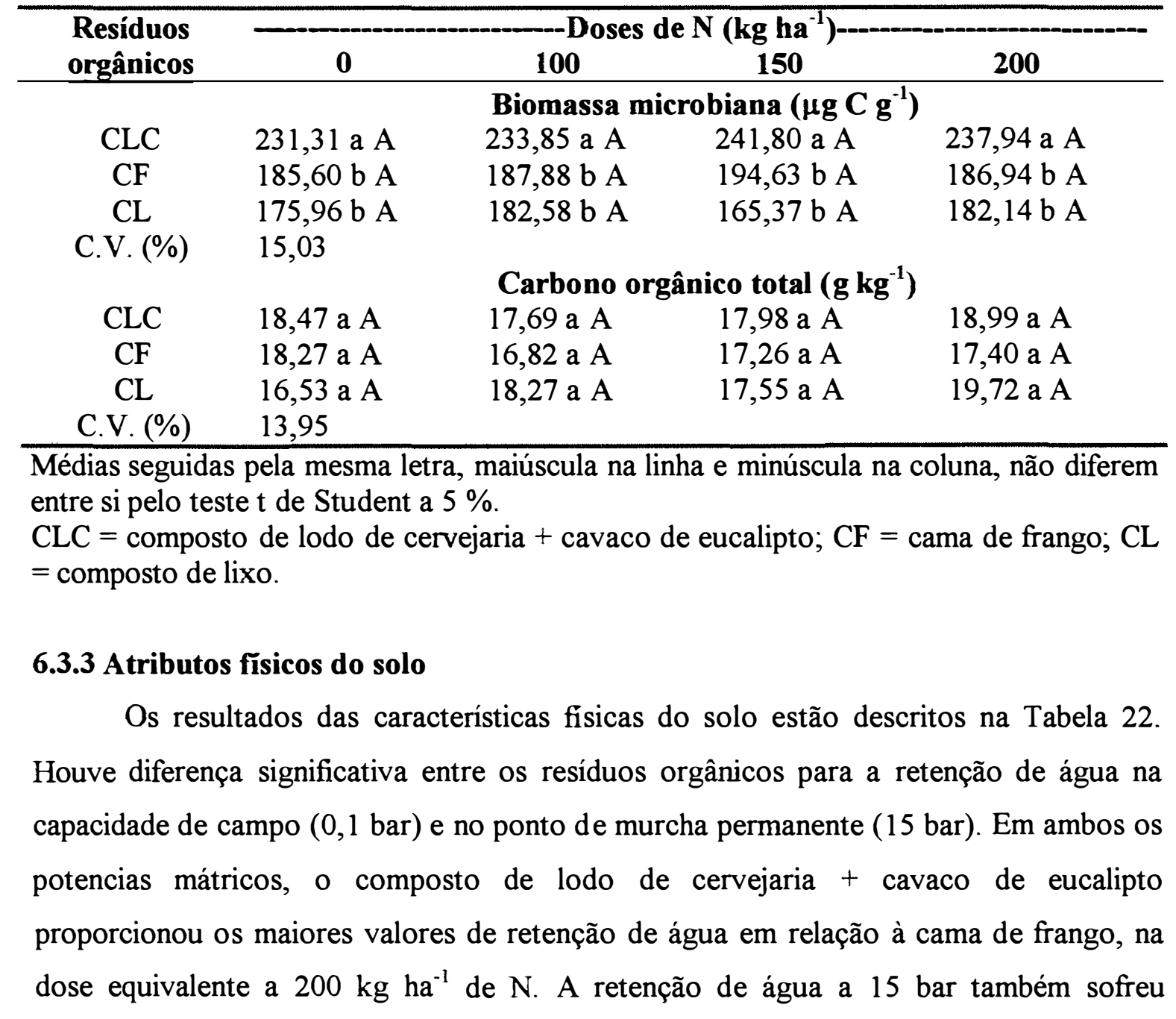


influência do tipo de material orgânico na dose equivalente a $150 \mathrm{~kg} \mathrm{ha}^{-1}$ de $\mathrm{N}$, sendo que o composto de lodo de cervejaria + cavaco de eucalipto foi responsável pelo maior conteúdo de água em relação ao composto de lixo. Estes resultados podem ser explicados principalmente pela menor degradabilidade do composto de lodo de cervejaria + cavaco de eucalipto, que levou à maior persistência do seu carbono orgânico no solo. Barreto (1995) observou, em Areia Quartzosa, maior retenção de água próximo a capacidade de campo com a adição de materiais menos degradáveis, neste caso do composto de lixo e do lodo petroquímico em relação à torta de filtro, de fácil decomposição.

A adição do composto de lodo de cervejaria + cavaco de eucalipto reduziu a densidade do solo, sendo que para a dose mais elevada o decréscimo foi de 11,8\%. Concomitante com este resultado, foram obtidos aumentos significativos nos conteúdos de água na capacidade de campo e no ponto de murcha permanente do solo tratado com $200 \mathrm{~kg} \mathrm{ha}^{-1}$ de $\mathrm{N}$ na forma deste composto. Zeng et al. (1992) também constataram redução na densidade do solo e incremento na retenção de água com as adições de $52 \mathrm{e}$ $105 \mathrm{Mg} \mathrm{ha}^{-1}$ de esterco de suíno. Por sua vez, o conteúdo de água "disponível" não foi alterado com a adição do composto de lodo de cervejaria + cavaco de eucalipto, o que pode ser explicado pelo decréscimo na densidade do solo, que possivelmente, segundo Khaleel et al. (1981) contrabalança qualquer aumento no conteúdo de água "disponível" em unidade de peso. Os demais materiais orgânicos não alteraram as características fisicas avaliadas, com exceção da dose de cama de frango equivalente a $150 \mathrm{~kg} \mathrm{ha}^{-1} \mathrm{de} \mathrm{N}$, que reduziu o conteúdo de água "disponível" em relação ao controle, sem contudo, alterar a retenção de água a 0,1 e 15 bar.

Dessa forma, pode-se inferir que materiais de degradação mais lenta, como o composto de lodo de cervejaria + cavaco de eucalipto, podem melhorar as propriedades fisicas do solo, após seis meses de sua aplicação, mesmo quando são empregadas baixas doses, como foi o caso da adição de $14 \mathrm{Mg} \mathrm{ha}^{-1}$ do composto de lodo de cervejaria + cavaco de eucalipto equivalente a $200 \mathrm{~kg} \mathrm{ha}^{-1}$ de $\mathrm{N}$. 
Tabela 22. Efeitos de tipos e doses de resíduos orgânicos sobre a densidade do solo, retenção de água na capacidade de campo ( 0,1 bar) e no ponto de murcha permanente (15 bar) e conteúdo de água "disponível" (0,1 - 15 bar).

\begin{tabular}{|c|c|c|c|c|}
\hline \multirow[t]{2}{*}{ Resíduos orgânicos } & \multicolumn{4}{|c|}{ Doses de $\mathrm{N}\left(\mathrm{kg} \mathrm{ha}^{-1}\right)$} \\
\hline & $\mathbf{0}$ & 100 & 150 & 200 \\
\hline \multicolumn{5}{|l|}{ Densidade $\left(\mathrm{g} \mathrm{cm}^{-3}\right)$} \\
\hline CLC & 1,27 a $\mathrm{A}$ & 1,11 a B & 1,09 a B & 1,12 a $\mathrm{B}$ \\
\hline $\mathrm{CF}$ & 1,18 a $\mathrm{A}$ & 1,15 a $\mathrm{A}$ & 1,19 a $\mathrm{A}$ & 1,13 a $\mathrm{A}$ \\
\hline CL & 1,07 a $\mathrm{A}$ & 1,10 a $\mathrm{A}$ & 1,16 a $\mathrm{A}$ & 1,12 a $\mathrm{A}$ \\
\hline C.V. (\%) & 6,03 & & & \\
\hline \multicolumn{5}{|c|}{ Retenção de água 0,1 bar $\left(\mathrm{g} \mathrm{g}^{-1}\right)$} \\
\hline CLC & 0,2207 a B & 0,2280 a $A B$ & 0,2437 a $A B$ & 0,2667 a $\mathrm{A}$ \\
\hline $\mathrm{CF}$ & 0,2477 a $\mathrm{A}$ & 0,2312 a $\mathrm{A}$ & 0,2097 a $\mathrm{A}$ & $0,2106 \mathrm{~b} \mathrm{~A}$ \\
\hline CL & 0,2134 a $\mathrm{A}$ & 0,2138 a $\mathrm{A}$ & 0,2128 a $\mathrm{A}$ & $0,2389 \mathrm{ab} \mathrm{A}$ \\
\hline C.V. (\%) & 8,97 & & & \\
\hline \multicolumn{5}{|c|}{ Retenção de água a 15 bar $\left(\mathrm{g} \mathrm{g}^{-1}\right)$} \\
\hline CLC & 0,1483 a B & 0,1626 a AB & 0,1778 a $\mathrm{AB}$ & 0,1920 a $\mathrm{A}$ \\
\hline $\mathrm{CF}$ & 0,1501 a $\mathrm{A}$ & 0,1611 a $\mathrm{A}$ & $0,1523 \mathrm{ab} \mathrm{A}$ & 0,1402 b A \\
\hline CL & 0,1574 a $\mathrm{A}$ & 0,1583 a $\mathrm{A}$ & 0,1430 b A & $0,1689 \mathrm{ab} \mathrm{A}$ \\
\hline C.V. (\%) & 9,87 & & & \\
\hline \multicolumn{5}{|c|}{ Água "disponivel" ( $\left.\mathrm{g} \mathrm{g}^{-1}\right)$} \\
\hline CLC & $0,0724 \mathrm{ab} \mathbf{A}$ & 0,0654 a A & 0,0659 a $\mathrm{A}$ & 0,0747 a A \\
\hline $\mathrm{CF}$ & 0,0976 a $\mathrm{A}$ & 0,0701 a $\mathrm{AB}$ & 0,0574 a B & 0,0704 a $\mathrm{AB}$ \\
\hline $\mathrm{CL}$ & $0,0561 \mathrm{~b} \mathrm{~A}$ & 0,0555 a $\mathrm{A}$ & 0,0699 a $\mathrm{A}$ & 0,0701 a $\mathrm{A}$ \\
\hline C.V. (\%) & 25,68 & & & \\
\hline
\end{tabular}

Médias seguidas pela mesma letra, maiúscula na linha e minúscula na coluna, não diferem entre si pelo teste t de Student a $5 \%$.

CLC = composto de lodo de cervejaria + cavaco de eucalipto; $\mathrm{CF}=$ cama de frango; $\mathrm{CL}=$ composto de lixo.

\subsection{Conclusões}

O composto de lodo de cervejaria + cavaco de eucalipto foi o mais estável no solo, pois apresentou as menores taxas de degradação.

As doses empregadas dos materiais orgânicos não alteraram a biomassa microbiana e o conteúdo de carbono orgânico total do solo. 
A adição de $200 \mathrm{~kg} \mathrm{ha}^{-1}$ (14 $\left.\mathrm{Mg} \mathrm{ha}^{-1}\right)$ como composto de lodo de cervejaria + cavaco de eucalipto aumentou a retenção de água na capacidade de campo e no ponto de murcha permanente e reduziu a densidade do solo. 


\section{CONCLUSÕES}

Decréscimos de 4 a $8 \%$ observados na altura das plantas, até 72 dias após o transplante, devido à adição de materiais orgânicos não afetaram a produção total de tomate.

A adição de 5,9 $\mathrm{Mg} \mathrm{ha}^{-1}$ de cama de frango equivalente a $200 \mathrm{~kg} \mathrm{ha}^{-1}$ de $\mathrm{N}$, material com maior teor de potássio, aumentou em $24,6 \%$ a produção de frutos comercializáveis, no Podzólico Vermelho-Amarelo textura arenosa/média.

Em ambos os solos, Ultissol e Oxisol, adubados com $380 \mathrm{~kg} \mathrm{ha}^{-1}$ de $\mathrm{N}$ na forma de fertilizante mineral, as doses empregadas dos materiais orgânicos não aumentaram a produção total de tomate.

O composto de lodo de cervejaria + cavaco de eucalipto foi o mais estável tanto no solo de textura arenosa como no de textura arenosa/média.

Materiais de degradação mais lenta (composto de lodo de cervejaria + cavaco de eucalipto) melhoram as propriedades fisicas do solo, através do aumento na capacidade de retenção de água e redução na densidade do solo, mesmo quando são aplicados em pequenas quantidades.

O composto de lodo de cervejaria + cavaco de eucalipto foi o único material responsável pelo aumento do $\mathrm{pH}$ e da capacidade de troca de cátions ao $\mathrm{pH} 7,0$ nos dois solos.

A biomassa microbiana não foi alterada com a adição de materiais orgânicos no solo de textura média (Oxissol com $26 \mathrm{~g} \mathrm{dm}^{-3}$ de matéria orgânica), enquanto que no solo de textura arenosa/média (Ultissol com $17 \mathrm{~g} \mathrm{dm}^{-3}$ de matéria orgânica) ocorreram aumentos significativos. 


\section{REFERÊNCIAS BIBLIOGRÁFICAS}

AGUILAR-TORRES, F.J.; GONZALES-FERNANDEZ, P.; PASTOR-MUNOZ, C.M. Improvement of soil fertility in olive orchards by periodically applying composted solid urban waste comparison with the system of non-tillage with bare soil. Olivae, n.64, p.40-45, 1996. /Resumo em CAB Abstracts on CD-ROM, 1996-98/.

ALBREGTS, E.E.; HOWARD, C.M. Effects of poultry manure on strawberry fruiting response, soil nutrient changes and leaching. Journal of the American Society for Horticultural Science, v. 106, p.295-298, 1981.

ALEXANDER, M. Introduction to soil microbiology. New York: John Willey, 1977. $467 p$.

ANCHENG, L.; XI, S. Effect of organic manure on the biological activities associated with insoluble phosphorus release in a Blue Purple Paddy soil. Communications in Soil Science and Plant Analysis, v.25, p.2513-2522, 1994.

ANDERSON, F.N.; PETERSON, G.A. Effects of continuous corn (Zea mays L.), manuring and nitrogen fertilization on yield and protein content of the grain and on the soil nitrogen content. Agronomy Journal, v.65, p.697-700, 1973.

ANDERSON, J.P.E. Soil respiration. In: PAGE, A.L.; MILLER, R.H.; KEENEY, D.R. (Ed.) Methods of soil analysis: part two: chemical and microbiological properties. 2. ed. Madison: ASA, SSSA, 1982. p. 831-871.

ANDERSON, T.H.; DOMSCH, K.H. Ratios of microbial biomass carbon to total organic carbon in arable soils. Soil Biology and Biochemistry, v.21, p.471-479, 1989. 
ASIEGBU, J.E.; OIKEH, S. Evaluation of chemical composition of manures from different organic wastes and their potential for supply of nutrients to tomato in a tropical Ultisol. Biological Agriculture Horticulture, v.12, p.47-60, 1995.

BALDOCK, J.O.; MUSGRAVE, R.B. Manure and mineral fertilizer effects in continuous and rotational crops sequences in Central New York. Agronomy Journal, v.72, p.511-518, 1980.

BARRETO, M.C. de V. Degradação da fração orgânica de diferentes resíduos e efeitos em algumas propriedades químicas e físicas de dois solos. Piracicaba, 1995. 106p. Tese (Doutorado) - Escola Superior de Agricultura "Luiz de Queiroz", Universidade de São Paulo.

BERNAL, M.P.; ROIG, A. The influence of pig slurry fertilization on the mineral content of horticultural crops grown in calcareous soils. Journal of the Science of Food and Agriculture, v.62, p.129-135, 1993.

BERTON, R.S.; CAMARGO, O.A.; VALADARES, J.M.A.S. Absorção de nutrientes pelo milho em resposta à adição de lodo de esgoto a cinco solos paulistas. Revista Brasileira de Ciência do Solo, v. 13, p. 187-192, 1989.

BRACCINI, A.L.; BRITO, C.H.; PÔNZIO, J.B.; MORETTI, C.L.; LOURES, E.G. Efeito da aplicação de resíduos orgânicos com diferentes relações $\mathrm{C} / \mathrm{N}$ sobre algumas características químicas de um Latossolo Vermelho-Escuro. Revista Ceres, v.42, n.244, p.671-684, 1995.

BRADY, N. C. Natureza e propriedade dos solos. Rio de Janeiro: Freitas Bastos, 1983. $647 p$. 
CAMPBELL, C.A. Soil organic carbon, nitrogen and fertility. In: SCHNITZER, M.; KHAN, S.U. (Ed.) Soil organic matter . New York: Elsevier Scientific, 1978. p 173271.

CAMPBELL, C.A.; SCHNITZER, M.; STEWART, J.W.B.; BIEDERBECK, V.O.; SELLES, F. Effect of manure and $P$ fertilizer on properties of a black chernozem in southern saskatchewan. Canadian Journal of Soil Science, v.66, p.601-613, 1986.

CARDOSO, E.J.B.N. Degradação de resíduos orgânicos pela microbiota do solo. In: REUNIÃO BRASILEIRA DE FERTILIDADE DO SOLO E NUTRIÇÃO DE PLANTAS, 20., Piracicaba,1992. Anais. Piracicaba: ESALQ, 1992. p.179-193.

CASTELlANE, P.D. Podridão apical em frutos de tomateiro. Jaboticabal: FUNEP, 1988. 39p.

CERRI, C.C.; ANDREUX, F.; EDUARDO, B.P.; CHONE, T.; PICCOLO, M.C. Incubador para estudos sobre decomposição de material orgânico no solo. Revista Brasileira de Ciência do Solo, v. 18, p.1-5, 1994.

CHANG, A. C.; PAGE, A. L.; VARNEKE, J.E. Soil conditioning effects of municipal sludge compost. Journal of Environmental Engineering, v.109, p.574-583, 1983.

CHANG, C.; SOMMERFELDT, T.G.; ENTZ, T. Soil chemistry after eleven annual applications of cattle feedlot manure. Journal of Environmental Quality, v.20, p.475-480, 1991.

CHU, L.M.; WONG, M.H. Heavy metal contents of vegetable crops treated with refuse compost and sewage sludge. Plant and Soil, v.103, p.191-197, 1987. 
ELLIOTT, H.A.; SINGER, L.M. Effect of water treatment sludge on growth and elemental composition of tomato (Lycopersicon esculentum) shoots. Communications in Soil Science and Plant Analysis, v. 19, p.345-354, 1988.

EPSTEIN, E.; TAYLOR, J.M.; CHANEY, R.L. Effects of sewage sludge and sludge compost applied to soil on some soil physical and chemical properties. Journal of Environmental Quality, v.5, p.422-426, 1976.

FLIEßACH, A.; MARTENS, R.; REBER, H.H. Soil microbial biomass and microbial activity in soils treated with heavy metal contaminated sewage sludge. Soil Biology and Biochemistry, v.26, p.1201-1205, 1994.

FRASER, D.G.; DORAN, J.W.; SAHS, W.W.; LESOING, G.W. Soil microbial populations and activities under conventional and organic management. Journal of Environmental Quality, v.17, p.585-590, 1988.

FREITAS, M.B. de; FARIA, C.M.B. de. Influência de práticas agrícolas na fertilidade do solo e no rendimento do tomateiro no Agreste Pernambucano. Revista Brasileira de Ciência do Solo, v.5, p.54-57, 1981.

FRITZ, D.; VENTER, F. Heavy metals in some vegetable crops as influenced by municipal waste composts. Acta Horticulturae, n.222, p.51-62, 1988.

GARGANTINI, H.; BLANCO, H.G. Marcha de absorção de nutrientes pelo tomateiro. Bragantia, v.22, p.693-714, 1963.

GERBER, J.M.; SWIADER, J.M.; PECK, T.R. Sewage sludge on vegetables -A mixed Blessing. nlinois Research, v.23, p.12-13, 1981. 
GHOSHAL, N.; SINGH, K.P. Effects of farmyard manure and inorganic fertilizer on the dynamics of soil microbial biomass in a tropical dryland agroecosystem. Biology and Fertility of Soils, v.19, p.231-238, 1995.

GILL, H.S.; MEELU, O.P. Studies on the substitution of inorganic fertilizers with organic manure and their effect on soil fertility in rice-wheat rotation. Fertilizer Research, v.3, p.303-314, 1982.

GIUSQUIANI, P.L.; MARUCCHINI, C.; BUSINELLI, M. Chemical properties of soils amended with compost of urban waste. Plant and Soil, v.109, p.73-78, 1988.

GIUSQUIANI, P.L.; PAGLIAI, M.; GIGLIOTTI, G.; BUSINELLI, D.; BENETTI, A. Urban waste compost: Effects on physical, chemical and biochemical soil properties. Journal of Environmental Quality, v.24, p.175-182, 1995.

GOYAL, S.; MISHIRA, M.M.; HOODA, I.S.; SINGH, R. Organic matter microbial biomass relationships in field experiments under tropical conditions: effects of inorganic fertilization and organic amendments. Soil Biology and Biochemistry, v.24, p. 1081-1084, 1992.

GOYAL, S.; MISHRA, M.M.; DHANKAR S.S.; KAPOOR, K.K.; BATRA, R. Microbial biomass turnover and enzyme activities following the application of farmyard manure to field soils with and without previous long-term applications. Biology and Fertility of Soils, v.15, p.60-64, 1993.

GUPTA, S.C.; LARSON, W.E. Hydraulic and thermal properties of a sandy soil as influenced by incorporation of sewage sludge. Soil Science Society of America Journal, v.41, p.601-605, 1977. 
GUPTA, S.K. Effect of organic manures on rice yield and moisture retention in Alfisoil soil. Journal of Hill Research, v.8, n.2, p.169-173, 1995. / Resumo em CAB Abstracts on CD-ROM, 1996-98/

HALL, J. E.; COKER, E.G. Some effects of sewage sludge on soil physical conditions and plant growth. In: CATROUX, G.; L'HELMITE, P.; SUESS, E. (Ed.) The influence of sewage sludge application on physical and biological properties of soil. Dordrecht: D. Reidel, 1983. p.43-61.

HAMPTON, M.O.; SCHAFFER, B.; BRYAN, H.H. Nutrient concentrations growth and yield of tomato and squash in municipal solid-waste amended soil. HortScience, v.29, p.785-788, 1994.

HARDING, S.A.; CLAPP, C.E.; LARSON, W.E. Nitrogen availability and uptake from field soils five years addition of sewage sludge. Journal of Environmental Quality, v.14, p.95-100, 1985.

HASHIM, I.B.; SPLITTSTOESSER, W.E.; VANDEMARK, J.S. Response of vegetable crops to three kinds of fertilizer. Ilinois Research, v. 20, p. 12-13, 1978.

HOLANDA, J.J. de; MIELNICZU, J.; STAMMEL, J.G. Utilização de esterco e adubo mineral em quatro sequências de culturas em solo de encosta basaltica do Rio Grande do Sul. Revista Brasileira de Ciência do Solo, v.6, p.47-51, 1982.

HOUOT, S.; CHAUSSOD, R. Impact of agricultural practices on the size and activity of the microbial biomass in a long-term field experiment. Biological and Fertility of Soils, v.19, p.309-316, 1995.

HOYT, P.B.; TURNER, R.C. Effects of organic materials added to very acid soil on $\mathrm{pH}$, aluminum, exchangeable $\mathrm{NH}_{4}$ and crop yields. Soil Science, v. 119, p.227-237, 1975. 
HUE, N.V. Correcting soil acidity of a highly weathered Ultisol with chicken manure and sewage sludge. Communications in Soil Science and Plant Analysis, v.23, p.241264, 1992.

JACOBOWITZ, L.A.; STEENHUIS, T.S. Compost impact on soil moisture and temperature. Biocycle, v.25, p.56-60, 1984.

JENKINSON, D.S.; LADD, J.N. Microbial biomass in soil: measurement and turnover. In: PAUL, E.A.; LADD, J.N. (Ed.) Soil biochemistry, New York: Marcel Dekker, 1981. v.5, p.415-471.

JOHNSTON, A.E. Fertility and soil organic matter. In: WLLSON, W.S. (Ed.) Advances in soil organic matter research: the impact of agriculture and the environment. Cambridge: Royal Society of Chemistry, 1991. p.297-314.

KANAZAWA, S.; ASAKAWA, S.; TAKAI, Y. Effect of fertilizer and manure application on microbial numbers, biomass and enzyme activities in volcanic ash soils. Soil Science and Plant Nutrition, v.34, p.429-439, 1988.

KHALEEL, R.; REDDY, K.R.; OVERCASH, M.R. Changes in soil physical properties due to organic waste applications: a review. Journal of Environmental Quality, v.10, p.133-141, 1981.

KIEHL, E.J. Manual de edafologia: relações solo-planta. São Paulo: Ceres, 1979. 94p.

KIEHL, E.J. Fertilizantes orgânicos. São Paulo: Ceres, 1985. 492p.

KING, L.D.; MORRIS, H.D. Land disposal of liquid sewage sludge. II. The effect on soil $\mathrm{pH}$, manganese, zinc and growth and chemical composition of ryce (Secale cereale L.). Journal of Environmental Quality, v. 1, p.425-429, 1972. 
LUIZÃO, F.J. Influência da calagem e adubação orgânica na mesofauna e nas propriedades físicas de um Latossolo Amarelo textura argilosa. Revista Brasileira de Ciência do Solo, v.9, p.81-84, 1985.

LUND, Z.F.; DOSS, B.D. Residual effect of dairy cattle manure on plant growth and soil properties. Agronomy Journal, v.72, p.123-130, 1980.

MAHER, M.J. Growth and nutrient content of glasshouse tomato crop grown in peat. Scientia Horticulturae, v.4, p.23-26, 1976.

MALAVOlTA, E.; VITTI, G.C.; OLIVEIRA, S.A. de. Avaliação do estado nutricional das plantas: princípios e aplicações. Piracicaba: POTAFOS, 1997. 319p.

MARTIN, J. P.; FOCHT, D. D. Biological properties of soils. In: STELLY, M. (Ed.) Soils for management of organic wastes and waste waters. Madison: ASA; CSSA; SSA, 1977. cap.6, p.115-169.

MASKINA, M.S.; SINGH, Y.; SINGH, B. Response of Wetland Rice to fertilizer N in a soil amended with cattle, poultry and pig manures. Biological Wastes, v.26, p.1-8, 1988.

MATTIAZZO, M.E.; GLÓRIA, N.A. da. Avaliação em condições de laboratório da torta de filtro como fertilizante fosfatado. In: CONGRESSO NACIONAL DA SOCIEDADE DE TÉCNICOS AÇUCAREIROS E ALCOOLEIROS DO BRASIL, 1., Olinda, 1987. Anais. Piracicaba: STAB, 1987. p.189-193.

MAZUR, N.; SANTOS, G. A.; VELLOSO, A. C. X. Efeito do composto de resíduo urbano na disponibilidade de fósforo em solo ácido. Revista Brasileira de Ciência do Solo, v.7, p.153-156, 1988. 
MAZUR, N.; VELLOSO, A.C.X.; SANTOS, G. A. Efeito do composto de resíduo urbano no pH e alumínio trocável em solo ácido. Revista Brasileira de Ciência do Solo, v.7, p. 157-159, 1983.

MELO, W.J.; MARQUES, M.O.; SANTIAGO, G.; CHELLI, R.A. Efeito de doses crescentes de lodo de esgoto sobre frações da matéria orgânica e CTC de um Latossolo cultivado com cana-de-açúcar. Revista Brasileira de Ciência do Solo, v. 18, p.449-455, 1994.

METZGER, L.; YARON, B. Influence of sludge organic matter on soil physical properties. Advances in Soil Science, v.7, p. 141-163, 1987.

MIYAZAWA, M.; PAVAN, M.A.; CALEGARI, A. Efeito de material vegetal na acidez do solo. Revista Brasileira de Ciência do Solo, v.17, p. 411-416, 1993.

MUGWIRA, L.M. Residual effects of dairy cattle manure on millet and Rye Forage and soil properties. Journal of Environmental Quality, v.8, p. 251-255, 1979.

MURILLO, J.M.; HERNANDEZ, J.M.; BARROSO, M.; LOPEZ, R. Produccion frente a contaminacion en la utilizacion agricola de composts urbanos. Anales de Edafologia y Agrobiologia, v.48, p.143-160, 1989.

NAGANAWA, T.; KYUMA, K. H.; YAMAMOTO, Y.; YOKOI, H.; TATSUYAMA, K. Measurement of soil respiration in the field: influence of temperature, moisture level and application of sewage sludge compost and agro-chemicals. Soil Science and Plant Nutrition, v.35, p.509-516, 1989. 
NDAYEGAMIYE, A.; CÔTÉ, D. Effect of long-term pig slurry and solid cattle manure application on soil chemical and biological properties. Canadian Journal of Soil Science, v.69, p.39-47, 1989.

NORDGREN, A. A method for determining microbially available $\mathrm{N}$ and $\mathrm{P}$ in an organic soil. Biology and Fertility of Soils, v.13, p.195-199, 1992.

OKANO, S.; KONDO, H.; SAWADA, Y. Soil microbial biomass in a sasa-type (Pleioblastus) grassland. Japanese Journal of Grassland Science, v.34, p. 280-285, 1989.

OLIVEIRA FILHO, J.M. de; CARVALHO, M. A. de; GUEDES, G. A. A. Matéria orgânica do solo. Informe Agropecuário, v. 13, p.22-36, 1987.

PAGLIAI, M.; GUIDI, G.; LAMARCA, M.; GIACHETTI, M.; LUCAMANIE, G. Effects of sewage sludges and composts on soil porosity and aggregation. Journal of Environmental Quality, v.10, p. 556-561, 1981.

PERA, A.; VALLINI, G.; SIRENO, I.; BIANCHIN, M.L.; BERTOLDI, M. de. Effect of organic matter on rhizosphere microorganisms and root development of sorghum plants in two different soils. Plant and Soil, v.74, p.3-18, 1983.

POWLSON, D.S.; JENKINSON, D.A. Comparison of the organic matter, biomass, adenosine triphosphate and mineralizable nitrogen contents of ploughed and directdrilled soils. Journal of Agricultural Science, v.97, p.713-721, 1981.

QUAGGIO, J.A.; RAIJ, B. van. Comparação de métodos rápidos para a determinação da matéria orgânica em solos. Revista Brasileira de Ciência do Solo, v.3, p.184-187, 1979. 
RAIJ, B. van. A capacidade de troca de cátions das frações orgânica e mineral em solos. Bragantia, v.28, p.85-112, 1969.

RODELLA, A.A. Métodos de avaliação de materiais orgânicos e efeitos de sua incorporação ao solo sobre a mobilização de macronutrientes. Piracicaba, 1995. 148p. Tese (Livre-Docência) - Escola Superior de Agricultura "Luiz de Queiroz", Universidade de São Paulo.

SALEK, R.C.; ALMEIDA, D.L.; OLIVEIRA, M.F.; PENTEADO, A.F. Efeito do esterco de galinha e sua associação com fertilizantes sobre a produção do tomateiro no município de Teresópolis-RJ. Rio de Janeiro: PESAGRO, 1981. 3p.(PESAGRO. Comunicado Técnico, 70).

SCHNÜRER, J.; CLARHOLM, M.; ROSSWALL, T. Microbial biomass and activity in an agricultural soil with different organic matter contents. Soil Biology and Biochemistry, v.17, p.611-618, 1985.

SILVA Jr.; A.A.; VIZZOTTO, V. J. Efeito da adubação mineral e orgânica sobre a produtividade e tamanho de fruto de tomate. Horticultura Brasileira, v.8, p.17-19, 1990.

SOMMERFELDT, T. G.; CHANG, C.; ENTZ, T. Long-term annual manure applications increase soil organic matter and nitrogen, and decrease carbon to nitrogen ratio. Soil Science Society of America Journal, v.52, p.1668-1672, 1988.

SPOSITO, G. Chemistry of soils. New York: Oxford University Press, 1989. 277p.

STEWART, B.A., WEBBER, R.L. Consideration of soils for accepting wastes. In: Land application of waste materials. Ankeney: Soil Science Society of America, 1976. p.821. 
TEDESCO, M.J.; VOLKWEISS, S.J.; BOHEN, H. Análise de solos, plantas e outros materiais. Porto Alegre: Universidade Federal do Rio Grande do Sul, 1985. 188p. (UFRGS. Boletim Técnico, 15)

TESTER, C.F. Organic amendment effects on physical and chemical properties of a sandy soil. Soil Science Society of America Journal, v.54, p. 827-831, 1990.

TIWARI, S.C. Effects of organic manure and NPK fertilization on earthworm activity in an oxisol. Biology and Fertility of Soils, v.16, p.293-295, 1993.

TRANI, P.E.; RAIJ, B.van. Hortaliças. In: RAIJ, B. van; CANTARELLA, H.; QUAGGIO, J.A.; FURLANI, A.M.C. (Ed.) Recomendações de adubação e calagem para o Estado de São Paulo. Campinas: Instituto Agronômico, 1996. p.155-203. (IAC. Boletim Técnico, 100)

TRANI, P.E.; NAGAI, H.; PASSOS, F.A. Tomate (estaqueado). In: RAIJ, B. van; CANTARELLA, H.; QUAGGIO, J.A.; FURLANI, A.M.C. (Ed.) Recomendações de adubação e calagem para o Estado de São Paulo. Campinas: Instituto Agronômico, 1996. p. 184. (IAC. Boletim técnico, 100)

UNIVERSITY OF CALIFORNIA. Division of Agricultural Sciences. Mechanical growing and harvesting of processing tomatoes. Berkeley, 1979. 30p. (Leaflet, 2686).

URQUIAGA, C.S.; LIBARDI, P.L.; REICHARDT, K.; MORAES, S.O.; PADOVESE, P.P; COSTA, A.C.S. da. Efeito da adição de matéria orgânica e de vermiculita expandida em algumas propriedades de um Oxisol com graminea (Melinis minutiflora Beauv.) In: COLÓQUIO REGIONAL SOBRE MATÉRIA ORGÂNICA DO SOLO, Piracicaba, 1982. Anais. Piracicaba:CENA, 1982. p.237-243. 
VANCE, E.D.; BROOKES, P.C.; JENKINSON, D.S. An extraction method for measuring soil microbial biomass. Soil Biology and Biochemistry, v.19, p.703-707, 1987.

VIVANCOS, A. D. Fertirrigacion. Madrid: Mundi-Prensa, 1993. 217p.

VLAMIS, J.; WILLIAMS, D.E. Utilization of municipal organic wastes as agricultural fertilizers. Compost Science, v.13, p.26-28, 1972.

WARMAN, P.R. Fertilization with manures and legume intercrops and then influence on Brassica and tomato growth, and on tissue and soil copper, manganese and zinc. Biological Agriculture Horticulture, v.6, p.325-335, 1990.

WEBBER, L.R.; BEAUCHAMP, E.G. Land utilization and disposal of organic wastes in cool subhumid and humid regions. In: STELLY, M. (Ed.) Soils for management of organic wastes and waste waters. Madison:ASA; CSSA; SSSA, 1977. cap.17, p.457-470.

WEI, Q.F.; LOWERY, B.; PETERSON, A.E. Effect of sludge application on physical properties of a silty clay loam soil. Journal of Environmental Quality, v.14, p.178$180,1985$.

WEIL, R.R.; KROONTJE, W. Physical condition of a Davidson clay loam after five years of heavy poultry manure applications. Journal of Environmental Quality, v.8, p.387-392, 1979.

WITTER, E.; MARTENSSON, A.M; GARCIA, F.V. Size of the soil microbial biomass in a long-term field experiment as affected by different $\mathrm{N}$-fertilizers and organic manures. Soil Biology and Biochemistry, v.25, p.659-669, 1993. 
ZENG, M.X.; JIN, W.X.; YAO, Y.X.; YANG, Y.F. Advantages of application of manure with chemical fertilizers in a long - term in situ experiment. Soils and Fertilizers Beijing, n. 1, p.1-6, 1992. /Resumo em CAB Abstracts on CD-ROM, 1993-94/ 